Historical Doses from Tritiated Water and Tritiated Hydrogen Gas Released to the Atmosphere from Lawrence Livermore National Laboratory (LLNL). Part 5. Accidental Releases

S-R. Peterson

September 17, 2007 
This document was prepared as an account of work sponsored by an agency of the United States Government. Neither the United States Government nor the University of California nor any of their employees, makes any warranty, express or implied, or assumes any legal liability or responsibility for the accuracy, completeness, or usefulness of any information, apparatus, product, or process disclosed, or represents that its use would not infringe privately owned rights. Reference herein to any specific commercial product, process, or service by trade name, trademark, manufacturer, or otherwise, does not necessarily constitute or imply its endorsement, recommendation, or favoring by the United States Government or the University of California. The views and opinions of authors expressed herein do not necessarily state or reflect those of the United States Government or the University of California, and shall not be used for advertising or product endorsement purposes.

This work was performed under the auspices of the U.S. Department of Energy by University of California, Lawrence Livermore National Laboratory under Contract W-7405-Eng-48. 


\title{
Historical Doses from Tritiated Water and Tritiated Hydrogen Gas Released to the Atmosphere from Lawrence Livermore National Laboratory (LLNL)
}

\author{
Part 5. Accidental Releases
}

\author{
S. Ring Peterson
}

\begin{abstract}
Over the course of fifty-three years, LLNL had six acute releases of tritiated hydrogen gas (HT) and one acute release of tritiated water vapor (HTO) that were too large relative to the annual releases to be included as part of the annual releases from normal operations detailed in Parts 3 and 4 of the Tritium Dose Reconstruction (TDR). Sandia National Laboratories/California (SNL/CA) had one such release of HT and one of HTO. Doses to the maximally exposed individual (MEI) for these accidents have been modeled using an equation derived from the time-dependent tritium model, UFOTRI, and parameter values based on expert judgment. All of these acute releases are described in this report. Doses that could not have been exceeded from the large HT releases of 1965 and 1970 were calculated to be $43 \mu \mathrm{Sv}(4.3 \mathrm{mrem})$ and $120 \mu \mathrm{Sv}$ (12 mrem) to an adult, respectively. Two published sets of dose predictions for the accidental HT release in 1970 are compared with the dose predictions of this TDR. The highest predicted dose was for an acute release of HTO in 1954. For this release, the dose that could not have been exceeded was estimated to have been $2 \mathrm{mSv}$ (200 mrem), although, because of the high uncertainty about the predictions, the likely dose may have been as low as $360 \mu \mathrm{Sv}$ (36 mrem) or less. The estimated maximum exposures from the accidental releases were such that no adverse health effects would be expected. Appendix A lists all accidents and large routine puff releases that have occurred at LLNL and SNL/CA between 1953 and 2005. Appendix B describes the processes unique to tritium that must be modeled after an acute release, some of the time-dependent tritium models being used today, and the results of tests of these models.
\end{abstract}


This page intentionally left blank. 


\section{TABLE OF CONTENTS}

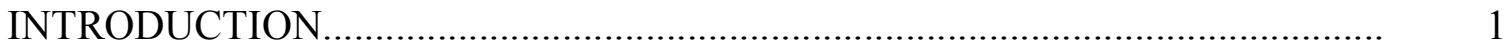

MODELING ACUTE RELEASES OF TRITIUM............................................... 2

Dispersion using HOTSPOT...................................................................

Methods to estimate dilution factors and uncertainty..................... 7

Methods for releases at unknown times $(1954,1964$, 1966).

Method when wind direction was known........................... 8

Method when meteorological data were known................ 10

Plume centerline vs. off-center........................................ 10

Dose Calculations................................................................................ 10

Inhalation dose.................................................................... 10

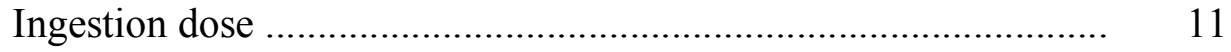

Equation.................................................................... 11

Ingestion assumptions................................................. 13

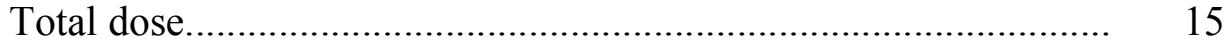

RELEASE DESCRIPTIONS, MODELING ASSUMPTIONS, AND RESULTS... 16

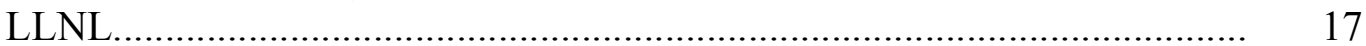

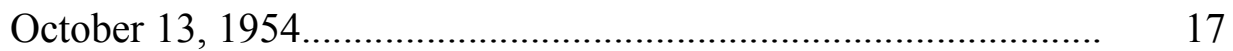

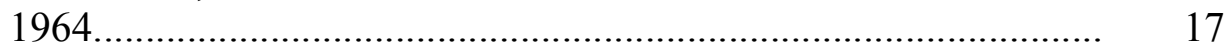

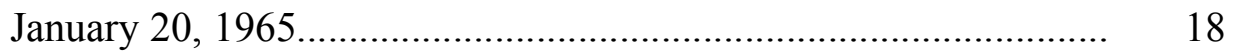

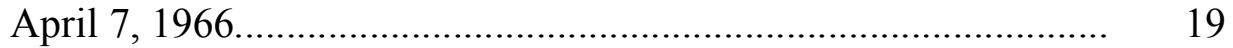

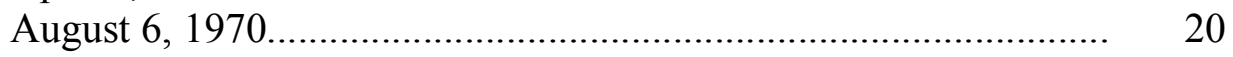

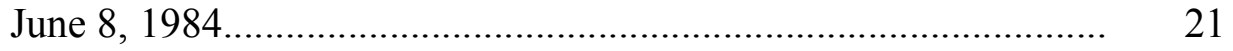

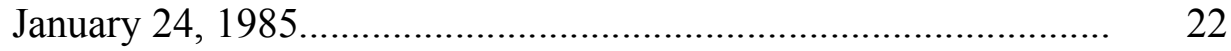

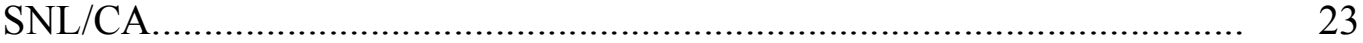

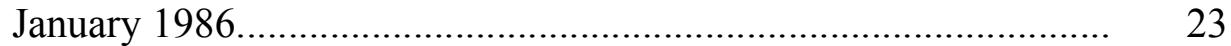

August 18, 1987..................................................................... 23

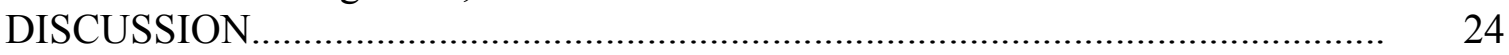

Predictions........................................................................................... 24

Dispersion modeling and air concentrations.................................... 24

Dose predictions......................................................................... 27

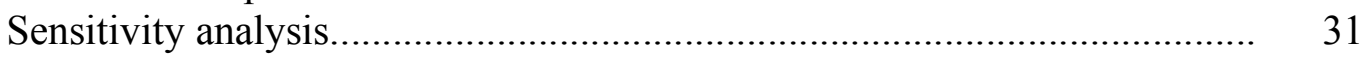

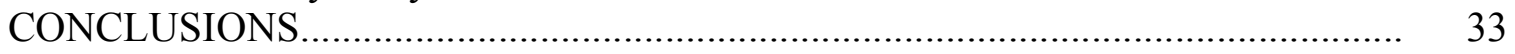

ACKNOWLEDGMENTS............................................................................... 35

LIST OF FIGURES

Figure 1. Sources of tritium $(\bullet)$ accidentally released from LLNL and

SNL/CA relative to the potential locations of the maximally exposed individual $(\mathbf{\Lambda})$

Figure 2. Doses and their $95 \%$ confidence intervals for accidental releases from LLNL and SNL/CA.

LIST OF TABLES

Table 1. Input parameter values for HOTSPOT for accidental releases

Table 2. Input parameter values for DCART to calculate centerline and off-centerline HTO inhalation doses at the locations of the maximally exposed individual for accidental releases. 


\section{TABLE OF CONTENTS CONTINUED}

Table 3. Parameters, values, and distributions used to estimate doses from accidents from HTO inhalation doses predicted by DCART and relationships derived from UFOTRI about ingestion.

Table 4. Months when common edible plants may have growth above ground in Livermore.

Table 5. Comparison of doses $(\mu \mathrm{Sv})$ to the MEI predicted by ingestion / HTO inhalation ratios, ATSDR (2003), and Myers et al. (1973) for the 1970 accidental release.

APPENDIX A - RECORD OF ROUTINE PUFF RELEASES AND

ACCIDENTAL RELEASES FROM LLNL AND SNL/CA

APPENDIX B- TIME-DEPENDENT DISPERSION AND TRITIUM DOSE

MODELING

DISPERSION MODELS FOR ACUTE RELEASES................................ 40

TRITIUM PROCESSES AND PATHWAYS TO DOSE.......................... 43

Conversion of HT to HTO............................................................... 44

Cycling of HTO between Air, Soil, and Vegetation........................ 44

Organically Bound Tritium Formation in Plants............................ 46

Uptake by Animals............................................................... 47

Time of Ingestion after Plume Passage ........................................ 48

TRITIUM SPECIFIC DOSE MODELS.................................................. 48

Processes as Modeled by the Process-oriented Models, UFOTRI,

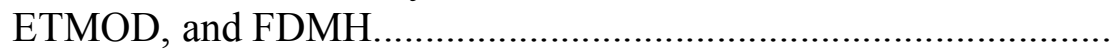

Dispersion.................................................................. 49

Deposition to soil......................................................... 50

Deposition to plants and uptake by plants........................ $\quad 50$

Re-emission from soil and plants to the atmosphere.......... 51

Plant growth and OBT formation................................... 51

Concentrations in animal products................................. 52

Dose calculations....................................................... 52

Compartment model, STAR-H3 ........................................... 53

TESTING MODELS.................................................................... 53

UFOTRI.................................................................... 53

International Model Validation Programs.................................... 53

Re-emission from soil and vegetation (BIOMOVS 11).... $\quad 55$

Formation of organically bound tritium in grain of spring wheat (BIOMOVS II)

Intercomparison of model prediction of contamination in soil, crops, milk and beef after a short exposure to tritiated water vapour in air (BIOMOVS II)

EMRAS soybean experiment........................................ 56

EMRAS hypothetical scenario...................................... 57

EQUILIBRIUM VS TIME-DEPENDENT MODELING.......................... 57

UNCERTAINTY ON DOSE PREDICTIONS......................................... 59

REFERENCES.

ABBREVIATIONS, ACRONYMS, AND DEFINITIONS....................................... 69 


\section{INTRODUCTION}

This Tritium Dose Reconstruction (TDR) has been undertaken to account for hypothetical dose to the public from all sources of tritium released to the atmosphere over the lifetime of the Livermore site of Lawrence Livermore National Laboratory. This report, which is Part 5 of "Historical Doses From Tritiated Water and Tritiated Hydrogen Gas Released to the Atmosphere from Lawrence Livermore National Laboratory (LLNL) ${ }^{1}$ " describes the seven accidental releases from LLNL and the two from neighboring Sandia National Laboratories/California $(\mathrm{SNL} / \mathrm{CA})^{2}$ that were too large to be modeled as routine ${ }^{3}$. A method to model radiological doses from these accidental releases is introduced, and dose predictions are presented. Appendix A lists all accidental releases and all large routine puff releases that have occurred at LLNL and SNL/CA between 1953 and 2005. Appendix B describes the processes unique to tritium that must be modeled after an acute release, some of the time-dependent tritium models being used today, and the results of tests of these models.

Accidental releases have contributed about $75 \%$ of tritium released to the atmosphere from LLNL ${ }^{4}$. An estimated $612,000 \mathrm{Ci}^{5}(22,700 \mathrm{TBq})$ of tritiated hydrogen gas $\left(\mathrm{HT}^{6}\right)$ have been released accidentally from the Tritium Facility (Building 331), primarily during the two large releases of 1965 and 1970. In contrast, there was just one accidental release of tritiated water vapor $\left(\mathrm{HTO}^{7}\right)$ (in 1954) of about $1,450 \mathrm{Ci}(53.7 \mathrm{TBq})$ to the atmosphere. The dose impact of a release of HT is much less than that from an equivalent release of HTO. It is the HTO formed when HT is converted by microorganisms in the soil to HTO and emitted to the atmosphere that results in the inhalation and ingestion doses after a release of HT. A dose from an accidental release of HT can range from about $1 \%$ to over $7 \%$ of the dose from an equivalent release of HTO and the same meteorological conditions.

Prior to the dose analysis of past accidents presented in this TDR, only inhalation and ingestion doses to the public after the release of 1970 were explicitly calculated (Myers et al. 1973; ATSDR $2003^{8}$ ). Inhalation dose alone was calculated after the 1985 (Howe

\footnotetext{
1 TDR Part 1. Description of Tritium Dose Model (DCART) for Chronic Releases from LLNL (Peterson 2006).

TDR Part 2. LLNL Annual Site-specific Data 1953 - 2005 (Peterson 2007a).

TDR Part 3. Routine Releases 1973 - 2005 (Peterson 2007b).

TDR Part 4. Routine Releases 1953 - 1972 (Peterson 2007c).

TDR Part 6. Summary; in draft

TDR Part 7. Tritium Dose Reconstruction using Organically Bound Tritium in Wood of Trees; proposed.

${ }^{2}$ The accidental releases modeled in this report are only those that were large relative to the routine releases for the year of the accident. Because modeling an acute release of tritium is very difficult and uncertain (see Appendix B), acute releases were modeled as routine releases (see Parts 3 and 4 of the TDR) whenever possible.

${ }^{3} \mathrm{SNL} / \mathrm{CA}$ had eight accidental releases (Appendix A), two of which could not be modeled as routine because they were large relative to the routine releases. These accidents have been modeled in this report for completeness, because the routine releases from SNL/CA were included in Part 3 of the Tritium Dose Reconstruction.

${ }^{4}$ At SNL/CA, the two accidental releases contributed about $21 \%$ of the tritium released to the atmosphere.

${ }^{5}$ This value lies within a 95\% confidence interval of 490,000 $\mathrm{Ci}(18,100 \mathrm{TBq})$ and 730,000 $\mathrm{Ci}(27,000 \mathrm{TBq})$.

${ }^{6}$ Throughout the report, gaseous tritium in any form (e.g., $\mathrm{T}_{2}$, DT, and HT) will be referred to as HT.

${ }^{7}$ Throughout the report, aqueous tritium in any form (e.g., $\mathrm{T}_{2} \mathrm{O}$, DTO and HTO) will be referred to as HTO.

${ }^{8}$ The Agency for Toxic Substances and Disease Registry carried out an independent assessment of potential doses from the 1965 and 1970 releases (ATSDR 2003) as part of a Public Health Assessment of the Livermore site (ATSDR 2004). For both releases, a dispersion model (RASCAL - see Appendix B) was used to estimate the time-integrated concentrations of HT in air and the time-integrated concentrations of HTO emitted from the soil at various distances from the release point. (Emission rates were obtained by multiplying the cumulative HT concentrations in air times the
} 
1985b), $1989^{9}$ (Brown 1989) and $1991^{9}$ (Galles 1991) accidental releases. Although the 1970 accidental HT release has been shown to have no impact on public health (ATSDR 2003), additional analyses are nonetheless valuable because of the importance of ingestion to dose after a tritium (particularly HT) release and because all important dose assessments should be made using more than one model or by more than one modeler (Peterson et al. 1996; Thiessen et al. 1997).

Doses from the accidental releases were modeled using the dispersion model, HOTSPOT (Homann 1994) (to calculate the dilution factors ${ }^{10}$ ), the equilibrium model DCART ${ }^{11}$ (to calculate inhalation dose from each release [as HTO]), and a set of equations using distributed parameter values based on expert judgment and the time-dependent tritium model, UFOTRI (Raskob 1990, 1993).

This report completes the modeling assessment (and re-assessment) of tritium doses to the public from routine and acute releases of tritium to the atmosphere at the Livermore site (and SNL/CA) between 1953 and 2005.

\section{MODELING ACUTE RELEASES OF TRITIUM}

The record of acute releases from LLNL and SNL/CA (Appendix A) includes puff releases that were reported as normal operations as well as releases that were reported as accidents. As sensitivity to larger releases grew, puff releases that would have previously been characterized as normal operations were classified as accidental (Souers 1988); by 1989, any unplanned tritium release greater than $100 \mathrm{Ci}(3.7 \mathrm{TBq})$ had to be reported, at least within LLNL (Facility Safety Procedures 1989). All the incidents shown in Appendix A occurred at the LLNL Tritium Facility (Building 331) or the SNL/CA Tritium Research Facility (TRL), with the exception of the ones in 1954 (Building 231 ${ }^{12}$ ) and 1961 (Building 212 $2^{13}$ ).

In an ideal world, all the releases in Appendix A would have been modeled as acute, because they were either large planned puff releases or they were accidental. The hypothetical dose impact at any one location of a few large puff releases a year is unlikely to be the same as the impact from the same quantity of tritium released uniformly over the year. However, because the large puff releases in the early years were

deposition velocity for HT times the HTO loss rate in percent per second). Because the predicted concentrations of HTO in air after the 1965 release were much lower off-site than those for 1970, only doses from the 1970 release were explicitly calculated. For the 1970 release, another model (ISC) was used to estimate the dispersion of the HTO emitted from the soil and the resulting HTO concentrations in air for the twelve days following the acute release. No uncertainty was applied to the tritium-in-air predictions of the two dispersion models used, but a Monte Carlo analysis accounted for uptake of tritium by adult and child.

9 This was not one of the accidental releases modeled in this tritium dose reconstruction because it was small enough relative to the routine release of this year to be modeled as part of the routine releases.

10 The term "dilution factor" will be used throughout this report to refer to the air concentration for unit source strength (or $\chi / \mathrm{Q}$ ); units are actually $\mathrm{Bq} \mathrm{m} \mathrm{m}^{-3} / \mathrm{Bq} \mathrm{s}^{-1}$ or $\mathrm{Ci} \mathrm{m}^{-3} / \mathrm{Ci} \mathrm{s}^{-1}$. The term, although standard for $\chi / \mathrm{Q}$, can be misleading, because the higher the dilution factor, the higher the air concentration.

${ }^{11}$ DCART (Doses from Chronic Atmospheric Releases of Tritium) is the stochastic equilibrium model described in Part 1 of the TDR and used in Parts 3 and 4 to calculate inhalation and ingestion doses from routine releases of tritium from LLNL and SNL/CA.

${ }^{12}$ At the time of the release, this building was called Building 102.

${ }^{13}$ At the time of the release, this building was called Building 153. 
part of routine operations and occurred somewhat randomly in time (at least on a multiyear basis) and were similar in magnitude, it was likely that their dose impact at any one location would have averaged out, at least over several years. Therefore, these releases were modeled assuming equilibrium conditions (see TDR Part 4). Similarly, dose impacts from smaller accidental releases (less than 1,000 Ci HT) after 1965, which were quite small compared with the routine annual releases, would have averaged out over time and were modeled as chronic releases in Parts 3 and 4 of the TDR.

For this TDR, only LLNL's accidental releases of 1954, 1964, 1965, 1966, 1970, 1984 and 1985 were modeled as acute; the SNL/CA accidental releases of 1986 and 1987 were also modeled. All of these releases were too large relative to the annual routine emissions to be modeled as routine for Part 3 of this TDR.

Tritium can be dispersed and deposited using many different dispersion models, and many dispersion models for acute releases calculate inhalation dose from tritium during the passage of the plume. Inhalation dose after an acute release can also be modeled using an equilibrium model, because the dose integral over infinite time per unit of release is numerically equal to the dose at a future steady-state when that release is repeated indefinitely at unit rate (Barry 1979). If it is assumed that the accidental release is spread out over the year and that the winds during that year blow only in one direction, then the integrated air concentration to which the individual is exposed is the same as that to which the individual was exposed during the accidental release.

Very few accident consequence models calculate dose from ingestion of contaminated foodstuffs, which is by far the largest contributor to tritium dose, particularly after a release of HT. To calculate ingestion dose, a model must account for processes unique to tritium, such as the emission of HTO from the soil after deposition of HT or HTO, its uptake by plants, its conversion to organically bound tritium (OBT) and its transfer to animals (see Appendix B).

For a release of HTO, for example, the impact of re-emission on dose strongly depends on meteorological conditions. Releases during hours with stable atmospheric stratification combined with low wind speed result in a narrow plume geometry and high inhalation doses during plume passage. Low wind speed and low atmospheric turbulence, however, reduce the deposition velocity, which reduces the amount of tritium deposited to plant and soil and the resulting ingestion dose. Thus for stable weather conditions, re-emission is negligible. For releases during neutral to unstable meteorological conditions with moderate wind speed, the tritium is highly dispersed by turbulent mixing. Because the plume spreads more and concentrations are more uniform, lower inhalation doses may be expected. However, under these conditions, re-emission may play a more significant role in the dose through ingestion. The most important influence of re-emission, however, is the contamination of areas that were not reached by the primary plume (Gulden and Raskob 1992).

Transfer of tritium from air to plant (and the resulting ingestion dose) is therefore highly dependent upon the meteorology both during and after the accidental release. To properly estimate tritium dose from a puff release (i.e., accidental release), time-dependent models for tritium require hourly meteorological data for at least a few days after the release. Except for the most recent LLNL and SNL/CA accidental releases (which are those with 
the lowest potential doses), no hourly meteorological data were available for the accidental releases, so the use of a tritium-specific time-dependent model of any sort (see Appendix B) was ruled out.

The use of an equilibrium model to calculate ingestion dose was also ruled out because ingestion/inhalation dose ratios for time-dependent models are very different than those ratios for equilibrium models ${ }^{14}$. Furthermore, as noted, ingestion/inhalation ratios change depending upon the meteorological conditions during the release. Because the inhalation dose can be calculated using an equilibrium model, because hourly meteorological data were not available, and because ingestion/inhalation dose ratios can be estimated using a sophisticated time-dependent model, a new approach to modeling dose from acute releases of tritium was devised. This approach, used in this TDR and described below, drew exclusively on the expertise of Wolfgang Raskob, the author of UFOTRI ${ }^{15}$ (1990, 1993; see Appendix B), and the world authority on modeling the behavior of tritium in the environment.

The location of the maximally exposed individual (MEI) for each release was assumed to be that of the closest structure off-site and downwind from the release. These structures may or may not have been actual residences. The existence of such structures was determined from United States Geological Survey (USGS) topographic maps for 1943, 1953, 1970, and 1983.

An overview of the current state of time-dependent tritium modeling may be found in Appendix B. A list of abbreviations, acronyms, and definitions of terms used in this report concludes the report

\section{Dispersion using HOTSPOT}

HOTSPOT (Homann 1994) is the accident consequence model that was used to calculate dilution factors ${ }^{10}$ at the locations of the maximally exposed individual using the input from Table 1. HOTSPOT is a version of the well-established Gaussian plume model, widely used for initial emergency assessment or safety-analysis planning. The adequacy of this model for making initial dispersion estimates or worst-case safety analyses has been tested and verified over many years. The primary advantage to HOTSPOT for the TDR was that it needs minimal input data. Without detailed meteorological data, which were unavailable for the TDR, large, complex, and time-consuming models are no more accurate than a simple Gaussian model.

Although HOTSPOT has a module specifically for tritium releases and calculates inhalation dose from releases of HT and HTO, the output used for the TDR was not the dose calculations but the time-integrated concentration in air at the location of the MEI.

\footnotetext{
${ }^{14}$ Comparative ingestion/inhalation ratios are found in the results of the Hypothetical Scenario of the Tritium Working Group of the International Atomic Energy Agency's (IAEA) coordinated research program, EMRAS (Environmental Modeling for Radiation Safety [see Appendix B]).

${ }^{15}$ UFOTRI is the best established of all the time-dependent tritium models and was used as the model to calculate doses to determine the best site at which to construct ITER, the proposed international experimental fusion reactor based on the tokamak concept (Raskob et al. 1999).
} 
Table 1. Input parameter values for HOTSPOT for accidental releases.

\begin{tabular}{|c|c|c|c|c|c|}
\hline & $\begin{array}{c}\text { October 13, } \\
1954\end{array}$ & 1964 & $\begin{array}{c}\text { January 20, } \\
1965\end{array}$ & $\begin{array}{c}\text { April 7, } \\
1966\end{array}$ & $\begin{array}{c}\text { August 6, } \\
1970\end{array}$ \\
\hline Stack height $(\mathrm{m})$ & 9 & 30 & 30 & 30 & 30 \\
\hline Stack diameter & 0.13 & 1.22 & 1.22 & 1.22 & 1.22 \\
\hline $\begin{array}{l}\text { Exit velocity } \\
\left(\mathrm{m} \mathrm{s}^{-1}\right)\end{array}$ & $2.3 ; 7.6 ; 12.8^{\mathrm{a}}$ & 5.45 & $5.45 ; 7.26^{\mathrm{b}}$ & 5.45 & 5.37 \\
\hline Duration (minutes) & 2 & $5 ; 30$ & $1 ; 2 ; 5 ; 10$ & $5 ; 30$ & 30 \\
\hline $\begin{array}{c}\text { Mean wind speed } \\
\left(\mathrm{m} \mathrm{s}^{-1}\right) \& \% \\
\text { frequency per } \\
\text { Stability Class }\end{array}$ & $\begin{array}{l}\text { Values from } \\
15 \text { minute } \\
\text { data for } 6 \\
\text { Octobers }\end{array}$ & $\begin{array}{c}\text { Values } \\
\text { from } 5 \\
\text { years of } \\
\text { hourly data }\end{array}$ & $\begin{array}{l}\text { Peterson et } \\
\text { al. } 2002\end{array}$ & $\begin{array}{c}\text { Values } \\
\text { from } 15 \\
\text { minute data } \\
\text { for } 6 \text { Aprils }\end{array}$ & $\begin{array}{l}\text { Myers et } \\
\text { al. } 1973\end{array}$ \\
\hline $\mathrm{A}$ & $1.7 ; 19.3 \%$ & $2.1 ; 15.3 \%$ & ----- & $1.8 ; 18.2 \%$ & ----- \\
\hline $\mathrm{B}$ & $2.4 ; 17.0 \%$ & $2.9 ; 20.3 \%$ & $3.0 ; 3.6$ & $2.9 ; 20.4 \%$ & ----- \\
\hline $\mathrm{C}$ & $3.6 ; 23.0 \%$ & $3.8: 31.3 \%$ & ----- & $4.1 ; 31.3 \%$ & ----- \\
\hline $\mathrm{D}$ & $3.6 ; 24.0 \%$ & 3.6: $20.1 \%$ & ----- & $4.5 ; 25.6 \%$ & ----- \\
\hline $\mathrm{E}$ & $1.6 ; 5.00 \%$ & $1.3 ; 7.10 \%$ & ----- & $1.7 ; 1.58 \%$ & 1.35 \\
\hline $\mathrm{F}$ & $0.92 ; 11.7 \%$ & $0.96: 5.90 \%$ & ----- & $0.99 ; 2.84 \%$ & ----- \\
\hline $\begin{array}{l}\text { Wind speeds } \\
\left(\mathrm{m} \mathrm{s}^{-1}\right) \text { at } 10 \% \& \\
90 \% \text { probability }\end{array}$ & & & & & \\
\hline $\mathrm{A}$ & $0.80 ; 2.6$ & $1.4 ; 2.8$ & ----- & $0.9 ; 2.7$ & ----- \\
\hline $\mathrm{B}$ & $1.4 ; 3.7$ & $1.5 ; 3.9$ & ----- & $1.2 ; 4.0$ & ----- \\
\hline $\mathrm{C}$ & $2.3 ; 4.9$ & $1.4 ; 5.4$ & ----- & $2.7 ; 5.5$ & ----- \\
\hline $\mathrm{D}$ & $1.2 ; 6.3$ & $0.88 ; 6.7$ & ----- & $1.7 ; 6.8$ & ----- \\
\hline $\mathrm{E}$ & $0.60 ; 2.3$ & $0.50 ; 2.3$ & ----- & $0.66 ; 2.4$ & ----- \\
\hline $\mathrm{F}$ & $0.30 ; 1.8$ & $0.40 ; 1.8$ & ----- & $0.30 ; 1.8$ & ----- \\
\hline Wind towards & Unknown & Unknown & $\begin{array}{c}50-70 \\
\text { degrees }(N E \\
-E N E)\end{array}$ & Unknown & $\begin{array}{c}\mathrm{N} \text { through } \\
\mathrm{NE}\end{array}$ \\
\hline $\begin{array}{l}\text { Distance to MEI } \\
(\mathrm{m})^{\mathrm{c}}-\text { Location } \\
(\text { see Figure } 1)\end{array}$ & $646 \mathrm{SW}-\mathrm{R}$ & 707 SW - Q & $1,930-X$ & $707 \mathrm{SW}-\mathrm{Q}$ & $2,020-V$ \\
\hline \multicolumn{6}{|c|}{$\begin{array}{l}\text { a Values represent the } 15 \% \text {, median, and } 85 \% \text { percentiles of present day exit velocities from similar stacks and were } \\
\text { used to get a distribution of dilution factors using HOTPSPOT. } \\
\text { b Both exit velocities were modeled. The lower is the value obtained from information about routine release rate; the } \\
\text { higher was the value used to model dispersion in } 1965 \text {. } \\
\text { c } \text { When the wind direction during the release is unknown, the worst case (i.e., public location closest to the release) }\end{array}$} \\
\hline
\end{tabular}


Table 1 continued. Input parameter values for HOTSPOT for accidental releases.

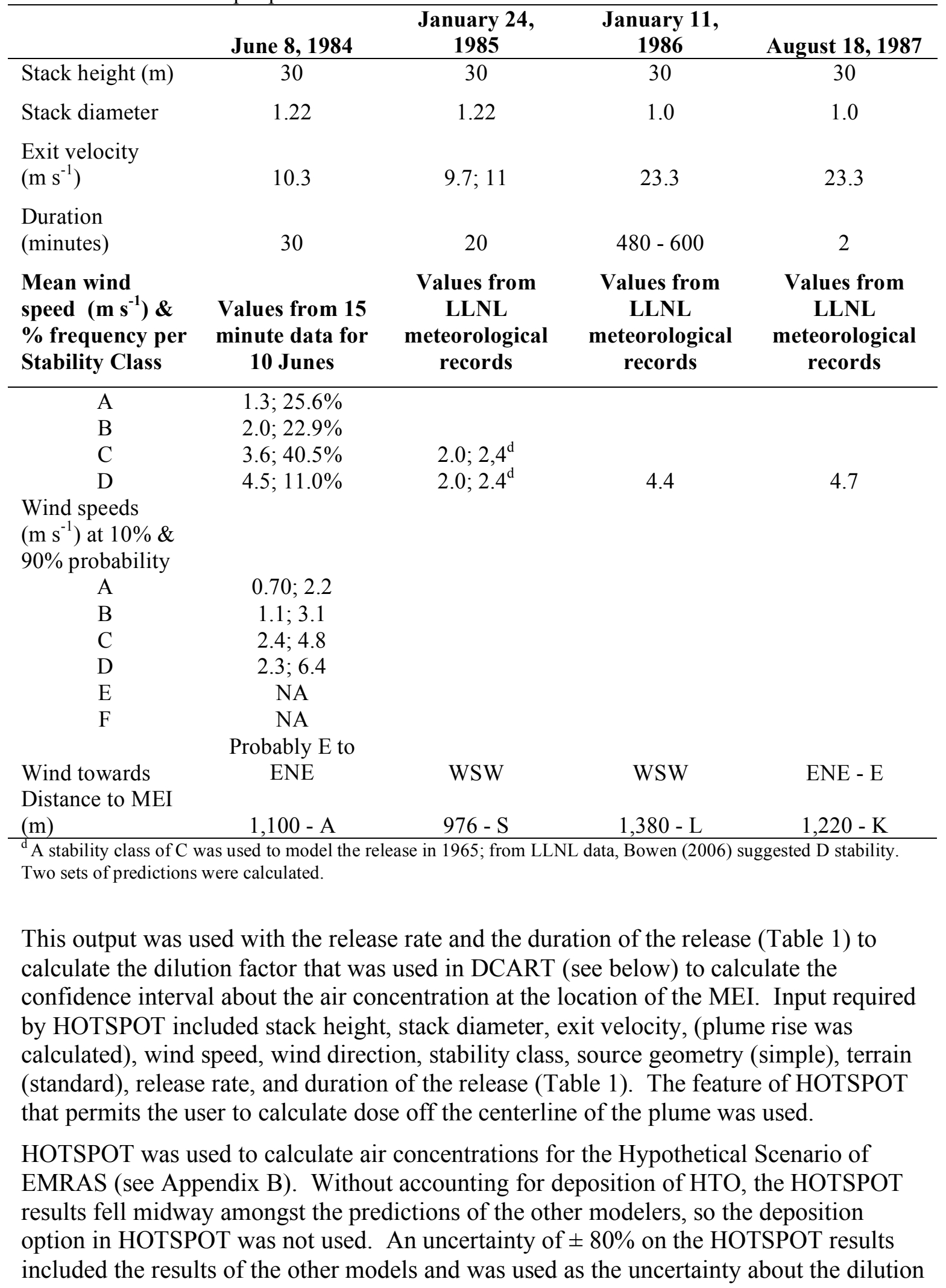


factors calculated by HOTSPOT. This uncertainty is somewhat higher than the uncertainty expected under ideal conditions ${ }^{16}$.

Methods to estimate dilution factors and uncertainty

Three different methods were used to estimate the dilution factor and its uncertainty depending upon what was known about the meteorological conditions during the releases and the durations of the releases.

\section{Method for releases at unknown times (1954, 1964, and 1966)}

In 1954 and 1966, the dates of the releases are known, but the approximate times of the releases are not; in 1964, even the month of the possible release is not known ${ }^{17}$. Knowing the time of day of a release is very important because, during the day, wind speeds are normally faster than in early morning and evening, and thus the dilution factor will be lower and the uncertainty on it will be less. When the time of the release was unknown, the assumption was made that the release occurred during work hours. Work hours were defined as 6:00 through 19:00 hours to include some stable worst-case conditions with low wind speeds to ensure that the dilution factor would not be underestimated. Generic meteorological profiles for these hours were prepared from the 15-minute LLNL meteorological data (available for September 6, 1996 through the present at the LLNL Weather Pages [http://www-metdat.llnl.gov/]). To have a sample large enough to statistically embrace likely seasonal conditions during the plume passage, all values for the months of October (1954) and April (1966) were taken from all years the data were electronically available. Data were sorted first by stability class; then, mean wind speeds and wind speeds that occurred with $10 \%$ and $90 \%$ probability were calculated for each stability class. HOTSPOT was run with each of the three wind speeds for each stability class for the assumed durations in minutes (Table 1) to obtain deterministic timeintegrated air concentrations at the location of the MEI. For the 1964 release, the same approach was used except that hourly data for wind speed and stability class for every day of the years 2000 through 2004 were used to calculate time-integrated air concentrations.

Because the direction towards which the wind was blowing is unknown, a conservative assumption ${ }^{18}$ was made for these releases that the MEI lived at the closest building open to the public that existed at the time of the accidental releases.

Dilution factors for each stability class and each wind speed were calculated from the integrated air concentration predicted by HOTSPOT and the known release rate and duration of release. The dilution factors used as input to DCART (Table 2) were weighted means of the dilution factors for each stability class based on the fraction of time that each stability class occurred and the probability that a particular wind speed

\footnotetext{
${ }^{16}$ The HOTSPOT manual states, "Given accurate input assumptions, the standard deviation of the dose values as calculated in Hotspot is approximately a factor of 5 . Therefore, $68 \%$ of the time (i.e., the percentage of observations within 1 standard deviation, assuming a Gaussian distribution), the calculated dose values will be within a factor of 5." The uncertainty on the dose referred to is actually the uncertainty on the dilution factor.

${ }^{17}$ This release of 24,000 Ci HT was modeled as accidental, but its existence is in doubt because it has only been found mentioned in a talk about tritium releases (Souers 1988) and not in any quarterly memo to the Atomic Energy

Commission (see Table 1, Part 2 of the TDR).

${ }^{18}$ A conservative assumption is one that will tend to maximize the potential dose so that the dose will not be underestimated and will be health-protective.
} 
occurred. A standard deviation on the dilution factor was selected to include the highest (and lowest) dilution factors (obtained from the low and high probable wind speeds) that could occur with $95 \%$ probability. An uncertainty obtained this way is much greater than the uncertainty described in the HOTSPOT manual for well-characterized accidental releases ${ }^{16}$, but it should account for the potential meteorological conditions during the releases that would result in the highest most likely doses.

Table 2. Input parameter values for DCART to calculate centerline and off-centerline HTO inhalation doses at the locations of the maximally exposed individual for accidental releases. Distribution for relative humidity $(0.69 \pm 0.069)$ is normal; distributions for dilution factors $\left(\chi / \mathrm{Q}\right.$ in $\left.\mathrm{m} \mathrm{s}^{-1}\right)$ are lognormal; distributions for absolute humidity are uniform. Release rates have a normal distribution unless otherwise noted.

\begin{tabular}{lcccc}
\hline $\begin{array}{c}\text { Date of } \\
\text { release }\end{array}$ & Type & Source Term $(\mathbf{C i})$ & $\begin{array}{c}\text { Best estimate } \\
\chi / \mathbf{Q}\left(\mathbf{s ~ m}^{-3}\right)\end{array}$ & $\begin{array}{c}\text { Centerline } \\
\chi / \mathbf{Q}\left(\mathbf{s ~ m}^{-3}\right)\end{array}$ \\
\hline $10 / 13 / 1954$ & HTO & $1450 \pm 435$ & $6.27 \times 10^{-5} \pm 1.22 \times 10^{-4} *$ & $1.61 \times 10^{-4} \pm 2.82 \times 10^{-4}$ \\
1964 & HT & $0-24,000$ (uniform) & $5.77 \times 10^{-6} \pm 4.62 \times 10^{-6} *$ & $1.48 \times 10^{-5} \pm 1.18 \times 10^{-5}$ \\
& & $207,000-309,000-$ & & \\
$1 / 20 / 1965$ & HT & 360,000 (triangular) & $1.07 \times 10^{-6} \pm 1.05 \times 10^{-6}$ & $1.71 \times 10^{-6} \pm 3.47 \times 10^{-7}$ \\
$4 / 07 / 1966$ & HT & $12500 \pm 3090$ & $5.82 \times 10^{-6} \pm 1.32 \times 10^{-5} *$ & $1.49 \times 10^{-5} \pm 3.10 \times 10^{-5}$ \\
$8 / 06 / 1970$ & HT & $288,000 \pm 51,600$ & $2.66 \times 10^{-6} \pm 5.64 \times 10^{-6}$ & $1.69 \times 10^{-5} \pm 1.35 \times 10^{-5}$ \\
$6 / 8 / 1984$ & HT & $5510 \pm 1110$ & $1.56 \times 10^{-6} \pm 1.25 \times 10^{-6}$ & $5.71 \times 10^{-6} \pm 4.57 \times 10^{-6}$ \\
$1 / 24 / 1985$ & HT & $972 \pm 182$ & $8.28 \times 10^{-6} \pm 8.13 \times 10^{-6}$ & $1.47 \times 10^{-5} \pm 1.18 \times 10^{-5}$ \\
$1 /(11) / 1986$ & HTO & $200 \pm 20$ & $9.36 \times 10^{-7} \pm 7.49 \times 10^{-7}$ & $3.38 \times 10^{-6} \pm 2.70 \times 10^{-6}$ \\
$8 / 18 / 1987$ & HT & $1100 \pm 55$ & $2.34 \times 10^{-6} \pm 1.87 \times 10^{-6}$ & $1.15 \times 10^{-5} \pm 9.44 \times 10^{-6}$ \\
\hline \multirow{2}{*}{$*$ These were estimated from the centerline dilution factors reduced by the mean value plus uncertainty $(0.389 \pm 0.165)$} \\
of the off centerline dilution factors compared with centerline dilution factors when both were based on actual \\
meteorological data.
\end{tabular}

\section{Method when wind direction was known}

In 1965, 1970, and 1984, the directions towards which the wind was blowing during the releases were quite well characterized; in addition, wind speeds and stability classes were known for the releases of 1965 and 1970. Thus integrated air concentrations could be calculated using HOTSPOT for several potential downwind locations of the MEI.

For 1965, dilution factors for potential receptors at locations A, X, W, and Y (Figure 1) were calculated for two potential wind speeds $\left(3.0\right.$ and $\left.3.6 \mathrm{~m} \mathrm{~s}^{-1}\right)$ and for three sets of wind directions (from 230, 240 and 250 degrees). These results were then averaged to obtain the mean and standard deviation dilution factor. The resulting uncertainty (percent standard deviation divided by the mean) was combined with the $80 \%$ uncertainty due to dispersion modeling to estimate the overall uncertainty.

Similarly, for 1970, dilution factors were calculated at locations A, V, W, X, and Y (Figure 1) to determine the location exposed to the highest integrated air concentration over the half-hour of the release. At each potential location of the MEI, a dilution factor was obtained by averaging the dilution factors calculated for wind directions 180 through 225 degrees at five-degree increments using a single wind speed $\left(1.35 \mathrm{~m} \mathrm{~s}^{-1}\right)$ and stability class (E) (Table 1). The standard deviation on each mean dilution factor was combined with the dispersion uncertainty to arrive at the overall uncertainty on the dilution factor. 


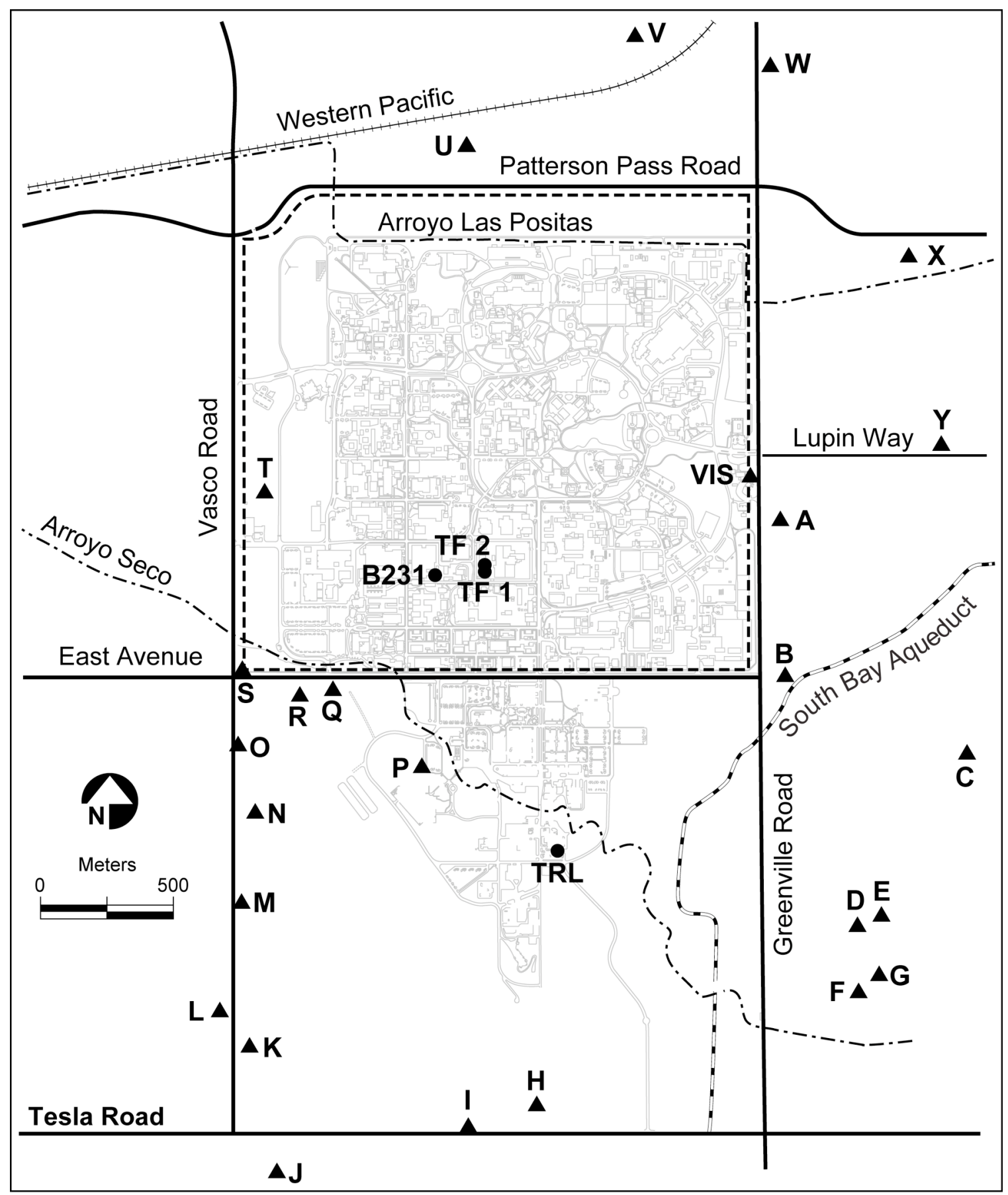

Figure 1. Sources of tritium $(\bullet)$ accidentally released from LLNL and SNL/CA relative to the potential locations of the maximally exposed individual $(\Delta)$. $\Delta$ VIS is the location of the Discovery Center; $\Delta \mathrm{A}$ through $\Delta \mathrm{W}$ (except $\Delta \mathrm{Q}$, which was a garage) were potential residences. Modeled sources include B231 (the Tritium Facility until 1958), TF1 and TF2 (the south and north stacks of the current Tritium Facility), and TRL (Tritium Research Facility of SNL/CA).

The meteorological conditions in 1984 were not available from the LLNL records, so, as was done for the releases in 1954, 1964, and 1966 a generic wind file was developed 
from data for the month of June except only for the known time of the release. Potential locations for the MEI were A, U, V, W, X, and Y (Figure 1) based on where the environmental sampling efforts were concentrated after the release (Hill 1984). The uncertainty that included the highest likely dilution factor did not result in an overall uncertainty of $80 \%$, so the generic uncertainty of $80 \%$ was applied.

\section{Method when meteorological data were known}

For 1985, 1986, and 1987, LLNL 15-minute meteorological data were available for the durations of the releases. A dilution factor was calculated for each potential location of the MEI for each 15-minute wind speed, direction, and stability class. The uncertainty about the dilution factor included the uncertainty about the mean (i.e., the standard deviation) and the uncertainty on the dispersion model.

For 1985, potential locations of the MEI included Q, R, S, and T. Two different exit velocities were used for the HOTSPOT calculations (Table 1). In 1986, potential locations of the MEI were H, I, J, K, L, M, N, O, and P. In 1987, potential locations of the MEI were $\mathrm{J}, \mathrm{K}, \mathrm{L}, \mathrm{M}, \mathrm{N}, \mathrm{O}, \mathrm{P}$, and Q.

Plume centerline vs. off-center

The dilution factor for the location of each potential MEI was calculated based on two assumptions, 1) the conservative assumption that the plume blew directly onto the location of the MEI and 2) the assumption that the locations were off the plume centerline. To do this, each potential location of the MEI was provided with $\mathrm{x}$ and $\mathrm{y}$ coordinates off a grid with the source at the center. The off-centerline approach was used because the assumption that the location was directly downwind from the release is overly conservative.

Values for the dilution parameters used as input to DCART for the calculation of HTO inhalation dose, both centerline and off centerline, are shown in Table 2.

\section{Dose Calculations}

\section{Inhalation Dose}

As mentioned, an equilibrium model (in this case, DCART) can be used to predict the same inhalation dose as a time-dependent model after an acute release. This is only true, however, for a release of HTO (at least for DCART). Thus for the two accidental releases of HTO, inhalation dose with its $95 \%$ confidence interval was calculated in DCART from the HTO release rates and dilution factors. (HOTSPOT equally could have been used to calculate a deterministic HTO inhalation dose, but DCART was used because a probabilistic dose distribution was needed for the total dose calculations.)

For a release of HT, DCART overestimates inhalation dose compared with UFOTRI for the same release assumptions. As a result, inhalation dose calculated by DCART after a release of HT could not be used to calculate ingestion dose using the ingestion/inhalation ratios based on UFOTRI (below). Instead, it was necessary to assume the accidental releases of HT were HTO so that HTO inhalation doses could be calculated for each accidental HT release. Each predicted HTO inhalation dose was then reduced by the HT/HTO inhalation dose ratios (Table 3) obtained in UFOTRI for identical HT and HTO release rates. 


\section{Ingestion dose}

\section{Equation}

One equation applies to the calculation of ingestion dose from all accidental releases based on HTO inhalation doses and their $95 \%$ confidence intervals calculated in DCART. This equation uses distributed input parameter values (Table 3) based on Dr. Raskob's expert judgment and experience with UFOTRI. The equation was calculated in Microsoft Excel $\AA$ coupled to the risk assessment software, Crystal Ball ${ }^{19}$.

$$
D_{\text {ing }}=D_{\text {inh }} D_{H T / H T O} R C_{O B T}\left[F_{d V}\left(G_{R f}-A_{R f}\right)+F_{d A} A_{R f}\right]
$$

where:

$D_{\text {ing }} \quad$ is the ingestion dose $(\mu \mathrm{Sv})$

$D_{\text {inh }} \quad$ is the inhalation dose $(\mu \mathrm{Sv})$ for the release, assuming the release was HTO, calculated by DCART

$\mathrm{D}_{\mathrm{HT} / \mathrm{HTO}}$ is the HT inhalation dose/HTO inhalation dose ratio from UFOTRI

$\mathrm{R}$ is the ingestion/inhalation ratio obtained from UFOTRI adjusted for the variability in ingestion rate.

$\mathrm{C}_{\mathrm{OBT}}$ is the adjustment to the dose coefficient in UFOTRI to give it the same value and distribution as in DCART.

$\mathrm{F}_{\mathrm{dV}} \quad$ is the fraction of intake of plant products that is potentially contaminated.

$\mathrm{G}_{\mathrm{Rf}}$ is the fraction of the ingestion dose received when the contribution of grain has been removed (from UFOTRI).

$A_{R f}$ is the fraction of ingestion dose from animal products (from UFOTRI). The distribution is triangular: $0.06-0.11-0.22$. Note that these values are calculated from 1 minus the values in Table 3.

$\mathrm{F}_{\mathrm{dA}} \quad$ is the fraction of intake of animal products that is potentially contaminated in January, April and 1964 (month unknown). For all other accidental releases, $\mathrm{F}_{\mathrm{dA}}$ is zero.

\footnotetext{
${ }^{19}$ Decisioneering, Inc. 1515 Arapahoe Street, Suite 1311, Denver Colorado 80202 USA
} 
Table 3. Parameters, values, and distributions used to estimate doses from accidents from HTO inhalation doses predicted by DCART and relationships derived from UFOTRI and assumptions about ingestion.

\begin{tabular}{lll}
\hline Parameter & Values & Distributio \\
\hline $\begin{array}{l}\text { Factor to convert HTO inhalation dose } \\
\text { to HT inhalation dose }\end{array}$ & $0.0012-0.0022-0.010$ & triangular \\
& & \\
& & \\
$\begin{array}{l}\text { Fraction of diet that could have been } \\
\text { homegrown vegetables: }\end{array}$ & $0.0417 \pm 0.0291^{\mathrm{a}}$ & lognormal \\
$\quad$ January & $0.127 \pm 0.0881^{\mathrm{b}}$ & lognormal \\
$\quad$ April & $0.164 \pm 0.114^{\mathrm{c}}$ & lognormal \\
$\quad$ June, August, October & & \\
& & \\
Ratio of ingestion/inhalation dose & $13 \pm 7.63^{\mathrm{d}}$ & lognormal \\
1954 (HTO) & $10.8 \pm 5.62^{\mathrm{e}}$ & lognormal \\
1986 (HTO) & $151 \pm 75.6^{\mathrm{f}}$ & lognormal \\
All HT releases &
\end{tabular}

Fraction of ingestion dose remaining when contribution of grain is removed

$0.18-0.4-0.7 \quad$ triangular

Fraction of ingestion dose remaining when contribution of animal products is removed

$0.78-0.89-0.94 \quad$ triangular

Fraction of diet that could have been contaminated homegrown animal products $^{\mathrm{g}}$

$0.244 \pm 0.136 \quad$ lognormal

OBT dose coefficient adjustment

$$
\begin{aligned}
& 1.83 \pm 0.473 \text { (adult) } \\
& 2.29 \pm 0.821 \text { (child) } \\
& 3.13 \pm 1.13 \text { (infant) }
\end{aligned}
$$

lognormal

\footnotetext{
${ }^{a}$ Obtained by multiplying the potential fraction of homegrown vegetables $(0.219 \pm 0.143$, lognormal - see Table 4$)$ times the fraction of total vegetables growing at the time of the accident $(0.19 \pm 0.04$, normal).

${ }^{\mathrm{b}}$ Obtained by multiplying the potential fraction of homegrown vegetables $(0.219 \pm 0.143$, lognormal - see Table 4$)$ times the fraction of total vegetables growing at the time of the accident $(0.58 \pm 0.12$, normal).

${ }^{\mathrm{c}}$ Obtained by multiplying the potential fraction of homegrown vegetables $(0.219 \pm 0.143$, lognormal - see Table 4$)$ times the fraction of total vegetables growing at the time of the accident $(0.75 \pm 0.15$, normal $)$.

${ }^{\mathrm{d}}$ Derived from a uniform ingestion/inhalation distribution of $4-20$ times an adjustment for variability of intake (a lognormal distribution of 1 [geometric mean] \pm 1.5 [geometric standard deviation]).

${ }^{\mathrm{e}}$ Derived from a uniform ingestion/inhalation distribution of $5-15$ times an adjustment for variability of intake (a lognormal distribution of 1 [geometric mean[ \pm 1.5 [geometric standard deviation]).

${ }^{\mathrm{f}}$ Derived from a uniform ingestion/inhalation distribution of $80-200$ times an adjustment for variability of intake (a lognormal distribution of 1 [geometric mean] \pm 1.5 [geometric standard deviation]).

${ }^{\mathrm{g}}$ Fraction for releases in April, June, August, and October is assumed 0 because dried pasture would not be contaminated.
} 
Ingestion/inhalation ratios depend upon the meteorological conditions during and after an acute release and upon the diet. Because it did not rain during any of the LLNL or SNL/CA releases and all releases occurred during daylight, the variability in the ratios was smaller than it might have been otherwise. Ingestion/inhalation ratios for HTO have been estimated as low as a factor of 4 (Gulden and Raskob 1992) or 5 to 6 (Raskob et al. 1999), but they also can go as high as about 20 depending upon inhalation and ingestion rates and wind conditions during and after an accidental release. For the 1954 release, when conditions were unknown (except that it did not rain), a uniform distribution from 4 - 20 was assigned for the ingestion/inhalation ratio. In 1986, when wind speeds and stability (D) class were known, a uniform distribution of 5 - 15 was assigned.

Ingestion/inhalation ratios are much larger after an HT release, because ingestion is much more important relatively. In addition, the uncertainty is much greater. The uniform distribution for ingestion/inhalation ratios ranges from $80-200$ for daylight conditions ${ }^{20}$.

These ratios only account for variability due to differences in meteorological conditions; they do not account for the uncertainty about ingestion rates (ingestion rates in UFOTRI are deterministic). The values for ingestion/inhalation ratios shown in Table 3 were obtained by multiplying the uniform distributions for the uncertainty in the meteorological conditions by a lognormal distribution with a geometric standard deviation of 1.5 to account for the variability in ingestion rates.

\section{Ingestion Assumptions}

The ingestion/inhalation ratios obtained from UFOTRI are based on the conservative assumption that, after a release, the potential exists for the entire diet to be contaminated. However, the dose potentially received after an acute release depends very much on both the diet and what could have been growing at the time.

Grain can be a very important contributor to dose because of its high OBT content. OBT can be found in grain after exposure of the leafy plant to tritium during much of its growth cycle, so if grain were growing in a particular location, its dose impacts should be taken into account. In UFOTRI, grain can contribute between $30 \%$ and $82 \%$ of the ingestion dose depending upon meteorological conditions during and after the accidental release. The Livermore Valley was noted for the grain it produced in the late 1800s and early 1900s. Even as late as 1970 (Gudikson 1971) grain was referred to as one of the four major crops in the Livermore Valley, along with grapes, roses, and hay. Grain, however, was not grown as close to the Laboratory as any potential location of the MEI, and it most certainly was not grown in someone's garden for human consumption. The contribution of grain to total dose has been removed.

The portion of the diet affected by any one accidental release was probably very small unless the release occurred at the height of the growing season. Obviously, with releases having occurred in January, April, June, August, and October (Table 2), different vegetables would have been growing at different times. From experiments it is known that acute exposure that occurs even before flowering will result in elevated levels of OBT in the fruit. Thus, for example, young strawberry plants that can be planted in

\footnotetext{
${ }^{20}$ For releases that occur at night, ingestion doses may be even more important relative to the inhalation dose.
} 
January or February, if exposed, can accumulate OBT and contribute to dose by ingestion when harvested. April is an important month for planting seedlings of tomato, eggplant, peppers, broccoli, cabbage, and cauliflower. Plants harvested in the fall will be growing in August. In the Livermore Valley, some sort of vegetable might be growing at any time of year.

A table of vegetables and the months they are potentially exposed to the atmosphere was compiled from information posted on the web by several local nurseries (Table 4). Shaded areas indicate the months that the plant could be above-ground at some stage of growth (perennial plants such as artichoke or asparagus grow year round after the first year). The cool-weather plants that do not do well in the hot summers common to the Livermore Valley are marked with vertical lines. To estimate the fraction of vegetables in a complete diet that might have been growing at the time of any one accidental release, the list in Table 4 was broken down into those plants growing in January, in April, in June and August, and in October. The potential fraction of contaminated diet for each release was calculated by dividing the number of plants potentially growing in the month of the release by the number of plants listed in Table $4^{21}$. For those plants that do not grow well during the heat, the fraction for June and August was reduced by weighting those plants by $33 \%$, which brought the potential fraction of plants that could be ingested down from $97 \%$ to $75 \%$.

If the grass on the hillsides had been dry, as it seems to have been for the April and October releases (the daily rainfall records for Livermore indicated minimal rainfall for the month or months preceding), and would have been for the June and August releases, cows would not have been ingesting tritium as HTO or OBT after the accidental releases, because the pasture would not have been growing. However, because grass begins growing in the fall and continues to grow throughout the winter, animals could have been exposed to tritium from releases that may not have impacted vegetables particularly. Thus it was assumed that animals were exposed significantly ${ }^{22}$ to tritium only during the January releases of 1965, 1985 and 1986 when the grass would have been growing. Therefore, in this TDR, dose from ingestion of animal products was only calculated for the accidental releases that occurred in January.

The Environmental Protection Agency's Exposure Factors Handbook (EFH) (US EPA 1999) provides fractions of total foods ingested that are homegrown. To assume a conservative intake of homegrown vegetables and animal products to apply to ingestion/inhalation dose ratios, values from the EFH for households that had gardens or households that raised animals for consumption were averaged across all plant and animal products to obtain fractions of $0.219 \pm 0.143$ for plant products $\left(\mathrm{F}_{\mathrm{dV}}\right.$ in the equation above) and $0.244 \pm 0.136$ for animal products $\left(\mathrm{F}_{\mathrm{dA}}\right.$ in the equation above).

To obtain the fraction of potentially contaminated diet that could have been homegrown, the fraction of homegrown vegetables was multiplied by the fraction of vegetables that could have been growing at the time of the accidental release using the Crystal Ball ${ }^{\circledR}$ probabilistic software. For animals, it was assumed that if a household raised animals,

\footnotetext{
${ }^{21}$ January 19\%; April 58\%; June and August 97\%; October 75\%

${ }^{22}$ All animals would have inhaled tritium during and after the passage of the plume, but only ingestion would have resulted in significant concentrations of HTO and OBT in the animal products.
} 
the fraction of animal products in the diet for the January releases would be the same as the potential fraction homegrown; for releases at other times of the year, the fraction of contaminated animal products in the diet was assumed zero.

\section{Total dose}

The total dose $\left(\mathrm{D}_{\mathrm{T}}\right.$ in $\left.\mu \mathrm{Sv}\right)$ after an acute release then becomes

$$
D_{T}=D_{\text {inh }}+D_{\text {ing }}
$$

Table 4. Months when common edible plants may have growth above ground.

\begin{tabular}{|c|c|c|c|c|c|c|c|c|c|c|c|c|}
\hline \multirow{2}{*}{\multicolumn{13}{|c|}{ Artichoke }} \\
\hline & & & & & & & & & & & & \\
\hline Asparagus & & & & & & & & & & & & \\
\hline Beans, green & & & & & & & & & & & & \\
\hline Beans, lima & & & & & & & & & & & & \\
\hline Beets & & & & & & & & & & & & \\
\hline Broccoli & & & & & & & & & & & & \\
\hline Brussels sprouts & & & & & & & & & & & & \\
\hline Cabbage & & & & & & & & & & & & \\
\hline Carrots & & & & & & & & & & & & \\
\hline Cauliflower & & & & & & & & & & & & \\
\hline Celeriac & & & & & & & & & & & & \\
\hline Celery & & & & & & & & & & & & \\
\hline Corn, sweet & & & & & & & & & & & & \\
\hline Cucumbers & & & & & & & & & & & & \\
\hline Eggplant & & & & & & & & & & & & \\
\hline Fruits & & & & & & & & & & & & \\
\hline Greens & & & & & & & & & & & & \\
\hline Kolhrabi & & & & & & & & & & & & \\
\hline Leeks & & & & & & & & & & & & \\
\hline Lettuce & & & & & & & & & & & & \\
\hline Melons & & & & & & & & & & & & \\
\hline Okra & & & & & & & & & & & & \\
\hline Onions, bulb & & & & & & & & & & & & \\
\hline Onions, green & & & & & & & & & & & & \\
\hline Peas & & & & & & & & & & & & \\
\hline Peppers & & & & & & & & & & & & \\
\hline Potatoes & & & & & & & & & & & & \\
\hline Potatoes, sweet & & & & & & & & & & & & \\
\hline Pumpkins & & & & & & & & & & & & \\
\hline Radish & & & & & & & |III & & & & & \\
\hline Rhubarb & & & & & & & & & & & & \\
\hline Spinach & & & & & & WI & W. & 110 & 110 & & & \\
\hline Squash, summer & & & & & & & & & & & & \\
\hline Squash, winter & & & & & & & & & & & & \\
\hline Tomatoes & & & & & & & & & & & & \\
\hline Turnips & & & & & & & & & & & & \\
\hline
\end{tabular}

Note: These data synthesized from data on the web obtained November 10, 2006 from http://www.sacramentogardening.com/vegetables.html; $h \mathrm{ttp}: / / \mathrm{www}$. thegardenhelper.com;

http://wihort.uwex.edu/fruitveggies/HarvestDates.htm; http://www.ext.colostate.edu/pubs/Garden/07850.html; http//redwoodbarn.com/vegplantingcalend.html; and a pdf dated 2/6/98 from The Sonoma County Master Gardener. The vertical lines indicate cool-weather plants that do not do well in hot weather. See text. 


\section{RELEASE DESCRIPTIONS, MODELING ASSUMPTONS, AND RESULTS}

Predicted doses at the locations of the MEI for each accidental release (Figure 2) were calculated using off-centerline dilution factors which give a more accurate, less conservative, assessment than a centerline dilution factor that represents a worst case. When the wind direction was not known (1954, 1964, and 1966), the centerline doses were reduced by a value $(0.389 \pm 0.165$, lognormal $)$ based on the observed fractions (non-centerline/centerline dilution factor) obtained for the accidents when wind direction was known (described below) ${ }^{23}$.

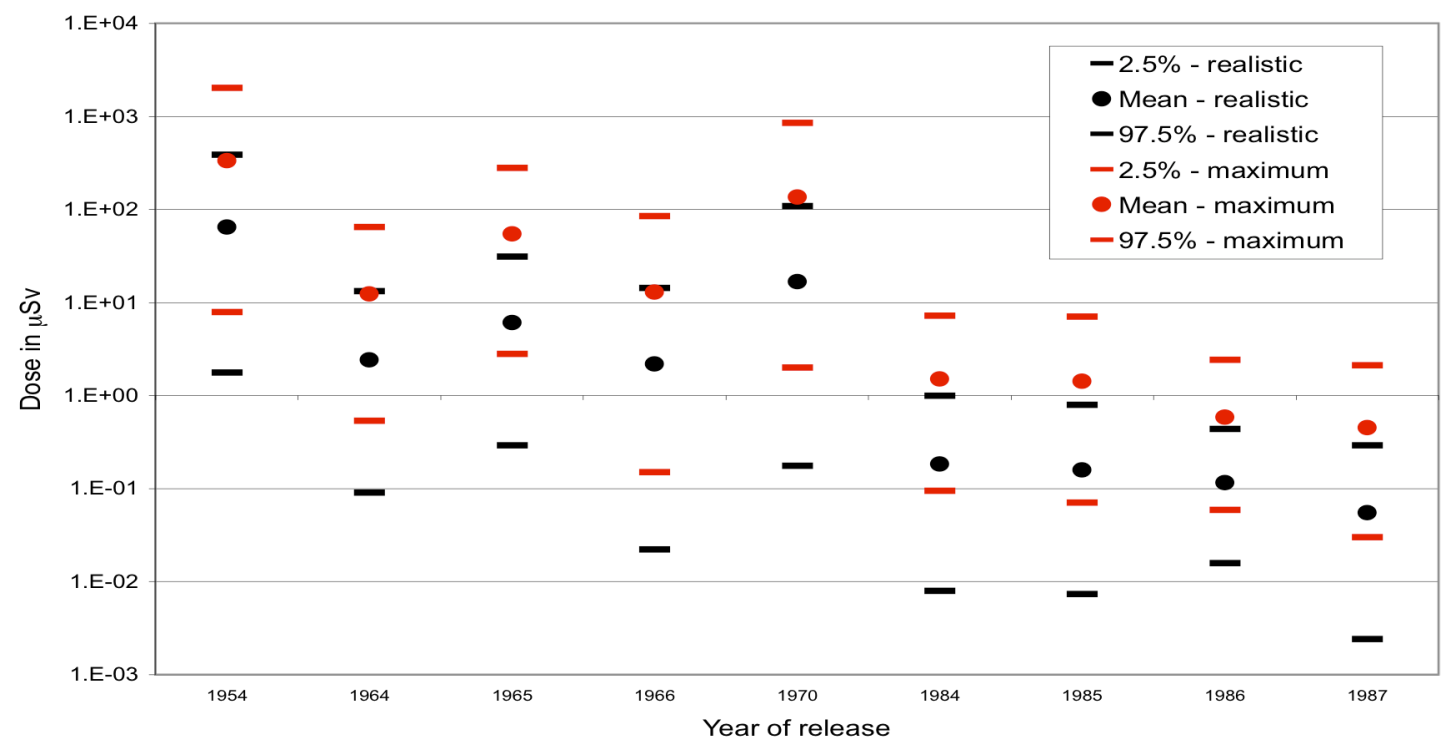

Figure 2. Predicted doses and their $95 \%$ confidence intervals for accidental releases from LLNL and SNL/CA. Realistic doses are based on the assumption that only a limited fraction of the diet could have been exposed to the plume; maximum doses assume all the diet was contaminated except grain.

Two sets of dose predictions are shown. One set assumes that, of the entire diet, only grain was not contaminated by the plume passage. This set will be referred to as the "maximum" dose throughout this report. The other set of dose predictions, which will be called the "realistic" dose, is based on the assumptions about ingestion described above and in Table 4. The reasons for the two sets of calculations and the interpretation of the results will be addressed in the Discussion.

Input data used to calculate the dilution factors using HOTSPOT are summarized in Table 1 for all accidental releases. Input data used in DCART to calculate initial HTO inhalation doses are summarized in Table 2.

\footnotetext{
${ }^{23}$ Off-centerline dose $=0.389 \times$ centerline dose.
} 


\section{LLNL}

October 13,1954

The only record of this accidental release is a handwritten memo (Stanhope 1954) obtained from LLNL incident reports that stated that approximately $1 \mathrm{cc}$ of $\mathrm{T}_{2} \mathrm{O}$ was lost from a cold trap because a stopcock blew out of a line. Because $\mathrm{T}_{2} \mathrm{O}$ is not stable, the liquid that was seen was most likely HTO (Souers 2006; Hafner 2006). Stanhope was the building monitor of Building 102, so the release must have taken place in what is now Building 231.

Two individuals were exposed to the release. One person exposed had a concentration of $500 \mu \mathrm{Ci} \mathrm{L}^{-1}\left(1.8510^{7} \mathrm{~Bq} \mathrm{~L}^{-1}\right)$ in urine 1.5 hours after exposure; the other's urine had no measurable tritium.

For the TDR, this accidental release has been treated as a stack release of 1,450 Ci HTO. The uncertainty on the source term was estimated to be $\pm 30 \%$ to account for inaccuracies in the $1 \mathrm{cc}$ estimate. From a memo (Thaxter 1954), it has been assumed that work took place in a glove box with an exhaust duct 5 inches $(0.127 \mathrm{~m})$ in diameter. Based on several years worth of exit velocity data for glove boxes obtained from LLNL NESHAPs reports ${ }^{24}$, HOTSPOT was run with three different exit velocities $\left(2.3,7.6\right.$, and $\left.12.8 \mathrm{~m} \mathrm{~s}^{-1}\right)$ representing the $15^{\text {th }}, 50^{\text {th }}$, and $85^{\text {th }}$ percentiles of exit velocities of glove boxes. The release was assumed to last 2 minutes. Stack height was assumed $9 \mathrm{~m}$ to clear the roof of the building. Meteorological data were prepared as described above using data for October for all years 1997 through 2005. The uncertainty was adjusted to include the highest likely dilution factor $\left(8.13 \times 10^{-4} \mathrm{~s} \mathrm{~m}^{-3}\right.$ at $\mathrm{F}$ stability $)$ with $97.5 \%$ probability.

The closest offsite building to LLNL in 1954 was at Location R (Figure 1) about $650 \mathrm{~m}$ to the southwest of Building 231. The upper confidence limit (UCL) of the hypothetical dose based on maximum ingestion assumptions at Location R was $2000 \mu \mathrm{Sv}(200$ mrem $)^{25}$. The hypothetical dose to an adult at this location based on realistic ingestion assumptions would have been less than the UCL of $390 \mu \mathrm{Sv}(39 \mathrm{mrem})$ on the realistic dose predictions.

$\underline{1964}$

There are three conflicting accounts of the total tritium releases that occurred in 1964. Memos (Foster 1964a, 1964b, 1964c, 1965) to the Atomic Energy Commission (AEC) for 1964 report a total of 12,500 Ci released, of which 10,000 Ci were released in the second quarter (Foster 1964c); Olsen (1973), when summarizing the history of tritium releases from LLNL to the AEC, reported a total release from the Tritium Facility in 1964 of $2.6 \times 10^{4} \mathrm{Ci}$; Souers (1988), in a summary presentation about past tritium releases to the Director's Office, reported a total release in 1964 of $26,500 \mathrm{Ci}$, of which

\footnotetext{
${ }^{24}$ National Emissions Standards for Hazardous Waste Pollutants, 40 CFR 61 Subpart H. (National Emission Standards for emissions of Radionuclides other than Radon from Department of Energy Facilities).

${ }^{25}$ The dose that could not have been exceeded is that of the $97.5 \%$ confidence limit of the dose predictions based on the very conservative assumption that the entire diet, except for grain, was contaminated.
} 
24,000 $\mathrm{Ci}$ had been released on an unspecified date and had been retrospectively classified as an accidental release ${ }^{26}$.

Because the quarterly reports to the AEC at the time included all releases, both routine and accidental, it seems improbable that any accidental release or routine puff release that occurred in 1964 would not have been reported. It thus appears that the $10,000 \mathrm{Ci}$ reported for the third quarter (Foster 1964c) was probably a puff release from normal operations that, for a reason that cannot be tracked, grew to $24,000 \mathrm{Ci}$ in later accounts. The routine release rate $(2,500 \mathrm{Ci})$ is the same based on the 1964 memos and on Souer's presentation if the $10,000 \mathrm{Ci}$ is treated as an accidental release and is subtracted from the total. If this reasoning is correct, there was neither an accidental release of $24,000 \mathrm{Ci}$ in 1964 nor a 24,000 Ci puff release from normal operations, although there was probably an acute release of 10,000 Ci during normal operations. Souers (2006) believes that, to be conservative, the $24,000 \mathrm{Ci}$ should be included when calculating doses from LLNL accidents.

This release presents many modeling problems because of the discrepancy in the magnitude of the release, whether or not the release was acute, and not having a date for the release. In Part 4 of the TDR, it was assumed that all releases from apparently normal operations, including the 10,000 Ci released between May 1 and July 31, 1964, were spread out over the entire year, although the uncertainty on the release rate was enlarged to account for the fact that the release of 10,000 Ci could have been acute. In addition, in this TDR, it has been assumed that an accidental 24,000 Ci release did occur, but the distribution was uniform, $0-24,000$ to account for the fact that the release might not have occurred. If doses from routine and accidental releases were summed, at least a portion of this release would be counted twice.

The closest building open to the public in 1964 (not a residence) was an automotive garage (Location Q, Figure 1) on the south side of East Avenue about $700 \mathrm{~m}$ southsouthwest of the Tritium Facility. Dose was calculated there as if it had been a residence, in keeping with LLNL's history of assigning the location of the MEI or site-wide maximally exposed individual ${ }^{27}$ as the closest structure to which the public has access. The UCL of the hypothetical dose to an adult at Location Q based on maximum ingestion assumptions was $64 \mu \mathrm{Sv}$ (6.4 mrem). The dose at the UCL to an adult based on realistic ingestion assumptions was $13 \mu \mathrm{Sv}(1.3 \mathrm{mrem})$.

January 20, 1965

About 3:30 pm on January 20, 1965, "a few cubic feet" of tritium (Valley Times, January $21,1965)$ were released accidentally through the south stack of the Tritium Facility. Most of the estimated 350,000 Ci HT were released within two minutes. Wind was blowing from the southwest (230 to 250 degrees) at seven knots (about $3.6 \mathrm{~m} \mathrm{~s}^{-1}$ ). The stability class used for the dose modeling in 1965 was B (Peterson et al. 2002). It did not rain that day.

\footnotetext{
${ }^{26}$ In Souers' presentation, planned puff releases were listed as accidental if they were over a certain size; releases were being viewed retrospectively, so what was considered an acceptable puff release in the early days of LLNL was no longer considered acceptable at the time of Souers' presentation.

27 A hypothetical person who receives, at the location of a given publicly accessible facility the greatest LLNL-induced effective dose equivalent from all sources of radionuclide releases to air at the site.
} 
A team was deployed to carry out air surveillance monitoring. Samples of tritium (HT or HTO) in air were taken at various locations on and off-site between 15:40 and 17:06. All samples were below the detection limit $\left(5 \mu \mathrm{Ci} \mathrm{m}^{-3} ; 1.8510^{5} \mathrm{~Bq} \mathrm{~m}^{-3}\right)$ except for two onsite samples, and these detections could not be confirmed. Tritium was measured in the urine of three workers (Peterson et al. 2002); the highest concentration observed was 24.3 $\mu \mathrm{Ci} \mathrm{L}{ }^{-1}\left(8.99 \times 10^{5} \mathrm{~Bq} \mathrm{~L}^{-1}\right)$.

This release was very straightforward to model in HOTSPOT given the information about wind speed, wind direction, and stability class. The report of the incident mentioned a ceiling of $600 \mathrm{~m}$, but in HOTSPOT this does not affect dilution factors during an acute release except at distances greater than $4 \mathrm{~km}$. Winds were blowing towards the north to northeast. In 1965, only two nearby residences would have been in the path of the plume (Locations $\mathrm{W}$ and $\mathrm{X}$ in Figure 1), but a dilution factor was estimated at a third residence north on Greenville near the railroad crossing (Location V) as well. There was very little difference between the dilution factors calculated for Location $\mathrm{W}$ and $\mathrm{X}$, but the house on Patterson Pass road (Location X), about 1,900 $\mathrm{m}$ from the Tritium Facility, was selected as the location of the MEI. Dilution factors were calculated for several combinations of assumptions. The common assumption was that the accidental release may have lasted for $1,2,5$, or 10 minutes.

- Wind from 230 degrees, wind speed $3.0^{28} \mathrm{~m} \mathrm{~s}^{-1}$, exit velocity $5.45^{29} \mathrm{~m} \mathrm{~s}^{-1}$

- Wind from 230 degrees, wind speed $3.6^{30} \mathrm{~m} \mathrm{~s}^{-1}$, exit velocity $5.45 \mathrm{~m} \mathrm{~s}^{-1}$

- Wind from 230 degrees, wind speed $3.0 \mathrm{~m} \mathrm{~s}^{-1}$, exit velocity $7.26 \mathrm{~m} \mathrm{~s}^{-1}$

- Wind from 230 degrees, wind speed $3.6 \mathrm{~m} \mathrm{~s}^{-1}$, exit velocity $7.26 \mathrm{~m} \mathrm{~s}^{-1}$

The above was repeated for wind from 230, 240 and 250 degrees.

A dilution factor and standard deviation was calculated for each location using the 48 dilution factors generated. The source term was given a triangular distribution with a maximum of 360,000 $\mathrm{Ci}$ (the contents of the canister) and a minimum of 207,000 $\mathrm{Ci}$ (one interpretation of the quantity of tritium measured by the ion chambers). The midpoint of the triangular distribution $(309,000 \mathrm{Ci})$ is a mean of various reported values.

The off-centerline dilution factor predicted for the TDR was $62.7 \%$ of the centerline value. The UCL of the off-centerline dose to an adult based on maximum ingestion assumptions was predicted to be $280 \mu \mathrm{Sv}(28 \mathrm{mrem})$. The most likely dose based on realistic ingestion assumptions would have been less than its UCL of $31 \mu \mathrm{Sv}(3.1 \mathrm{mrem})$ to an adult.

April 7,1966

An accidental release of 11,000 Ci HT took place on April 7, 1966 (May 1966); Souers (1988) reported this release as $14,000 \mathrm{Ci}$. This release was accidental, but because it was

\footnotetext{
${ }^{28}$ This value was used to calculate dispersion and dose in 1965 (Peterson et al. 2002).

${ }^{29}$ Although no calibration records for a Tritium Facility stack have been found that predate 1965, for the south stack, all exit velocities between 1968 and 1981 were consistently $5.7 \mathrm{~m} \mathrm{~s}^{-1}$ or less. Thus, although the accident-report (Peterson 2002) used a stack flow rate of 18,000 cubic feet per minute (i.e., an exit velocity of $7.26 \mathrm{~m} \mathrm{~s}^{-1}$ ) in one calculation, the use of the more conservative exit velocity was considered equally likely.

${ }^{30}$ This value is the equivalent of 7 knots mentioned in the 1965 accident report.
} 
so small, it did not have to be reported as accidental to the AEC, and its off-site impact, being small, was not assessed at the time.

The preparation of likely meteorological conditions for April used 15-minute data for the years 1997 through 2005. Because the time of the release was not known, data from between 6:00 and 18:45 were used to develop the generic wind file. The uncertainty on the source term (Table 2) takes into account uncertainty in stack flow rate, ion chamber accuracy, how well the sampled air represented the air emitted, and reported source terms.

For the TDR, it has been assumed that the garage on East Avenue (Location Q) was the location of maximum dose impact. The release has been assumed to be from Stack 1 of the Tritium Facility because, having a lower exit velocity than Stack 2, the air concentrations at the location of the MEI will be higher. Both assumptions are conservative.

The UCL of the dose based on realistic ingestion assumptions at Location Q was $14 \mu \mathrm{Sv}$ (1.4 mrem); the UCL of the dose based on maximum ingestion assumptions was $84 \mu \mathrm{Sv}$ (8.4 mrem).

August 6, 1970

An accidental release of about 290,000 Ci HT occurred just before 6:00 am and lasted about thirty minutes. The wind was out of the south-to-southwest at $1-2 \mathrm{~m} \mathrm{~s}^{-1}$. At the time (Myers et al. 1973), dispersion modeling was carried out to determine the path of the plume. Extensive environmental monitoring was also undertaken. Samples of tritium in air, water vapor, and vegetation were collected over a large area. Only one HT sample had concentrations higher than the detection limit $\left(5 \mu \mathrm{Ci} / \mathrm{m}^{3} ; 1.85 \times 10^{5} \mathrm{~Bq} / \mathrm{m}^{-3}\right)$, and that was a few hundred meters east of the Laboratory boundary. The exact time at which this sample was collected was not published.

The highest air moisture sample $\left(12,000 \mathrm{pCi} \mathrm{m}^{-3} ; 444 \mathrm{~Bq} \mathrm{~m}^{-3}\right)$ was obtained on-site between 13:50 and 16:00. The highest air moisture sample $\left(1,400 \mathrm{pCi} \mathrm{m}^{-3} ; 52 \mathrm{~Bq} \mathrm{~m}^{-3}\right)$ off-site was collected along Greenville Road between 08:00 and 09:00. For vegetation, the highest value in plant water was $1.2 \times 10^{6} \mathrm{pCi} \mathrm{L}^{-1}\left(44,000 \mathrm{~Bq} \mathrm{~L}^{-1}\right)$ on-site and $6.8 \times 10^{5} \mathrm{pCi} \mathrm{L}^{-1}\left(25,000 \mathrm{~Bq} \mathrm{~L}^{-1}\right)$ at two locations off-site north of Interstate 580 . The times at which the vegetation was sampled were not published.

Urine samples were taken from 31 employees who were on-site at the time; all samples were below the minimum detectable level of $0.0510^{5} \mathrm{pCi} \mathrm{L}{ }^{-1}\left(185 \mathrm{~Bq} \mathrm{~L}^{-1}\right)$. Dose modeling that assumed that $1 \%$ of the release was HTO yielded an inhalation dose to an individual on the plume centerline at the nearest perimeter location of about 3 mrem. A dose of 70 mrem to a hypothetical child from milk obtained from a hypothetical cow that ate grass at the maximum observed on-site concentration was calculated using the model of $\mathrm{Ng}$ et al. 1968; this dose was considered a conservative maximum.

This release was very straightforward to model given the meteorological conditions described by Myers et al. (1973). The source term used is the mean of two reported values $(287,000$ and 289,000 Ci); the standard deviation (Table 2) accounts for uncertainties in stack sampling. Dilution factors were calculated for five potential locations identified from a 1970 USGS map. Assuming E stability, a wind speed of 1.35 
$\mathrm{m}^{-\mathrm{s}}$, and calculating the dilution factors for every 5 degrees from 180 through 225 , mean dilution factors and standard deviations were determined for each location. Two locations to the north to northwest of the Laboratory (Locations V and W in Figure 1) had nearly the same dilution factors. Location $\mathrm{V}$ was chosen as the MEI because of its very slightly higher dilution factor. The off-centerline dilution factor was calculated to be $15.7 \%$ of the centerline value. This is reasonable given that light winds, such as occurred during the release, rapidly shift directions.

The UCL of the hypothetical dose based on maximum ingestion assumptions was estimated to be $850 \mu \mathrm{Sv}$ ( $85 \mathrm{mrem})$; the most likely dose would have been less than the $\mathrm{UCL}$ of $110 \mu \mathrm{Sv}(11 \mathrm{mrem})$, the dose based on realistic ingestion assumptions.

June 8, 1984

Between about 8:30 and 11:00 am (when the source of the release was discovered) on June 8, 1984, about 5,200 Ci of HT were released from the North Stack (\#2) of Building 331 (Hill 1984). A later analysis (Howe 1985a) estimates the release to have been 5,600 $\pm 500 \mathrm{Ci}$, with the first release of $1,350 \mathrm{Ci}$ at $8: 20 \mathrm{am}$ and a second release of $4,280 \mathrm{Ci}$ at $8: 40 \mathrm{am}$. Five silica gel samples from the ambient air tritium monitoring network were collected the day of the release, but no concentrations distinguishable from normal operations were found ${ }^{31}$. Vegetation sampling was carried out, and tritium levels were indistinguishable from routine sampling (with the possible exception of one sample of $29,000 \mathrm{pCi} \mathrm{L}^{-1}\left[1,100 \mathrm{~Bq} \mathrm{~L}^{-1}\right]$ on Laboratory property to the northeast adjacent to Greenville $\operatorname{Road}^{32}$ ). Based on measurements, it was estimated that the dose equivalent (from inhalation) received by the hypothetical MEI on the plume centerline at the perimeter of the site would have been below 0.02 mrem (Howe 1985a).

No records of wind speed, wind direction or stability class are available now from the LLNL meteorological database for June 8, 1984, but it is known that no rain fell. However, in 1984, the Atmospheric Release Advisory Capability (ARAC), using actual meteorological conditions during the time period 1500 GMT to 2200 GMT, calculated a maximum dose equivalent of $2.3 \mathrm{mrem}$ (from inhalation assuming the release was HTO) (Howe 1985a). Howe reduced this estimate by a factor of 400 (using a conservative ratio of HTO/HT inhalation dose of 400) and concluded that maximum dose equivalent to an individual at the site boundary was between 0.02 and $0.06 \mathrm{mrem}$ (from inhalation). These doses were less than $0.01 \%$ of the appropriate DOE guidelines.

At the time of the incident, urine samples were taken from employees within and outside the building. All samples were below the limit of sensitivity, which implied a dose of less than $0.017 \mathrm{mrem}(<0.17 \mu \mathrm{Sv})$ (Howe 1985a). These doses would have been from inhalation alone.

For the TDR, wind data for the 15-minute segments between 8 and 9:15 am PDST (a time period that included when essentially all of the release occurred) were obtained for

\footnotetext{
${ }^{31}$ This assessment is based on review of the air tritium records in the database of the Data Management Team of the Operations and Regulatory Affairs Division. Howe (1985a) stated, "analysis of silica gel samples taken at the site boundary indicated levels at or below the level of sensitivity suggesting a very low airborne concentration at the boundary $\left(4 \times 10^{-11} \mu \mathrm{Ci} \mathrm{m}^{-3} ; 1.5 \mathrm{~Bq} \mathrm{~m}^{-3}\right)$.

32 This sample was taken from an irrigated lawn. There were no data to compare against this sample to determine if the level was caused by the release (Hill 1984).
} 
the months of June from 1997 through 2006 to estimate the dilution factor for the thirty minutes assumed for the release. It would appear from the pattern of vegetation sampling (File B331 1984) that the wind was blowing from between about 210 to 260 degrees (S/SSW to WSW/W) based on the numbers of samples taken along the perimeter and farther from Laboratory downwind from those directions compared with the number of samples taken elsewhere (File 331 1984). Given the duration of the release and the area sampled, the MEI potentially could have been at any of the locations shown in Figure 1 between the north and the east of the laboratory. Dilution factors at each potential location were calculated for every 10 degrees between 180 and 270 initially. However, the highest mean weighted integrated air concentration (based on 220 to 260 degrees, which gave a higher dilution factor than 210 to 260 degrees) was calculated to have been at Location A, a house across Greenville Road from what is now the UNCLE Credit Union; the predicted air concentration at that location was higher than that at any other location regardless of the assumptions about wind direction. The off-centerline dilution factor was $27.3 \%$ of the centerline estimate ${ }^{33}$.

The UCL of the dose based on maximum ingestion assumptions was estimated at $7.2 \mu \mathrm{Sv}$ $(0.72 \mathrm{mrem})$; the UCL of the dose based on realistic ingestion assumptions was $0.99 \mu \mathrm{Sv}$ (0.099 mrem).

January 24, 1985

Starting at 8:50 am, Thursday January 24, 1985, and continuing for nearly seven hours, approximately $1,000 \mathrm{Ci}$ of HT were accidentally released from the North Stack (\#2) of the Tritium Facility (Howe 1985b). The chart recorder indicated that most of the activity was released in first 19.2 minutes and that the release rate had three phases.

At the time of the release, using a wind speed of $2.4 \mathrm{~m} \mathrm{~s}^{-1}$ and Stability Class $\mathrm{C}$, the dose at the site boundary was estimated to have been 22 nanorem $(0.00022 \mu \mathrm{Sv})$ to the whole body and 185 nanorem $(0.00185 \mu \mathrm{Sv})$ to the lung from inhalation of HT alone.

To model the dose for the TDR, historical data were obtained from the LLNL meteorological tower for the half-an-hour that included the bulk of the release. Between $8: 45$ and 9:00, the wind was from the east ( 80 degrees) at $2.4 \mathrm{~m} \mathrm{~s}^{-1}$; between 9:00 and $9: 15$, the wind was from the east-northeast (67 degrees) at $2.0 \mathrm{~m} \mathrm{~s}^{-1}$. Wind speed and temperatures for that morning suggest a stability class of D (Bowen 2006). Potential locations of the MEI were Q, R, S, and T (Figure 1), because SNL/CA had not yet acquired the buffer zone. These locations were given $x-y$ coordinates in HOTSPOT, and calculations were made for each location using the two sets of 15-minute wind direction and wind speed data for both $\mathrm{C}$ and $\mathrm{D}$ stability classes and two different exit velocities. The dilution factors calculated for each location were averaged ${ }^{34}$. Location $\mathrm{S}$ had a much higher dilution factor than the other locations and was chosen as the MEI. The offcenterline dilution factor for C stability was $59.5 \%$ of the centerline estimate; for D stability, the dilution factor was $51.9 \%$ of the centerline estimate.

\footnotetext{
${ }^{33}$ This release was also modeled assuming the release occurred uniformly between 8 and 11 am PDST. Assuming a shorter release time (i.e., $30 \mathrm{~min}$ ) doubled the dilution factor.

${ }^{34}$ The highest dilution factor based on 15-minute meteorological data and assuming the release was uniform over seven hours was calculated for Location Q; it was slightly less than half the one calculated for Location S for the 19.2 minute release.
} 
The UCL of the dose based on maximum assumptions was estimated at $7.0 \mu \mathrm{Sv}(0.70$ mrem); the UCL of the dose based on realistic assumptions was $0.80 \mu \mathrm{Sv}(0.080 \mathrm{mrem})$.

\section{SNL/CA}

January 1986 (Garcia and Gorman 1996)

A weld crack in a storage container caused a leak of HTO. The spill occurred on a Friday when the ventilation fans were shut down for maintenance. The puddle was discovered Saturday when room monitors alarmed. Fans were turned on between 7:30 and 8:30 am to help evaporate the liquid. It took 8-10 hours for the liquid to evaporate (Hafner 2006) through the stack. The tritium released from the stack was measured as $200 \mathrm{Ci}$ HTO. Compared with annual release rates of HTO from LLNL and SNL/CA for several years, $200 \mathrm{Ci}$ was a relatively small release, but in 1986 it was about one-third of the HTO released from the TRL and thus has been modeled as an accidental release.

The date of the release has not been found in available records. Hafner (2006) remembers that he was called in on a Saturday morning and the weather was dry. This eliminates the first Saturday in January 1986, because it rained. Hafner also remembers that it was early in the month. Thus a release date of January 11 has been postulated. Weather data from LLNL were obtained for all the dry Saturdays in January 1986, and conditions were similar enough that modeling the release based only on the data from January 11 should be appropriate. This release has been modeled as a stack release even though some tritium must have escaped from the building itself.

Air concentrations at locations of the potential MEI (Locations $\mathrm{H}-\mathrm{P}$ in Figure 1) were predicted using HOTSPOT for each of 41 15-minute meteorological data sets of wind speed and wind direction obtained from LLNL records. Stability class was assumed to be D (Bowen 2006). The MEI was determined to be Location L, a structure on Vasco Road west-southwest of SNL/CA. The off-centerline dilution factor was $27.7 \%$ that of the straight-line dilution factor.

The UCL of the dose based on maximum ingestion assumptions was estimated at $2.4 \mu \mathrm{Sv}$ $(0.24 \mathrm{mrem})$; the UCL of the dose based on realistic ingestion assumptions was $0.44 \mu \mathrm{Sv}$ (0.044 mrem).

\section{August 18, 1987}

An "instantaneous" release of 1,100 Ci of HT caused the evacuation of the TRL, and one operator received a dose of 15 mrem (Garcia and Gorman 1996). The release occurred about mid-day on August $18^{\text {th }}$, most probably after lunch (Garcia 2006). LLNL meteorological data are available for this date. Assuming the release took place between 1 and $3 \mathrm{pm}$, the 15-minute wind speeds and wind directions were used in HOTSPOT to estimate dilution factors at Location $\mathrm{J}-\mathrm{Q}^{35}$ (Figure 1) for both stability class $\mathrm{C}$ and $\mathrm{D}$ (Bowen 2006). Winds were blowing towards the NE/ENE from the ESE/SE at $4.8 \mathrm{~m} \mathrm{~s}^{-1}$ $\pm 15 \%$ on average. The highest dilution factor under D stability was calculated at Location K, a structure off Jerrold Road (Figure 1). The highest dilution factor for C stability was found at Location $\mathrm{M}$, but it was about $60 \%$ of the value at Location $\mathrm{K}$. The

\footnotetext{
${ }^{35}$ Location Q was included although it is unlikely that any member of the public had access at the time of the release, because SNL/CA had purchased 228 acres that included Location Q between 1986 and 1987 (Holland 1999).
} 
off-centerline dilution factor for Location $\mathrm{K}$ was $20.2 \%$ of the straight-line dilution factor with mean wind speed and D stability.

The UCL of the dose based on maximum ingestion assumptions was estimated at $2.1 \mu \mathrm{Sv}$ $(0.21 \mathrm{mrem})$; the most likely dose would have been less than $0.29 \mu \mathrm{Sv}(0.029 \mathrm{mrem})$, the UCL of dose based on realistic assumptions.

\section{DISCUSSION}

The intention of the TDR was to predict doses based on reasonable assumptions that would nevertheless err on the side of over-estimation. Predictions would be safely conservative but not overly so. Contributing to this conservatism are the assumptions that

- All structures open to the public (such as the automotive garage - Location Q) were potential residences of the hypothetical MEI.

- When meteorological conditions were unknown, the location of the MEI was assumed to be the nearest structure to the release point.

- When the MEI could have been at several potential locations, the chosen location always had the highest integrated tritium in air concentration after the release.

- The highest probable dilution factor (which will result in the highest likely air concentration ${ }^{10}$ ) was included in each uncertainty distribution.

- When time of release was unknown, work hours were assumed to include early morning to early evening to include low wind speeds and E and F Stability Classes, conditions that will result in high dilution factors.

- All food grown was exposed to a single air concentration calculated for a single cubic meter of air.

- The assumed ingestion rate of homegrown foods was much greater than expected for an individual growing a few vegetables for home consumption.

- Ingestion of vegetables could occur within in an hour of the passage of the plume,

- The MEI lived at the exposed location $100 \%$ of the time.

\section{Predictions}

Dispersion modeling and air concentrations

The magnitude of the dilution factor depends upon how close the MEI is to the source and upon the meteorological conditions during the release. Thus, the largest centerline dilution factor was for the accidental release in 1954 (Table 2). Not only was it assumed that the MEI was close to the source, but the distribution of stability classes was quite heavily weighted to F (F stability accounted for $12 \%$ of all the data; E stability accounted for an additional 5\% for October data) with very low wind speeds. The second highest dilution factor for a centerline dose was for 1970 when the stability class was E and the wind speed was low. It was about a factor of ten lower than the dilution factor of 1954, but the MEI was more than three times farther away from the source than in 1954. 
When non-centerline dilution factors were estimated, the dilution factor for 1954 was still the highest, but the second highest was for 1966, while the dilution factor for the 1970 release dropped to fifth place in the list (Table 2). Quite possibly, the use of the mean factor $(0.389 \pm 0.165)$ by which the centerline dilution factors for 1954,1964 , and 1966 were reduced did not adequately account for the extreme reduction seen at one location when the winds were light (i.e., 1970), but this helps assure that the dilution factors were not underestimated.

Given the assumptions of the TDR, the minimum uncertainty about the dilution factor was a factor of 16 (UCL divided by lower confidence limit). This factor of 16 was the uncertainty about the dilution factor for the years when the meteorological data were known $(1985,1986$, and 1987), for June 1984, when the maximum likely dilution factor from the 15-minute data resulted in an uncertainty less than that assigned to HOTSPOT $( \pm 80 \%)$, and for 1964 , when the use of hourly mean data suppressed the variation that results in potential maximum dilution factors when 15-minute data are used. The highest uncertainties were for 1966 (a factor of 196 because of the maximum dilution factor derived from the generic 15-minute data) and 1970 (a factor of 167 because of the large variation in dilution factors at Location $\mathrm{X}$ due to the extremely variable winds), respectively.

During a normal workday from about 8 am until 5 pm, stability classes are usually restricted to A, B, C, and D, particularly in the summer. Under these conditions (e.g., June 1984), there is not a great deal of variability in the dilution factors. However, when an accidental release, such as the one in 1970, occurs during early morning or into the evening, dilution factors and dose impacts will be higher because wind speeds are lower and $\mathrm{E}$ and $\mathrm{F}$ stability classes can occur; centerline doses are particularly impacted by these assumptions because the plume is assumed to travel in a straight line (which it does not). For the accidental releases in 1954 and $1966^{36}$ that occurred at unknown times, the assumption that work may have taken place outside core work hours was necessary so that meteorological data from early morning and early evening hours could be used to calculate potential dilution factors. This approach assured that the predicted potential dose would probably not be underestimated. Higher dilution factors contribute to higher dose and to higher uncertainty about the dose.

Another unknown for the releases of 1964 and 1966 was their duration. The major releases of 1965 and 1970 were less than 10 minutes and 30 minutes respectively. The shorter the release, the higher the dose impact at any one particular location, although if conditions are stable, the duration of the release will have less effect on the timeintegrated air concentration than if conditions are unstable. Although some accidental releases extended over several hours (e.g., the accidental releases of 1984 and 1985 lasted 2.5 and nearly 7 hours, respectively), nearly all of the tritium in those incidents was released in the first 30 minutes. Thus, to err on the side of conservatism, no release of unknown duration was assumed to have exceeded 30 minutes (Table 1).

Unfortunately, by the time the first air measurements can be made after an acute release, the plume predicted by the model will have already passed, so there is no way to test

\footnotetext{
${ }^{36}$ The time of release was not known in 1964 either, but, as mentioned, the use of hourly data damped the potential for high dilution factors.
} 
predictions of air concentrations after an acute release unless the plume passed directly over an ambient air tritium monitor. According to Myers et al. (1973), on-site air measurements were made as early as 8:30 the morning of the 1970 release, but that was 2.5 hours after the release.

Models can be tested after an acute release if the environment has been well instrumented, as was done during the experimental release of October 27, 1969 (Silver 1970), which was carried out to test a dispersion model. Details of this experiment are included in Part 4 of the TDR, where it included with the routine releases for 1969. The magnitude of the conversion from HT to HTO observed in this experiment was similar to, although perhaps about a factor of two lower than, that estimated at $1,000 \mathrm{~m}$ from measured data at 5, 50, 183 and $400 \mathrm{~m}$ after a $100 \mathrm{Ci}$ half-hour release of HT that took place in June 1987 at the Chalk River Laboratories of Atomic Energy of Canada (Ogram 1988). More cannot really be said about the comparison because so many other conditions of the LLNL release were unknown. It appears that the arc of samplers extended over uncultivated ground. Earlier in the year, this ground would have been very dry and perhaps conversion might not have occurred so rapidly ${ }^{37}$, but an accumulation of 0.85 inches of rain between October 15 and 17, 1969 would have presumably raised the moisture content of the soil ${ }^{38}$.

A comparison of results of cumulative air concentrations between the RASCAL model used by the Agency for Toxic Substances and Disease Registry (ATSDR 2003 ${ }^{39}$ ) and the assumptions and parameter values used in HOTSPOT was made for the accidental release in 1965. Using the ATSDR assumptions ${ }^{40}$, HOTSPOT predicted $0.49 \mathrm{Ci}$-sec m${ }^{-3}$ at 1 mile on the plume centerline, while RASCAL predicted $0.643 \mathrm{Ci}-\mathrm{sec} \mathrm{m}^{-3}$ at one mile. This difference is only $30 \%$.

A comparison was also made between HOTSPOT centerline results and those reported in 1965 (Peterson et al. 2002) using the assumptions for the dispersion calculations of 1965 ( 1 minute release, B stability class, $3 \mathrm{~m} \mathrm{~s}^{-1}$ wind speed and $7.26 \mathrm{~m} \mathrm{~s}^{-1}$ exit velocity from the stack). Results were very similar. On average, over the distances of the comparison (from 0.1 to $100 \mathrm{~km}$ ), HOTSPOT's predictions were 20\% higher than the 1965 predictions. The most extreme maximum and minimum differences were a $71 \%$ higher prediction by HOTSPOT at $2 \mathrm{~km}$ and a $20 \%$ lower prediction at $7 \mathrm{~km}$.

ATSDR (2003) also modeled the time-integrated air concentration at the location of the MEI after the 1970 release. Assuming $1.5 \mathrm{~m} \mathrm{~s}^{-1}$ wind speed and E stability the cumulative air concentration at 1 mile $^{41}(1.6 \mathrm{~km})$ was estimated at $7.4 \mathrm{Ci}-\mathrm{s} \mathrm{m}^{-3}$. Using HOTSPOT with the same assumptions as were used in the ATSDR calculations, a time-

\footnotetext{
${ }^{37}$ Conversion rates are rapid as long as the soil is not saturated or too dry (less than $3 \%$ water by volume; Bunnenberg et al. 1986).

${ }^{38}$ The LLNL experiment lends support to the possible universality of the conversion rates measured at Chalk River that were used to develop the HT-to-HTO conversion factor used in DCART (see Part 1 of the TDR).

39 The Agency for Toxic Substances and Disease Registry calculated dose to the MEI after the 1970 accidental release of HT and calculated air concentrations after the 1965 release as part of a Public Health Assessment of the Livermore site that was completed in 2004.

${ }^{40} 350,000 \mathrm{Ci}$, wind speed 7 knots $\left(3.6 \mathrm{~m} \mathrm{~s}^{-1}\right)$, stability class B, 18,000 cubic feet per minute $\left(7.26 \mathrm{~m} \mathrm{~s}^{-1}\right)$ exhausted from the stack.

${ }^{41}$ The mean inhalation dose from HT predicted to an adult in 1970 by ATSDR was 0.1 mrem $(1 \mu$ Sv $)$; inhalation dose from HTO was calculated from re-emission over 12 days and was 10 mrem $(100 \mu \mathrm{Sv})$, including skin absorption.
} 
integrated air concentration of $7.5 \mathrm{Ci}-\mathrm{s} \mathrm{m}^{-3}$ was predicted at 1 mile, which is very good agreement.

\section{Dose predictions}

Two sets of dose predictions for all accidental releases are compared in Figure 2. The higher set of dose predictions ("maximum") is based on the assumption that the entire diet except for grain was contaminated, while the lower set of dose predictions ("realistic") is based on the assumption that the MEI grew vegetables and raised animals for his own consumption but that these plant and animal products could only have been contaminated if they had been exposed to the tritium plume at some point during their growth. Both sets of predictions are conservative (particularly because the location of the MEI was chosen to be a location of greatest exposure), but the assumptions about maximum ingestion were chosen so that the UCL of the predicted maximum dose is actually one that could not have been exceeded when meteorological conditions were unknown. Although the conservatism in the estimation of the dilution factor was increased whenever possible, there is a slight risk that the predicted air concentrations might have been underestimated when the time of the release was unknown. Therefore, the assumption that the entire diet except grain was contaminated adds another (probably unnecessary) layer of health protectiveness.

When meteorological conditions were known, the assumptions behind the realistic predictions are so conservative that the dose that could not have been exceeded has been defined as an average of the UCL of the dose based on realistic ingestion assumptions and the mean of the dose based on maximum ingestion assumptions. The values have been averaged because they are very similar for all releases (sometimes one is the higher, sometimes the other).

Although the emphasis in this report is on the UCLs or the doses that could not have been exceeded, it is very important to remember that the likely doses - the doses that were received by real members of the public - are expected to be much lower for both sets of assumptions. If the dilution factors were truly representative of wind conditions, the likely doses at the chosen locations of the MEI for all releases would fall within or somewhat below (given the conservative ingestion assumptions) the confidence intervals on the doses based on realistic assumptions. At locations at which real people might have lived for all releases, the doses could have even lower. For example, the probability that the daytime winds would carry the plume over the closest residence (Location R) in the October 1954 was less than 10\%; in April 1966, the probability that the plume would have passed over Location Q is smaller - less than 5\% (estimates based on Gouveia and Chapman 1989). Thus the probability is very good that the actual dose received by the true MEI was less than any reported here because the wind most probably was blowing towards a receptor farther from the source than was the conservatively chosen $\mathrm{MEI}^{42}$. However, given the great uncertainties that cannot be quantified and the need not to underestimate dose, the concept of dose that could not have been exceeded has been introduced.

\footnotetext{
${ }^{42}$ On average, the concentration (or dose) for a radionuclide that doesn't deposit or that gets re-emitted quickly, like tritium, will drop off with distance raised to the power 1.2. For other radionuclides, or for tritium in this TDR when HOTSPOT was used without the deposition of tritium, the concentration is expected go drop off with distance raised to the power 1.5 (UNSCEAR 2000).
} 
The predicted dose that could not have been exceeded of $2 \mathrm{mSv}$ (200 mrem) to an adult and $3 \mathrm{mSv}$ (300 mrem) to a child or infant for the 1954 accidental release of HTO is the highest dose predicted in the TDR because HTO (rather than HT) was released, the meteorology was not known so that conservative assumptions had to be made about the dilution factor, and the closest public structure to the Laboratory was assumed to be the location of the MEI. The magnitude of the dose is most likely overestimated, given the small likelihood that the winds were blowing towards Location $\mathrm{R}$ at the time of the release. Given the number of deliberately conservative assumptions, it is probably that the likely dose received by a real individual is lower, and perhaps much lower, than the dose that could not have been exceeded. If the meteorological conditions were assessed properly, the dose that could not have been exceeded would have been $360 \mu \mathrm{Sv}$ (36 mrem).

The dose to an adult predicted for the 1970 release is the second highest dose calculated in the TDR (Figure 2). The UCL of the maximum dose $(850 \mu \mathrm{Sv}$ [85 mrem]) is a factor of 2.4 lower than that for 1954 , and the mean realistic dose $(17 \mu \mathrm{Sv}[1.7 \mathrm{mrem}])$ is a factor of 3.8 lower than that for 1954. The hypothetical dose for 1970 is as accurate as it can be, given the methods of predicting dose and the assumptions made. The uncertainty on the 1970 release, although the largest of all the predictions (the UCL for the maximum dose divided by the lower confidence limit for realistic dose is a factor of about 4,900) is reasonable given all the assumptions. It is thus safe to state that the true dose lies within the confidence interval of the dose based on realistic ingestion assumptions and that the dose that could not have been exceeded was $120 \mu \mathrm{Sv}(12 \mathrm{mrem})$ to the hypothetical adult and $170 \mu \mathrm{Sv}(17 \mathrm{mrem})$ to the hypothetical child or infant.

Dose from the 1970 release was also calculated immediately after the release (Myers et al. 1973) and as part the Public Health Assessment (PHA) of ATSDR effort (2003). These results are compared with the TDR doses in Table 5.

Table 5.Comparison of doses $(\mu \mathrm{Sv})$ to the MEI predicted by the TDR, ATSDR (2003), and Myers et al. (1973) for the 1970 accidental release. Confidence intervals represent the $90^{\text {th }}$ percentile (UCL is $95 \%$ ). All doses, if rounded, were rounded to two significant figures so doses may not sum to the total. Symbols: $A=A T S D R, T=T D R ; M=$ Myers et al. T- $\mathrm{m}$ is the dose assuming a complete diet without grain; T-r is the dose assuming a realistic diet.

\begin{tabular}{ccccccccccc}
\hline & $\begin{array}{c}\text { Inhalation and skin } \\
\text { absorption }\end{array}$ & \multicolumn{3}{c}{ Ingestion } & \multicolumn{3}{c}{ Total Dose } \\
& A & T & M & A & T-m & T-r & M & A & T-m & T-r \\
\hline Infant mean & & 0.96 & & & 190 & 22 & & & 190 & 23 \\
Infant 95\% CL & & 3.7 & & & 750 & 83 & & & 760 & 86 \\
Child mean & 340 & 1.4 & & 4 & 200 & 22 & & 340 & 200 & 24 \\
Child 95\% CL & 1400 & 5.2 & & 15 & 770 & 84 & 700 & 1400 & 780 & 89 \\
Adult mean & 100 & 1.1 & 30 & 1 & 130 & 16 & & 100 & 140 & 17 \\
Adult 95\% CL & 400 & 4.3 & & 4 & 520 & 60 & & 400 & 530 & 64 \\
\hline
\end{tabular}

The locations of the MEI were different for the three assessments of the 1970 release. For Myers et al., the inhalation dose was calculated at the nearest perimeter location downwind of the release $(0.6$ to 0.75 miles [0.96-1.2 $\mathrm{km})$ ); ATSDR calculated the inhalation dose at the location of the maximum air concentration $(1-1.5$ miles $[1.6-2.4$ 
$\mathrm{km}]$ ); inhalation dose for the TDR was calculated at the location of the closest structure downwind of the Livermore site $(2.0 \mathrm{~km})$. The Myers et al. dose $(30 \mu \mathrm{Sv}$ [3 mrem]) was based on the conservative assumption that $1 \%$ of the release was HTO; ATSDR's mean dose to an adult (100 $\mu \mathrm{Sv}$ [10 mrem]) was based on the inhalation of HTO emitted from the soil for the 12 days following the release. The result for the TDR is much lower than either the Myers et al. or ATSDR prediction because only the upper end of the HTO/HT inhalation dose ratio based on UFOTRI modeling equals the assumption that $1 \%$ of the release was HTO and because the MEI for the TDR was about twice as far away as the Myers et al. calculation (which would mean roughly a decrease in dose by a factor of 2.3 from $30 \mu \mathrm{Sv}$ [3 mrem] to $13 \mu \mathrm{Sv}$ [1.3 mrem]). Using the dispersion assumptions of the TDR in HOTSPOT and Myers et al.'s assumption that the release was 1\% HTO, an inhalation centerline dose of $21 \mu \mathrm{Sv}(2.1 \mathrm{mrem})$ at $1.2 \mathrm{~km}$ was calculated; when a wind speed of $1 \mathrm{~m} \mathrm{~s}^{-1}$ was used, the inhalation centerline dose predicted by HOTSPOT rose to $29 \mu \mathrm{Sv}(2.9 \mathrm{mrem})$ at $1.2 \mathrm{~km}$. The dispersion modeling and inhalation assumptions used by Myers et al. and in HOTSPOT are therefore very similar.

Using the UFOTRI equation method and assuming the release had been $1 \% \mathrm{HTO}$, the mean tritium dose from inhalation and ingestion (regardless of ingestion assumptions) was calculated to be between 21 and $29 \%$ higher for adult, child, and infant than it was when the release was assumed to be $100 \%$ HT. If the release had been $1 \% \mathrm{HTO}$, the dose that could not have been exceeded based on the realistic ingestion assumptions of the TDR would have been $140 \mu \mathrm{Sv}$ (14 mrem) to an adult and $210 \mu \mathrm{Sv}(21 \mathrm{mrem})$ to a child.

The ingestion dose to a child $(700 \mu \mathrm{Sv})$ calculated by Myers et al. was intended to be impossibly high. It assumed that the child drank milk from a cow (assumed, contrary to fact, to be onsite) that consumed grass with the highest measured concentration of tritium. The Myers et al. estimate and the $95 \%$ confidence limit for the maximum dose predicted by the TDR are very similar, which demonstrates that the TDR's dose based on maximum ingestion assumptions is also impossibly high. The ATSDR $95 \%$ confidence limit for the child is lower than either prediction by about a factor of 50. ATSDR used the concentrations measured in vegetation and milk after the release, along with water contents and a factor to account for the dose effect due to OBT to calculate ingestion doses. However, ATSDR's approach was based on equilibrium relationships between HTO and OBT in plant and animal products and did not account for the potential importance of ingestion after an accidental release of HT. Nevertheless, ATSDR's predicted ingestion doses to child and adult fall within the TDR's $90 \%{ }^{43}$ confidence intervals (the $5 \%{ }^{43}$ confidence limit for the child and adult is 0.41 and 0.28 respectively) for the realistic doses. The uncertainty on the TDR's doses embraces both the Myers et al. and ATSDR predictions.

The total doses to child and adult predicted by ATSDR and this TDR (maximum ingestion assumed) are similar, but the assumptions behind them are very different, as described above. The doses based on realistic ingestion assumptions are much lower than the doses calculated by ATSDR. ATSDR considered their predicted doses to be below levels of health concern, so the doses predicted by the TDR are also below levels of health concern.

${ }^{43}$ This level of probability was selected instead of $95 \%$ confidence interval because a $90 \%$ confidence interval was used by ATSDR for calculations. 
The 1965 HT release was the largest in LLNL history. Because there is a record of the meteorological conditions during the release and the nearest possible location for the MEI was nearly $2 \mathrm{~km}$ from the release, the mean dose consequences of the 1965 release were about $40 \%$ that of the HT release of 1970 and $14 \%$ of the HTO release in 1954 . The dose that could not have been exceeded was $43 \mu \mathrm{Sv}(4.3 \mathrm{mrem})$ to an adult and $64 \mu \mathrm{Sv}(6.4$ mrem) to a child or infant. ATSDR (2003) did not explicitly calculate doses from the 1965 release because they determined that at the location of maximum impact to the public ( $1-1.5$ miles) air concentrations and deposition were less than for the 1970 release. (Even the air concentrations and deposition that occurred on the Livermore site in 1965 were lower than for the 1970 release offsite.) ATSDR reasoned that if there were no public health hazard from the 1970 release, then there would be none from the 1965 release. A mean dose to an adult in 1965 of $9 \mu \mathrm{Sv}(0.9$ mrem) can be estimated based on predicted soil emission rates at 1 mile (see Table 1, ATSDR 2003) scaled to the difference in magnitude between the 1965 and 1970 accidents. A similar estimate of an ATSDR dose to the $1965 \mathrm{MEI}$ can be made by scaling the cumulative air concentrations after the releases (see Tables A4 and A5 [ATSDR 2003]). This estimate of $9 \mu$ Sv lies within the TDR's 95\% confidence interval for realistic dose assumptions.

Mean dose impacts for 1964 and 1966 were essentially the same ${ }^{44}$ and only about $25 \%$ to $40 \%$ those for $1965^{45}$ even though more than 25 times more HT was released in 1965 than in the other two years (Table 2) and the UCL of the maximum dose was highest ${ }^{46}$ for 1965. The dilution factors for 1964 and 1966 (Table 2) are essentially identical even though they were prepared from very different data sets (hourly annual vs. 15-minute for April). They are about nine times greater than the dilution factor for 1965. For the 1965 release to have had the same impact at Location Q (the hypothetical MEI in 1964 and 1965) as it did at Location X (MEI for 1965), the release would have had to have been only about 100,000 $\mathrm{Ci}$ (or one-third the actual release). Therefore, most of the difference between the 1965 release and the releases of 1964 and 1966 is accounted for by the difference in dilution factor, which is a function of the wind speed, stability class, and the duration of the release (stack parameters being essentially the same).

The estimated doses that could not have been exceeded, however, are higher for the 1964 and 1966 releases than for the release in 1965 because meteorological conditions were unknown in 1964 and 1966 and known in 1965. The doses that could not have been exceeded for 1964 were $64 \mu \mathrm{Sv}(6.4 \mathrm{mrem})$ to an adult and $99 \mu \mathrm{Sv}$ (9.9) mrem to a child or infant; for 1966, the doses that could not have been exceeded were $84 \mu \mathrm{Sv}(8.4 \mathrm{mrem})$ to an adult and $120 \mu \mathrm{Sv}(12 \mathrm{mrem})$ to a child or infant.

The uncertainty in the dose predictions for 1964 (the UCL of the maximum dose divided by the lower confidence limit of the realistic dose) is a factor of 710, which is smaller than the confidence intervals for the other two accidents without known meteorological conditions (1954 - a factor of 1,200 and 1966, a factor of 3,800). This relatively small confidence interval is counter-intuitive, because the accidental release in 1964 was the

\footnotetext{
${ }^{44}$ For 1964 the mean doses (based on maximum and realistic ingestion assumptions, respectively) were $12 \mu \mathrm{Sv}(1.2$ mrem) and $2.4 \mu \mathrm{Sv}(0.24 \mathrm{mrem})$. Similarly, for 1966 the mean doses were $13 \mu \mathrm{Sv}(1.3 \mathrm{mrem})$ and $2.2 \mu \mathrm{Sv}(0.22$ mrem).

${ }^{45}$ For 1965 the mean doses (based on maximum and realistic ingestion assumptions, respectively) were $54 \mu \mathrm{Sv}$ and 6.1 $\mu \mathrm{Sv}$.

${ }^{46} 280 \mu \mathrm{Sv}$ ( $\left.28 \mathrm{mrem}\right)$.
} 
one that might not have occurred and had the largest uncertainty about the source term. The size of the 1964 confidence interval is small, however, because the meteorological data used to select the extreme conditions to obtain the highest likely dilution factors were obtained from hourly averages in which the fluctuations seen in the 15-minute data are damped out. Thus the uncertainty about the dose predictions may be artificially small. Applying the greatest magnitude of uncertainty seen in the TDR (that for 1970), these doses could be shifted upwards by about a factor of two. The confidence interval on the 1966 release is large because of the generic meteorological data for April.

The doses and uncertainties for the accidents of June 8, 1984, and January 24, 1985, are within $10-15 \%$ of each other ${ }^{47}$ (Figure 2), even though the 1984 release was about 5000 $\mathrm{Ci} \mathrm{HT}$ and the 1985 release was only about $20 \%$ as large. The differences are due to the locations of the MEI and the meteorological conditions either assumed (1984) or known (1985). Doses from these releases were an order of magnitude or more lower than doses from earlier accidents. The dose that could not have been exceeded in 1984 was $7.2 \mu \mathrm{Sv}$ $(0.72 \mathrm{mrem})$ to an adult and $11 \mu \mathrm{Sv}(1.1 \mathrm{mrem})$ to a child or infant. These values are the UCLs of the dose based on maximum ingestion assumptions because, although the wind direction was known with reasonable certainty in 1984, the wind speed and stability class were not. In contrast, the dose that could not have been exceeded in 1985, when meteorological conditions were known, was $1.1 \mu \mathrm{Sv}(0.11 \mathrm{mrem})$ to an adult and $1.6 \mu \mathrm{Sv}$ (0.16 mrem) to a child or infant.

Although the UCLs of the maximum doses for the two SNL/CA accidental releases in 1986 and 1987 are within about $10 \%$ of each other ${ }^{48}$, the mean realistic dose for 1986 is twice that of $1987^{49}$. On the one hand, the releases were very different (HTO in 1986 and HT in 1987; duration - 480 - 600 minutes in 1986; 2 minutes in 1987). On the other hand, the meteorological conditions were similar (D stability and about $4.5 \mathrm{~m} \mathrm{~s}^{-1}$ mean wind speed). The MEI in both cases was more than $1 \mathrm{~km}$ from the stack. The uncertainty about the HT release is greater than for the HTO release due to the additional uncertainty associated with converting HTO inhalation doses to HT inhalation doses before the ingestion to inhalation ratio is applied. The difference between the mean doses predicted using the maximum dose or realistic dose assumptions ranges from a about factor of 5 for $1986^{50}$ to about a factor of 8 for $1987^{51}$.

The dose that could not have been exceeded in 1986 was $2.4 \mu \mathrm{Sv}(0.24 \mathrm{mrem})$ to an adult and $3.8 \mu \mathrm{Sv}(0.38 \mathrm{mrem})$ to a child or infant. These values are the UCLs of the dose based on maximum ingestion assumptions to ensure that the doses were not underestimated, because, although the meteorological conditions of the release were known, other aspects of the release were highly uncertain. In contrast, the dose that could not have been exceeded in 1987, when reasonable confidence can be placed in the assumptions about the release, was $0.37 \mu \mathrm{Sv}(0.037 \mathrm{mrem})$ to an adult and $0.55 \mu \mathrm{Sv}$ (0.055 mrem) to a child or infant.

\footnotetext{
${ }^{47}$ For 1984 the mean doses (based on maximum, and realistic ingestion assumptions, respectively) were $1.51 \mu \mathrm{Sv}$ $(0.151 \mathrm{mrem})$ and $0.184 \mu \mathrm{Sv}(18.4 \mu \mathrm{rem})$. Similarly, for 1985 the mean doses were $1.42 \mu \mathrm{Sv}(0.142 \mathrm{mrem})$ and $0.158 \mu \mathrm{Sv}(15.8 \mu \mathrm{rem})$.

${ }^{48} 2.4 \mu \mathrm{Sv}(0.24 \mathrm{mrem})$ in 1986 and $2.1 \mu \mathrm{Sv}(0.21 \mathrm{mrem})$ in 1987.

${ }^{49} 0.12 \mu \mathrm{Sv}(12 \mu \mathrm{mrem})$ for 1986 and $0.055 \mu \mathrm{Sv}(5.5 \mu \mathrm{rem})$ for 1987 .

${ }^{50}$ From $0.12 \mu \mathrm{Sv}(12 \mu \mathrm{rem})$ for the realistic dose to $0.58 \mu \mathrm{Sv}(58 \mu \mathrm{rem})$ for the maximum dose.

${ }^{51}$ From $0.055 \mu \mathrm{Sv}(5.5 \mu \mathrm{rem})$ for the realistic dose to $0.45 \mu \mathrm{Sv}$ (4.5 $\left.\mu \mathrm{rem}\right)$ for the maximum dose.
} 
The environmental impact of a release of HTO is, as expected, considerably greater than that of a release of HT. As mentioned, an ingestion dose to a child of $700 \mu \mathrm{Sv}$ (70 mrem) was calculated after the 1970 release of 350,000 Ci based on measured concentration in grass. A similar calculation was carried after a small acute release in 1971 (Yoder 1971) that was included as a routine release in Part 4 of the TDR. About $200 \mathrm{Ci}$, of which 135 $\mathrm{Ci}$ were HTO, were released. Environmental monitoring was carried and concentrations in vegetation were measured. Based on the same assumptions as in 1970 (that a child consumed milk from a cow ingesting the grass with the highest measured concentrations), the maximum dose was estimated to be $6 \mathrm{mrem}$. The HT release in 1970 was 2,600 times larger and 1\% HTO was assumed, but the child's milk ingestion dose was only 12 times greater ${ }^{52}$ than the dose estimated after the 1971 release of HTO.

\section{Sensitivity Analysis}

Whether or not the output of a model can be considered sensitive to a parameter value depends on the endpoint of interest as well as the parameter values that are varying. Sensitivity analyses on both the maximum and realistic doses were calculated using the UFOTRI-based equation (Table 3) for the HTO release in 1954 and the HT release in 1970. The parameter to which all dose endpoints were highly sensitive was the HTO inhalation dose calculated using DCART ${ }^{53}$ and used as input to the equation. After this most important parameter, the parameters to which the maximum dose was most sensitive for the 1954 HTO release, in descending order, were

- the ingestion/inhalation ratio for HTO

- the fraction of ingestion dose remaining when the contribution from grain was removed

- the adjustment to the OBT dose coefficient, including the uncertainty due to ingestion rates

The list was similar for the maximum dose from the HT release of 1970, with the exception that, for HT, the model was sensitive to the HT inhalation / HTO inhalation ratio rather than to the ingestion/inhalation ratio. For both 1954 and 1970, for the realistic dose, the model was sensitive to the parameter that reduces the intake of vegetables based upon season and fraction homegrown.

The sensitivity of dose in the UFOTRI-based equation to varying parameter values was also investigated for the 1984 HT release and the 1986 HTO release when the dispersion uncertainty (and hence the uncertainty on the HTO inhalation doses predicted by DCART) was as small as it can be (i.e., $\pm 80 \%$ ). In spite of this restriction, as for 1954 and 1970, dose from both accidents was most sensitive to the HTO inhalation dose calculated by DCART. However, the HTO inhalation dose was less important for the 1984 release compared with the other releases (i.e., the correlation coefficient was about 0.7 instead of $0.8-0.9$ or higher). The realistic dose after the 1984 release was also sensitive to the fraction of diet that could have been homegrown vegetables because the accidental release occurred in June. Both the maximum dose and the realistic dose for

\footnotetext{
${ }^{52}$ This comparison, of course, depends upon how representative the maximum concentration in vegetation is of the release rate of the HTO or HT.

${ }^{53}$ The DCART HTO inhalation dose is sensitive to the dilution factor and, to a lesser extent, the release rate.
} 
1984 were sensitive to the HT/HTO inhalation ratio and to the ingestion/inhalation ratio. The HTO release in 1986, because it took place in January, was slightly sensitive to the fraction of diet that could have been contaminated, homegrown animal products, but it was primarily sensitive to the HTO inhalation dose.

From these results, it is clear that the uncertainty on the dose predictions cannot be reduced significantly unless the uncertainty on the dilution factor can be reduced. Better knowledge of meteorological conditions and the location of the MEI will help, but the uncertainty on the dose will always be affected by the inherently high uncertainty in the dispersion model.

\section{CONCLUSIONS}

Dispersion modeling of the path of the tritium plume is usually the only way to estimate dose after an accidental release because, even if emergency monitoring occurs rapidly, most of the tritium will have left the area before air monitoring can take place. If a previously deployed air tritium surveillance monitor were to lie in the path of the release, an assessment of inhalation and ingestion dose at that location could potentially be made with more confidence than could an assessment based on dispersion modeling. It is useful to collect plants after an accidental release and analyze for HTO because plants retain the HTO to which they have been exposed for longer periods than does the air, but the results can only be quantitative in a most general way. Nevertheless, measurements of vegetation can also be used to estimate potential doses at the location the vegetation was collected.

Sampling of air after the 1965 and 1970 accidents was carried out as part of emergency response, but the plume had largely passed, the detection limits at the time were high, and there was no stationary network of ambient air tritium monitors in place (the network was initiated in 1973). For the release of June 1984, five ambient air tritium samplers were collected and analyzed. Concentrations between 3,470 and $4,730 \mathrm{pCi} \mathrm{L}^{-1}$ of air moisture were measured at samplers to the S, ENE, NE, and NW of Building 331; a fifth sampler west of Building 331 had a concentration of just $335 \mathrm{pCi} \mathrm{L}^{-1}$. The samplers had been deployed the day before for routine sampling, and the measured concentrations may have been caused by the accidental release, but, because the annual mean and median air concentrations measured at these five locations for 1984 ranged between 3,390 and 5,470 $\mathrm{pCi} \mathrm{L}^{-1}$, the probability is high that the tritium measured was from routine releases and not from the accidental release. Possibly all that can be surmised from these data is that the wind had not blown towards the west since the day before.

The approach to dose modeling in this TDR is unique because the dose model is simply an equation with distributed transfer parameter values based on the performance of the most respected time-dependent tritium model currently in use and on the expert judgment of Wolfgang Raskob, its developer. This approach is the best available under the circumstances given that, except for the most recent accidental releases, there were insufficient meteorological data to run UFOTRI itself.

Because by far the largest potential contributor to ingestion dose after an acute release of tritium is grain and no record of grain growing within 2 or $3 \mathrm{~km}$ of LLNL or SNL/CA at 
the time of the accidental releases has been found (nor is direct personal consumption of locally grown grain likely), the most conservative dose from each release was calculated on the assumption that the entire diet was contaminated except for grain. The UCL on this maximum dose was defined as the dose that could not have been exceeded when meteorological conditions were unknown. The assumption of a completely contaminated diet (except for grain) was applied to compensate for any potential (but unlikely) underestimation of the dilution factor. When meteorological conditions and other aspects of the releases were well defined, a realistic set of assumptions (i.e., "realistic dose") about ingestion (that were nevertheless still conservative ${ }^{54}$ ) was used to determine the dose that could not have been exceeded (i.e, the UCL of the realistic dose, which was averaged with a similar value, the mean of the dose based on maximum ingestion assumptions). The true dose at the location of the MEI should have fallen within, or slightly below, the confidence interval on the realistic dose as long as the dilution factor adequately described the meteorological conditions at the time of the release. The dose to an actual individual living farther from the release could have been even lower. For the releases of 1954, 1964, and 1966, when meteorological conditions were unknown, the assumption that the MEI was as close as possible to the source of the release adds more conservatism to the dose that could not have been exceeded because the probability that the wind was blowing in the direction of the MEI at the time of the release was slight.

Dose to a child or infant ${ }^{55}$ is normally higher than dose to an adult for the same exposure pathways. In this TDR, because the ingestion/inhalation ratios were the same for adults, children, and infants, dose to a child or infant is estimated to be $40-50 \%$ higher than dose to an adult for each accidental release based solely on the difference in dose coefficients.

Even with many conservative assumptions to account for the unknowns and assure that dose would not be underestimated, the highest dose that could not have been exceeded (for the HTO release in 1954) was $2 \mathrm{mSv}(200 \mathrm{mrem})$ to an adult and $3 \mathrm{mSv}$ (300 mrem) to a child or infant. These doses are below the 500 mrem that is allowed by DOE as a subsidiary dose limit in a year (DOE 5400.5 $5^{56}$ ).

All the doses that could not have been exceeded were below the regulatory requirements of the time for routine releases. The 1954 doses would fall under the 1949 International Commission on Radiological Protection recommended annual limit for an individual member of the public of $15 \mathrm{mSv}$ (1.5 rem) (Jones 2005). In 1957, the National Council on Radiation Protection and Measurements (NCRP 1958) recommended annual limits to "persons outside of controlled areas" of $5 \mathrm{mSv}$ (500 mrem). This annual limit would have applied to the accidental releases of 1964, 1965, 1966, 1970, 1984, 1985, and 1986;

\footnotetext{
${ }^{54}$ Numerous conservative assumptions are applied even for the realistic dose. These include the assumption that all structures or public places (such as the automotive garage) were residences, the assumption that foods can be eaten the first hour after the release, and the assumption that the MEI grew a large fraction of his own food.

${ }_{55}^{55}$ Inhalation dose to an infant is usually lower than that of an adult.

56 "If avoidance of the higher exposures is impracticable, the Manager of the DOE Field Office, in coordination with their Program Office, may request from EH-1 specific authorization for a temporary public dose limit higher than 100 mrem $(1 \mathrm{mSv})$, but not to exceed $500 \mathrm{mrem}(5 \mathrm{mSv})$ for the year. The temporary higher dose limit derives from the International Commission on Radiological Protection recommendations (ICRP Publication 45) for a principal stochastic dose limit of $100 \mathrm{mrem}(1 \mathrm{mSv})$ effective dose equivalent in a year for exposures to the public, and a subsidiary dose limit of $500 \mathrm{mrem}(5 \mathrm{mSv})$ effective dose equivalent in a year, for some years, if the dose averaged over a lifetime does not exceed the principal limit of $100 \mathrm{mrem}(1 \mathrm{mSv})$ effective dose equivalent per year."
} 
the highest dose that could not have been exceeded for these years was $120 \mu \mathrm{Sv}$ (12 mrem) to an adult and $170 \mu \mathrm{Sv}(17 \mathrm{mrem})$ to a child or infant in 1970. In 1986 the Environmental Protection Agency introduced a radiation dose standard of $250 \mu \mathrm{Sv}$ (25 mrem) for compliance with 40 CFR 61 Subpart H [National Emission Standards for Emissions of Radionuclides other than Radon from Department of Energy Facilities] for releases to the atmosphere. This new limit would have applied to the highest dose that could not have been exceeded of $0.37 \mu \mathrm{Sv}(0.037 \mathrm{mrem})$ to an adult and $0.55 \mu \mathrm{Sv}(0.055$ mrem) to a child for the release in 1987. Doses that could not have been exceeded from all releases except 1954 and 1970 were below the current regulatory limit (dating from December 19, 1989) of $100 \mu \mathrm{Sv} \mathrm{y}^{-1}\left(10 \mathrm{mrem} \mathrm{y}^{-1}\right)$ for compliance with 40 CFR 61 Subpart H.

The doses reported in this TDR have been compared with regulatory limits for routine releases in effect at the time of the accidental releases. They can also be compared with what is known about the risks from exposure to tritium. Adverse health effects have only been conclusively demonstrated for exposures greater than $10 \mathrm{rem}(100 \mathrm{~Sv})$ (ATSDR 1999). Numerous studies have also demonstrated that no adverse health effects have been documented for doses less than $360^{57}$ mrem (3.6 mSv) per year (ATSDR 1999). Consequently, ATSDR (2003) defined 360 mrem as a "No Observed Adverse Effect Level", and even the dose to the child or infant that could not have been exceeded in 1954 was below this level. ATSDR also defined a Minimum Risk Level (MRL) of 100 mrem $(1 \mathrm{mSv})$ that covers acute exposures less than 14 days and chronic exposures of more than a year. All doses that could not have been exceeded except for 1954 fell below ATSDR's MRL.

For the 1954 release, it is likely that the dose received by an actual infant or child would have been less than $3 \mathrm{mSv}$ (300 mrem), given the probability that the plume did not blow over the nearest residence. However, this dose is still below levels of public health concern, as was concluded by ATSDR in the PHA of the Livermore site (ATSDR 2004): "Acute exposures to plutonium and tritium via the inhalation, ingestion, and dermal pathways described in this health assessment resulted in cumulative doses of less than $400 \mathrm{mrem}[4 \mathrm{mSv}]$...... These doses are unlikely to produce any adverse health effects and therefore are below levels of public health hazard". The TDR can also conclude, therefore, that, although some public exposure the accidental releases from LLNL and SNL/CA probably did occur, estimated maximum exposures were below levels of public health concern, and no adverse health effects would be expected.

\section{ACKNOWLEDGMENTS}

Without the support, interest, and considerable assistance of Dr. Wolfgang Raskob of Forschungszentrum Karlsruhe, Germany (the developer of the UFOTRI model), the dose calculations contained in this report could never have been made any reasonable degree of confidence. I also wish to thank Dr. Steve Homann for quickly modifying HOTSPOT at my request to accommodate negative $\mathrm{x}$-coordinates.

\footnotetext{
${ }^{57}$ Note that the dose from natural background radiation in the Livermore Valley is about $300 \mathrm{mrem}(3 \mathrm{mSv})$ per year.
} 


\section{APPENDIX A}

RECORD OF ROUTINE PUFF RELEASES AND ACCIDENTAL RELEASES FROM LLNL AND SNL/CA

\begin{tabular}{|c|c|c|c|c|}
\hline Year & $\mathbf{C i}$ & HT or HTO & Facility & Comments \\
\hline 1954 & 1,450 & HTO & 231 & 1 cc of HTO lost from cold trap and HT October $13^{1}$ (accidental) \\
\hline 1956 & 3,000 & $\mathrm{HT}$ & 231 & Released August $28^{2,3}$ (routine) \\
\hline 1957 & 11,000 & HT & 231 & $6,000 \mathrm{Ci}$ May 22 and 5,000 Ci June $12^{3,4}$ (routine) \\
\hline 1958 & 4,900 & $\mathrm{HT}$ & $331 ;$ Stack 1 & 3,000 Ci March 31, 5,6,3 and 1,900 Ci November $5^{7,3}$ (routine) \\
\hline 1959 & 2,700 & $\mathrm{HT}$ & $331 ;$ Stack 1 & $1,600 \mathrm{Ci}$ February $16^{8,3}$ and $1,100 \mathrm{Ci}$ May $12^{9,3}$ (routine) \\
\hline 1960 & 3,100 & HT & 331; Stack 1 & $2,000 \mathrm{Ci}$ May $2^{10,3}$ and $1,100 \mathrm{Ci}$ November $19^{11,3}$ (routine) \\
\hline 1961 & 200 & $\mathrm{HT}$ & 212 & From the 90 inch cyclotron $^{12}$ for the period $10 / 25$ to $10 / 28 / 61$ (accidental) \\
\hline 1964 & 24,000 & $\mathrm{HT}$ & 331 & No record except Souers $(1998)^{3}$ \\
\hline 1965 & 360,000 & $\mathrm{HT}$ & $331 ;$ Stack 1 & $\begin{array}{l}2 \text { minute release at } 3: 27 \text { pm January } 20 \text {; reported to AEC as } 360,000 \mathrm{Ci}^{13} \text { estimate based } \\
\text { on integrations of the chart trace range from } 207,000 \text { to } 300,000 \mathrm{Ci} \text {, but } 350,000 \\
\text { published }^{14} \text { (accidental) }\end{array}$ \\
\hline 1966 & 11,000 & HT & 331; Stack 1 & April $7^{15} ; 14,000^{3}$ (accidental) \\
\hline 1969 & 800 & $\mathrm{HT}$ & 331 & Experimental release October $27,10: 30-11: 30 \mathrm{am}^{16}$ \\
\hline 1970 & $287,000^{17}$ & HT & 331; Stack 1 & 30 minute release at $6: 14$ August, $289,000 \mathrm{Ci}^{18}$ (accidental) \\
\hline 1971 & $105+135$ & $\mathrm{HT}+\mathrm{HTO}$ & $331 ;$ Stack 1 & April 12 at 9:05; environmental monitoring followed ${ }^{19}$ (accidental) \\
\hline 1975 & 340 & $\mathrm{HTO}^{\mathrm{a}}$ & $331 ;$ Stack 2 & Reported by Souers $(1998)^{3} ; 460.7$ Ci HTO released 5-12 November ${ }^{20}$ \\
\hline 1976 & 175 & $\mathrm{HT}^{\mathrm{a}}$ & $331 ;$ Stack 2 & Reported by Souers $(1998)^{3} ; 146.8 \mathrm{Ci}$ HT released 3-10 $\mathrm{March}^{20}$ \\
\hline 1981 & 130 & $\mathrm{HTO}$ & $331 ;$ Stack 1 & $\begin{array}{l}\text { Possible } 130 \mathrm{Ci} \text { release in November }{ }^{21} \text {; possible } 142.8 \mathrm{Ci} \text { HTO release } 2-9 \text { November or } \\
\text { possible } 133.1 \mathrm{Ci} \text { HTO release } 16-23 \text { November }^{20} \text { (accidental) }\end{array}$ \\
\hline
\end{tabular}

${ }^{\mathrm{a}}$ The species was not reported by Souers and is assumed to be the same as the routine releases that were apparently being reclassified as accidental. 


\begin{tabular}{|c|c|c|c|c|}
\hline Year & $\mathbf{C i}$ & HT or HTO & Facility & $\begin{array}{c}\text { Comments } \\
\end{array}$ \\
\hline 1981 & 450 & HTO & 331; Stack 1 & $\begin{array}{l}\text { December } 12 \text { or } 13,450 \text { Ci measured by Ostlund Monitor but undetected by ion } \\
\text { chambers }^{21} \text {; environmental study carried out }{ }^{22} ; 477.8 \mathrm{Ci} \text { HTO released } 7-14 \text { December }^{20} \\
\text { (accidental) }\end{array}$ \\
\hline 1983 & 220 & $\mathrm{HT}^{\mathrm{a}}$ & 331; Stack 2 & $\begin{array}{l}\text { No record except Souers }(1998)^{3} \text {; possibly } 317 \mathrm{Ci} \text { HT released } 7-14 \text { March or } 379 \mathrm{Ci} \mathrm{HT} \\
\text { released } 28 \text { November }-5 \text { December. }\end{array}$ \\
\hline 1984 & 5,200 & HT & 331; Stack 2 & $\begin{array}{l}\text { June } 8 \text { at } 8 \mathrm{am} ; 6000 \mathrm{Ci} \text { estimated from pressure drop; } 5200 \text { best estimate based on } \\
\text { electronic integrator }\left(1400 \pm 300 \text { and } 4300 \pm 800^{23} ; 5,000 \mathrm{Ci} \text { reported officially }{ }^{24} ; 5,600\right. \\
\pm 500 \mathrm{Ci} \text { also reported }{ }^{25} ; \text { reported in } 1984 \mathrm{SAER} \text { as } 5,000 \mathrm{Ci} \text {. HT; } 5,155 \mathrm{Ci}^{3}(\text { accidental })\end{array}$ \\
\hline 1984 & 2.5 & HTO & SNL TRL ${ }^{26}$ & July (accidental) \\
\hline 1985 & 1034 & HT & 331; Stack 2 & $\begin{array}{l}\text { January } 24^{27} \text {; reported in } 1985 \text { SAER as } 1,000 \mathrm{Ci} \mathrm{HT} ; 1,000 \mathrm{Ci}^{3} ; 920 \mathrm{Ci} \text { from ion } \\
\text { chamber }^{27} ; 935 \mathrm{Ci} \text { HT released } 22-28 \mathrm{January}^{20} \text { (accidental) }\end{array}$ \\
\hline 1986 & 200 & HT0 & SNL TRL ${ }^{26}$ & January (accidental) \\
\hline 1986 & 125 & HT & 331 Stack 1 & December $15^{28} ; 135 \mathrm{Ci}^{3} ; 149.8 \mathrm{Ci}$ HT released $15-22$ December $^{20}$ \\
\hline 1987 & 198 & HT & 331; Stack 2 & April $14^{28} ; 185 \mathrm{Ci}^{3} ; 198.9 \mathrm{Ci}$ HT released 14-20 Aprill $^{20}$ \\
\hline 1987 & 1,100 & HT & SNL TRL ${ }^{26}$ & August $18^{29}$ (accidental) \\
\hline 1987 & 575 & HT & 331 & No record except Failor $(1999)^{28}$ \\
\hline 1988 & 145 & HT & 331; Stack 2 & January $19^{28} ; 121.7$ Ci released $11-19$ January $^{20}$ \\
\hline 1988 & 138 & HTO & 331; Stack 2 & January $25^{28} ; 138.6$ Ci HTO released 25 January -2 February ${ }^{20}$ \\
\hline 1988 & 653 & HT & 331; Stack 2 & May $15^{28} ; 651.6$ Ci HT released $16-18$ May $^{20}$ \\
\hline 1988 & 120 & HTO & 331; Stack 2 & August $^{28} ; 120.4$ Ci HTO released 2-10 August ${ }^{20}$ \\
\hline 1988 & 124 & HTO & SNL TRL ${ }^{26}$ & October (accidental) \\
\hline 1989 & 112 & HT & 331; Stack 2 & February $28^{28}$ \\
\hline 1989 & 11.5 & HTO & SNL TRL ${ }^{26}$ & March \\
\hline
\end{tabular}


Appendix A continued

\begin{tabular}{|c|c|c|c|c|}
\hline Year & $\mathbf{C i}$ & HT or HTO & Facility & Comments \\
\hline 1989 & $290+7$ & $\mathrm{HT}+\mathrm{HTO}$ & 331; Stack 2 & $\begin{array}{l}\text { August } 25^{30} \text { between } 10 \text { and } 11 \text { am reported as } 329 \mathrm{Ci} \text { HT in } 1989 \text { SAER; reported to } \\
\text { National Response Center }{ }^{31} ; 329 \mathrm{Ci} \text { HT and } 6.73 \mathrm{Ci} \text { HTO released 22-28 } \text { August }^{20} \\
\text { (accidental) }\end{array}$ \\
\hline 1989 & 112 & HTO & 331 Stack 1 & October $31^{28} ; 112 \mathrm{Ci}$ HTO released 31 October - November $6^{20}$ \\
\hline 1991 & $\sim 112$ & HT & 331; Stack 1 & $\begin{array}{l}\text { April } 2 \text { at } 3: 50 \mathrm{pm}^{32} \text {. Reported in SAER as } 144 \mathrm{Ci}^{33} ; 139 \mathrm{Ci} \text { HT released 1-3 April } \\
\text { (accidental) }\end{array}$ \\
\hline \multirow{2}{*}{1992} & 4 & $\mathrm{HT}$ & SNL TRL $^{34}$ & May 28 (accidental) \\
\hline & 36 & HT & SNL $\mathrm{TRL}^{34}$ & June 1 (accidental) \\
\hline 1993 & 2 & HTO & $\mathrm{SNL} \mathrm{TRL}^{26}$ & October (accidental) \\
\hline
\end{tabular}

\section{REFERENCES (Appendix A):}

${ }^{1}$ Stanhope, Chester M. (Bldg. Monitor, Bldg. 102). Memo to Dusty Meadors. Subject: $T_{2}$ accident and personnel involved, October 13, 1954. October 26, 1954.

2 York, H.F. Memo 11, 127, "Release of Tritium to the Atmosphere" for quarter ending September 30, 1956 to S.G. English, U.S. Atomic Energy Commission, Washington D.C.

Secret, restricted, later unclassified. March 1, 1957.

3 Souers, C. Overheads from a talk "Tritium Releases from B331" prepared for the Director's Office, June 1988.

${ }^{4}$ Southwick, E.W. Memo 57-21, "Release of Tritium to the Atmosphere" for quarter ending June 30, 1957 to S.G. English, U.S. Atomic Energy Commission, Washington, D.C.

Secret restricted, later unclassified. July 3, 1957.

5 Street, K. Memo 58-17, "Release of Tritium to the Atmosphere" for quarter ending March 31, 1958 to S.G. English, U.S. Atomic Energy Commission, Washington D.C. Secret restricted, later unclassified. April 2, 1958.

6 Fleming, E.H. Memo "MINT" to Director's Office. April 1, 1958.

7 Batzel, R.E. Memo "MINT" to Directors Office. November 5, 1958.

${ }^{8}$ Street, K. Memo "Release of Tritium to the Atmosphere" for quarter ending March 31, 1959 to S.G. English, U.S. Atomic Energy Commission, Washington D.C. Secret restricted, later unclassified. August 3, 1959.

9 Brown, H. Memo "Release of Tritium to the Atmosphere" for quarter ending July 31, 1959 to S.G. English, U.S. Atomic Energy Commission, Washington D.C. Secret restricted, later unclassified. April 7, 1959

10 Brown, H. Memo "Release of Tritium to the Atmosphere" for quarter ending April 30, 1960 to S.G. English, U.S. Atomic Energy Commission, Washington D.C. Secret restricted, later unclassified. May 2, 1960.

${ }^{11}$ Brown, H. Memo "Release of Tritium to the Atmosphere" for quarter ending January 31, 1961 to S.G. English, U.S. Atomic Energy Commission, Washington D.C. Secret restricted, unclassified in 1975. February 1,1961 


\section{REFERENCES (Appendix A continued)}

12 Foster, J.S. Jr. Memo "Release of Tritium to the Atmosphere" for quarter ending October 31, 1961 to D.R. Miller, U.S. Atomic Energy Commission, Washington, D.C. Secret, restricted; unclassified in 1975. November 4, 1961.

${ }^{13}$ Foster, J.S. Jr. Memo "Release of Tritium to the Atmosphere" for period January 1 to March 31, 1965 to A.R. Van Dyken, U.S. Atomic Energy Commission, Washington D.C. Secret restricted, unclassified in 1975. April 8, 1965.

14 Peterson, S-R., G.M. Gallegos, R.J. Harrach. A review of the January 20, 1965 tritium release from Lawrence Radiation Laboratory. Lawrence Livermore National Laboratory, Livermore CA, UCRL-AR-148811, July 2002.

${ }^{15}$ May, M.M. Memo "Release of Tritium to the Atmosphere" for period April 1 through June 301966 to A.R. Van Dyken, U.S. Atomic Energy Commission, Washington D.C. Secret restricted, unclassified in 1975. July 11, 1966.

16 Silver, W.J. Memo to Building 331 File, January 20, 1970. Subject: Summary of Tritium Stack Release Test.

17 May, M.M. Memo "Release of Tritium to the Atmosphere" for period July through September 1970 to A.R. Van Dyken, U.S. Atomic Energy Commission, Washington D.C.

Secret restricted, unclassified in 1975. October 19, 1970

18 Myers, D.S.; Tinney, J.F.; Gudiksen, P.H. Health physics aspects of a large accidental tritium release. In: Moghissi, A.A.; Carter, M.W., eds. Tritium. Phoenix: Messenger Graphics; 1973: 611-622.

19 Yoder, R.E. Memo to J.S. Kane, April 26, 1971; Subject LRL Incident/Accident Report Serial No. 003.

20 Value from the spreadsheets prepared from analytical data (see discussion under Table 5 in the text).

${ }^{21}$ Morris, R.L., Health Physics Group, Hazards Control Department; Tritium Releases from Building 331 During 1981, memo to distribution February 18, 1982.

22 Handwritten notes from Hazards Control Records.

${ }^{23}$ Hill, R.W. Memo to R.M. Alire June 29, 1984. Subject: LLNL Incident Analysis Report, Serial No. 0317 Tritium Releases B331.

${ }^{24}$ King. W.C., Radiation and Environmental Safety Division, Hazards Control Department, memo to distribution January $22,1985$.

${ }^{25}$ Howe, H. Memo to C. Souers January 22, 1985; Subject: Dose Equivalent Estimates - Tritium Release, June 8, 1984.

${ }^{26}$ Garcia, T.B.; Gorman, T.P. Radiological characterization and final facility status report Tritium Research Laboratory. Sandia CA, Livermore, CA. Sandia Report. SAND968004UC-407. August 1996.

27 Howe, H. Memo to C. Souers February 26, 1985; Subject: Tritium Release from Building 331 - January $24,1985$.

28 Obtained in 1999 from papers in the possession of Rebecca Failor.

${ }^{29}$ Garcia, T. 2006.

30 Brown, M. Memo to J. Steenhoven, September 15, 1989. Subject: Reassessment of the 8/25/89 tritium release with actual source term data from Building 331 molecular sieve (reference EQVG memo 2159-89).

${ }^{31}$ Ragaini, R. Memo to S. Rosenblum, EPA, San Francisco dated August 30, 1989. Subject Report on Release of Tritium August 30,1989

32 Galles. H. Draft letter to Ed Howell, Alameda County Health Care, Oakland, CA. April 5, 1991.

33 Lee, J.D.; Gary Mansfield. Memorandum to R.A. Failor. Subject: Mole sieve results for 4/1/91 - 4/3/01. April 8, 1991.

${ }^{34}$ Johnson, Alice J. Tritium Research Laboratory Cleanup and Transition Final Report. Sandia National Laboratory, Livermore CA. SAND97-8009. February 1997. 


\section{APPENDIX B TIME-DEPENDENT DISPERSION AND TRITIUM DOSE MODELING}

\section{DISPERSION MODELS FOR ACUTE TRITIUM RELEASES}

For a tritium release of short duration to the atmosphere, the dispersion of tritium can be calculated with any accident consequence model that accounts for dispersion of radioactivity because tritium is advected by the wind and diffused by turbulent eddies in the same way as other radionuclides. Napier (2001) summarized a number of dispersion models that were developed to estimate the consequences of atmospheric releases of radionuclides. Some of these models are for emergency response while others are for emergency planning. For emergency response, codes should be fast, easy to use and not require much input information. Three codes of this type mentioned by Napier are HOTSPOT, RASCAL, and NARAC. HOTSPOT ${ }^{1}$ health physics programs (Homann 1994) are reasonably accurate for a timely initial assessment and use the well-established Gaussian plume model; RASCAL ${ }^{2}$ (Radiological Assessment System for Consequence Analysis) was developed by the U.S. Nuclear Regulatory Commission (NRC) for power reactors (NRC 2001) and uses a straight-line Gaussian plume model for distances between 25 and $800 \mathrm{~m}$ and a lagrangian puff model for longer distances; NARAC (National Atmospheric Release Advisory Center) (Sullivan et al. 1993), operated by LLNL, provides near real-time assessments with more sophisticated modeling capabilities, e.g., complex terrain. NARAC is a centralized, worldwide emergency response service. The NARAC suite of software tools include simple stand-alone, localscale plume modeling tools for end-user's computers, and Web- and Internet-based software to access advanced modeling tools and expert analyses from the national center at LLNL. Initial automated, 3-D predictions of plume exposure limits and protective action guidelines for emergency responders and managers are available from the center in 5 to 10 minutes. Model predictions include the 3-D spatial and time-varying effects of weather, land use, and terrain, on scales from the local to regional to global (Nasstrom et al. 2005). Only time-integrated air concentrations and doses from inhalation ${ }^{3}$ (and skin absorption for HTO) during passage of the plume are calculated by these models.

For emergency response planning, codes require more information to run and are stochastic. Napier mentions two examples of these codes, GENII (Napier et al. 2002) and MACCS2 (Melcor Accident Consequence Code System [MACCS]), which was developed for the NRC (Jow et al. 1990). GENII and MACCS2 calculate ingestion doses as well as inhalation doses and may account for seasonality. MACCS2 can consider mitigation effects and economic costs.

Although it does not specifically account the dispersion of tritium (or any other radionuclide), CALPUFF, an advanced non-steady-state meteorological and air quality modeling system (http://www.src.com/calpuff/calpuff1.htm) was recommended by

\footnotetext{
${ }^{1}$ HOTSPOT was chosen to calculate time-integrated concentrations in air for the LLNL Tritium Dose Reconstruction (TDR).

${ }^{2}$ RASCAL was used by the Agency for Toxic Substances and Disease Registry (ATSDR) to calculate time-integrated air concentrations and inhalation doses for the 1965 and 1970 accidental releases of HT from LLNL.

${ }^{3}$ In this appendix, when inhalation is mentioned, the contribution of skin absorption to dose is assumed.
} 
Thomas et al. (1999) as the best model out of a survey of 94 dispersion models to predict dispersion of tritium from the National Tritium Labeling Facility (NTLF) in Berkeley, CA. In the case of the NTLF, annual doses were of interest, but the location of the stack ${ }^{4}$ meant that simple Gaussian plume models failed to predict the correct dispersion of the released tritium. Thomas et al. also recommended the NARAC service. CALPUFF can only be used to calculate air concentrations.

At Los Alamos National Laboratory (LANL), three or four models are used to calculate dose from unplanned releases (Jacobson 1999). HOTSPOT is used for emergency response if the release time is 15 minutes or less or unknown. A model called "PUFFI", apparently developed at LANL, is used if the release is between 15 minutes and 24 hours in duration and 15 minute wind data are available. Results from HOTSPOT for more than 15-minutes are considered conservative. MIDAS (http://www.absconsulting.com/midas/runningplume.html), which provides real-time dynamic processing with results being updated every five minutes, can be used for any length of release. Dispersion calculations for flat terrain are made using a time-integrated, variable trajectory, Gaussian, plume segment model. Neither MIDAS nor PUFFI were included on the list of models reviewed for the NTLF ${ }^{5}$. Either MIDAS or GENII is recommended for releases lasting more than 24-hours. PUFFI only calculates a timeintegrated concentration of tritium in air; MIDAS appears to calculate inhalation dose.

For tritium, dispersion is particularly important because it determines how much HTO diffuses into growing plants as well as the air concentrations used to calculate inhalation dose (see discussions below). Furthermore, after an acute release, tritium deposits to the soil and is re-emitted over time, which also contributes to inhalation dose and uptake by plants. None of the models described above accounts for environmental pathways unique to tritium and thus should not be used for any purpose other than to predict timeintegrated air concentrations or, at most, inhalation doses. Thus the only reasonable way to model tritium movement in the environment to dose is with a tritium-specific model that includes atmospheric dispersion. Tritium-specific models are discussed below.

HOTSPOT was chosen as the model to predict the time-integrated air concentrations ${ }^{6}$ for the TDR because it is straightforward to use, fast, and reliable. HOTSPOT is suitable for estimating air concentrations at potential locations of the MEI (between about $650 \mathrm{~m}$ and $2 \mathrm{~km}$ ) from a source on the Livermore site because of the lack of complex terrain. Features $^{7}$ of HOTSPOT were used to calculate best-estimate air concentrations (rather than conservative ones) to which uncertainty limits could be applied. HOTSPOT, of course, calculates inhalation doses, but because it only calculates deterministic dose, and probabilistic doses were needed for the TDR, doses calculated by HOTSPOT were not used.

Dispersion modeling is very uncertain even under the best conditions. Given accurate input assumptions, $68 \%$ of the time (i.e., the percentage of observations within 1 standard

\footnotetext{
${ }^{4}$ The stack was located on a hillside below the Lawrence Hall of Science in very complex terrain.

${ }^{5}$ HOTSPOT, RASCAL, MACCS, and GENII were included in the review for the NTLF (Thomas et al. 1999).

${ }^{6}$ From these time-integrated air concentrations, a dilution factor was calculated to use in DCART with the release rates to predict probabilistic inhalation doses.

${ }^{7}$ Plume rise was activated and off-centerline air concentrations were calculated, although it was assumed the plume did not deposit.
} 
deviation, assuming a Gaussian distribution), the air concentrations calculated by HOTSPOT will be within a factor of 5 (or even a factor of 3 [Cember 1985]) of measured concentrations. A minimum standard deviation of $80 \%$ on a lognormal distribution was assigned to the dilution factors derived from multiple runs of HOTSPOT for each release scenario. This magnitude of minimal uncertainty was chosen based on the author's experience with the Hypothetical Scenario of EMRAS (see below under "Testing Models"). The chosen uncertainty encompassed the deterministic predictions of the other modelers (see figure below). For the comparison in the figure, the integrated air concentrations were calculated at $1 \mathrm{~km}$ from the source for a 1-hour release of $10 \mathrm{~g}$ of either HT or HTO from a 20-meter stack for the stability classes shown. The HOTSPOT results (mean and $2.5 \%$ and $97.5 \%$ confidence limits) were calculated without accounting for plume depletion by deposition. Estimated this way, the $80 \%$ minimal uncertainty for the dilution factors used in the $\mathrm{TDR}^{8}$ becomes "global" uncertainty".

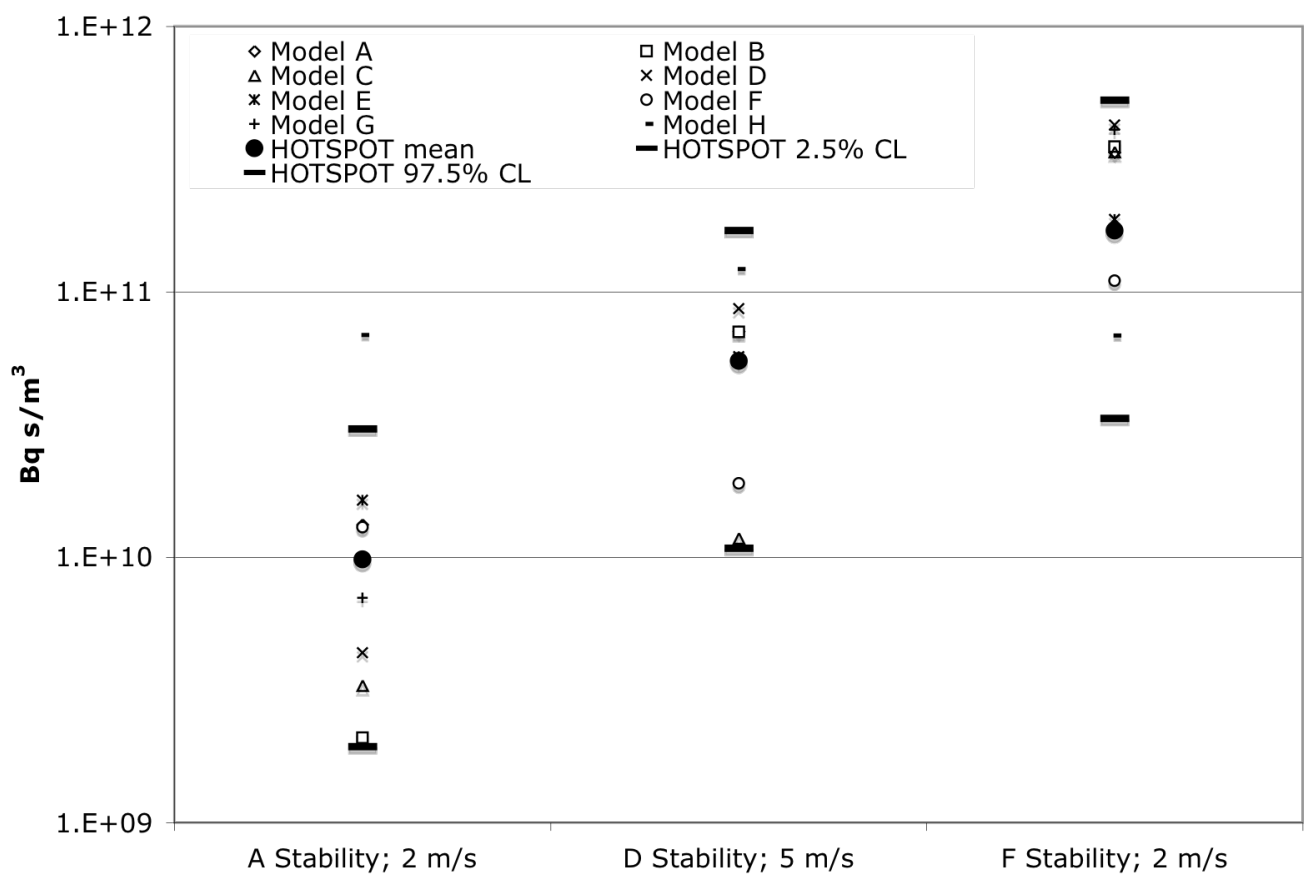

Significant differences between NARAC results and those of HOTSPOT (and other Gaussian plume models) have been observed (Probanz 2006) under stable nighttime conditions. To comply with regulations, a Gaussian Plume model may give a much more conservative result than NARAC due to the way a stable atmosphere with low wind speed is treated (i.e., F stability and $1 \mathrm{~m} \mathrm{~s}^{-1}$ wind speed). This occurs because Gaussian plume models typically assume minimal fluctuations in wind direction for F stability class, which results in narrower plumes and higher concentrations. In contrast, NARAC accounts for the fact that the wind direction commonly fluctuates significantly at such a low wind speed. HOTSPOT, however, has a G stability class option specifically for stable low-wind speed conditions. This option uses a more-typical, larger fluctuation in

\footnotetext{
${ }^{8}$ The maximum uncertainty for a release was estimated to be about $\pm 230 \%$ for the off-centerline dilution factor in 1966.

${ }^{9}$ When Monte Carlo calculations are not possible, an assessment of the likely total (i.e., global) uncertainty can be obtained from a collection of deterministic results predicted using various models and assumptions.
} 
the wind direction (standard deviation of 20 degrees is the default assumption), which produces a more rapid dilution of the plume and lower air concentrations. The G stability option agrees well with the NARAC model results for stable conditions under simple, homogenous meteorological conditions. Because of this, all the dispersion calculations for the TDR were carried out using both F and G stability so that, if the F stability gave rise to higher dilution factors than did the $\mathrm{G}$ stability, the $\mathrm{G}$ stability could be used. As it happens, G stability was never used, because, when plume rise was activated, the dilution factor obtained for $\mathrm{G}$ stability was always slightly greater than that obtained for $\mathrm{F}$ stability.

As will be discussed more below, a tritium dispersion model needs to account for emission of HTO from the soil. To estimate HTO concentrations in the breathing zone after passage of the HT plume in 1970, ATSDR (2003) modeled emission using the Industrial Source Complex Short-term (ISC) air dispersion model developed for the US Environmental Protection Agency. Concentrations of HTO in air were estimated using the ISC model with hourly site-specific meteorological data ${ }^{10}$ and soil HTO emission rates. This approach appears to overestimate inhalation doses (see Table 5).

\section{TRITIUM PROCESSES AND PATHWAYS TO DOSE}

The movement of tritium through the environment is in constant flux. Although annual mean tritium doses are calculated routinely for "equilibrium" conditions, the movement of HTO into and out of plants and the soil is constantly and rapidly shifting from areas of high concentration to areas of low concentration depending upon meteorological conditions. The amount of tritium that can enter the food chain - and consequently its dose impact - after an acute release of HT or HTO is dependent on the wind patterns of the time.

Time-dependent tritium models have to describe short-, intermediate-, and long-term consequences of a tritium releases. Short-term exposure pathways are those that occur during the passage of the contaminated plume and include direct inhalation of HT or HTO from the passing cloud together with an uptake of tritium in the form of HTO via the skin; intermediate term exposure includes dose from ingesting vegetables that are contaminated by HTO immediately after the passage of the plume or by HTO emitted from the soil; long-term exposure pathways are those from ingestion of the OBT in vegetables and animal products. Application of present models shows that most of the dose from tritium releases comes from the ingestion of OBT, particularly after a release of HT. Consequently the main task of any time-dependent tritium model is to carefully describe the intermediate- and long-term processes after an accidental release.

There are several dynamic processes that tritium-specific dispersion and dose models must address.

\footnotetext{
${ }^{10}$ Five years of hourly August weather data from the LLNL on-site weather station from 1990 to 1995 were used in model runs.
} 


\section{Conversion of HT to HTO}

Deposition and conversion to HTO in the soil are the only HT-specific processes that need to be explicitly considered in assessing the consequences of an HT release. Once the HT is converted to HTO, the HTO dominates any dose received from a release of HT.

HT deposition has been shown to depend primarily on two processes: diffusion of atmospheric HT into soil air space, followed by oxidation or exchange with water as catalyzed by soil microbes or free enzymes (Dunstall and Ogram 1991). When the plume is in contact with the ground, various soil microorganisms can oxidize HT to HTO through the mediation of the enzyme hydrogenase (Friedrich and Schwartz 1993; Ichimasa et al. 1995). HT deposition and oxidation rates are largely independent of soil particle composition, organic content, $\mathrm{pH}$ or chemical properties (McFarlane et al. 1978). They depend strongly on soil moisture content, porosity and the distribution of microorganisms in the soil profile (Sweet and Murphy 1981; Dunstall et al. 1985; Spencer and Vereecken-Sheehan 1994).

Soils with vegetation cover show higher deposition rates than bare soils, suggesting that root systems enhance soil porosity (and hence diffusion) and increase microbial activity. Most of the HT is oxidized within the top $6 \mathrm{~cm}$ of the soil, and local variations in soil conditions and vegetation cover can result in a 10-fold difference in deposition rate within a natural field. (Peterson et al. 1997).

The most important factor affecting the deposition of HT is the water content of the soil. It has been demonstrated that the water content, which controls free air space in soil, is a key variable influencing those processes (Garland and Cox 1980; Sweet and Murphy 1981; Dunstall et al. 1985; Bunnenberg et al. 1986; Förstel 1986; Spencer et al. 1988). The water content of the soil controls HT diffusion both into the soil and within the pore air to the reaction sites on pore walls. Water content also affects the degree to which soil particles are covered by water films, which restrict access of the relatively insoluble HT to reaction sites located on soil particle surfaces. The HT deposition rate therefore decreases with increasing soil water content.

HT deposition rates also decrease rapidly as soil moisture drops below 3\% (Bunnenberg et al., 1986). Biological activity is diminished in extremely dry soils, and in this case, HT deposition is limited by the reduced number of conversion sites. Only long dry spells, such as are found in the Livermore Valley, normally reduce HT deposition rates. This observation has little impact on the assumptions of the TDR, however, because homegrown vegetables would have had to have been watered.

\section{Cycling of HTO between Air, Soil and Vegetation}

HTO, like other radionuclides, can be lost from the atmosphere by wet or dry deposition to soil, plants or surface water, but some aspects of the dry deposition process to soil and plants are unique to HTO. As a vapor, HTO can diffuse directly into the soil pore space and into the leaf stomates (Belot et al., 1979; Garland and Ameen 1979). This deposition rate is driven by the gradient between the concentration of HTO in the atmosphere and in the air within the pore space of the soil or within the sub-stomatal cavities of plants.

HTO deposition can occur even when the water vapor flux is upward, as long as the HTO partial pressure gradient is downward. This happens, for example, when an airborne 
plume passes over a relatively uncontaminated surface on a clear summer day when evapotranspiration is in progress (Taschner et al. 1995). The deposition rate also depends on the diffusion resistances that the tritium molecules encounter (Hicks et al. 1987). In the atmosphere, HTO molecules encounter aerodynamic resistance. As they cross the laminar boundary layer to the plant or soil surface, they encounter boundary layer resistance, and as they try to enter the interior of the plant or soil matrix, they encounter stomatal and surface resistances respectively. Diurnal variations in the stomatal resistance of leaves occur in response to changes in photosynthetically active radiation, air temperature, humidity, and soil water content.

The wet deposition of HTO occurs as it does for other radionuclides but will not be described here because none of the LLNL or SNL/CA accidental releases took place while it was raining. Wet deposition affects more than deposition, however. It affects the rate at which HTO is re-emitted from the soil to the atmosphere.

When the wind blows the plume away from a receptor that previously experienced a period of deposition, the HTO partial pressure gradient and the diffusive flux will immediately reverse direction and HTO will be rapidly lost from soil and plants to the atmosphere by evapotranspiration. This is a highly dynamic situation because concentrations in air are constantly shifting as winds blow over the contaminated areas to areas of lesser contamination, and vice versa. Time of day and meteorological conditions (particularly rainfall) have a large effect on deposition and re-emission.

The rate of loss from soil and plants is determined by the HTO gradient and the aerodynamic, boundary layer, stomatal, and surface resistances discussed above in connection with deposition. In these circumstances, the soil and plants represent a ground-level area source that generates a secondary airborne HTO plume. For an HT release, the secondary HTO plume appears immediately, even in the presence of the initial HT cloud, because the HTO concentration gradient is always directed upward.

The rate of HTO emission from soils depends strongly on the HTO distribution with depth that resulted from earlier deposition. The distribution determines the initial availability of HTO at the soil surface and the subsequent resupply from deeper layers by diffusion and advection. The diffusion rate of HTO in soil is slower than that of HT, resulting in a higher surface concentration and a shallower profile. The initial emission rate for HTO deposition is therefore about three times higher than it is in the case of an HT source.

HTO deposited under dry conditions tends to be quickly re-emitted when the plume moves away from a given location. HTO not returned to the atmosphere by evaporation moves through the soil by vapor transport or by the mass flow of water. Vapor transport occurs by diffusion through the air-filled pores at a rate determined by the HTO concentration gradient and is usually important only in dry soils. The mass flow mechanism, common to other radionuclides, is more efficient for HTO, which undergoes no retardation and moves at essentially the same rate as water under the influence of gravity and capillary forces. HTO is lost from the soil by drainage and root uptake. The HTO concentration in soil water depends on all of the processes discussed above as well as on the soil water content. 
Like other radionuclides, HTO is carried from the soil into plant roots with the bulk water flow driven by transpiration. The HTO concentration in the transpiration stream is a weighted average of the concentrations in the soil layers from which the water is drawn. The HTO concentration in leaves is determined by the concentration in the transpiration stream, by the uptake or loss of HTO by vapor diffusion through the stomata, and by the volume of water in the plant.

\section{Organically Bound Tritium Formation in Plants}

Tritium from HTO in plants can enter into stable bonds with carbon compounds through various metabolic processes, primarily photosynthesis in green plants. This results in the formation of non-exchangeable $\mathrm{OBT}^{11}$, which has a much longer retention time in plants than HTO.

Non-exchangeable OBT formed by photosynthesis appears initially in carbohydrates. Subsequent polymerization results in the incorporation of OBT into such complex molecules as polysaccharides (starch and cellulose), proteins, lipids and nucleic acids. The amount of OBT produced depends on a large number of environmental factors and plant parameters including light levels, oxygen and carbon dioxide concentrations, temperature, air circulation, and water supply, all of which show considerable diurnal and seasonal variations. OBT concentrations are reduced by slow conversion back to HTO by maintenance respiration and, following an acute exposure, by subsequent plant growth.

OBT can also be produced in the dark, although at rates three to ten times lower than those resulting from photosynthesis (Moses and Calvin, 1959; Thompson and Nelson, 1971). The processes involve the metabolic turnover and synthesis of organic compounds such as proteins, oils, alkaloids and vitamins using the energy of respiration. Plant tissue is dynamic, breaking down and rebuilding continuously, and tritium atoms from HTO can be incorporated into non-exchangeable sites during the rebuilding phase.

OBT is formed only in the green parts of plants, but can be translocated to roots, stems and fruits. The compounds formed by photosynthesis at the beginning of the vegetative period (including those containing OBT) are used primarily to build the structural material of the plant organs. When leaf formation is complete, subsequent assimilates are transported in the form of sucrose, fructose and glucose to aid growth of roots and stems. Later in the growing season, usually after flowering, most of the assimilates are used in the development of fruits and tubers. The amount of OBT appearing in edible plant parts is therefore greatest if the exposure to atmospheric tritium occurs after flowering (Arai et al. 1985; Indeka 1981).

The large difference in mass between hydrogen and tritium gives rise to significant isotopic effects in OBT formation. Tritium is discriminated against in the cleavage of the $\mathrm{O}-\mathrm{H}$ bond of tritiated water during photosynthesis, so that less tritium than hydrogen is incorporated into organic molecules. Similarly, once fixed to carbon, tritium is cleft more slowly than $\mathrm{C}-\mathrm{H}$ bonds. The net result is a value between $20-35 \%$ lower for the ratio of the specific activity of tritium to hydrogen in the organic matter of plants to the

\footnotetext{
${ }^{11}$ HTO can exchange with labile hydrogen atoms attached to oxygen, nitrogen or sulfur compounds to produce exchangeable OBT, which is in equilibrium with HTO and behaves in a similar manner to HTO.
} 
specific activity in the water to which the plant is exposed (McFarlane 1976; Garland and Ameen 1979).

\section{Uptake by Animals}

Like other radionuclides, tritium is taken into the bodies of animals (including human beings) through inhalation (as HT and HTO) and ingestion of food and water (as HTO) (Robertson 1973; van den Hoek et al. 1979) A unique uptake pathway for HTO is absorption through the skin, which is less important in animals because of their thicker skins. Losses occur through respiration, sweating, excretion and (in the case of cows) milking. Tritium concentrations (as HTO and OBT) in the body depend on rates of uptake and loss, and on concentrations in the air, drinking water and food taken in by the animal. These concentrations may vary widely because animals are mobile and may draw their air, food and water from different parts of the environment.

Unlike other radionuclides, tritium does not accumulate in the body and has a relatively short retention time. HTO diffuses freely and rapidly across all cell membranes and equilibrates with body fluids within minutes. Turnover rates (biological half-times) of tritium in tissue water are closely related to body weight, exhibiting a log-log relationship for a wide variety of animals (Yousef 1973). Water turnover rates for most species are less than 10 days.

Between $4 \%$ and $10 \%$ of the OBT in food fed to animals appears as OBT in the animal itself. A small fraction $(<1 \%)$ of HTO taken into the body is irreversibly incorporated into organic molecules by exchange with ordinary hydrogen. This occurs primarily through the enzymatic reactions involved in carbohydrate metabolism (Kirchmann et al. 1977). Twenty times more OBT is incorporated into milk fat and casein after OBT ingestion than after HTO intake (van den Hoek et al. 1983, 1985). The extent of incorporation depends on the length of exposure and the metabolic activity, which differs from organ to organ. Thus, OBT can be localized in the body in a relatively small number of cells and at relatively high concentrations. However, most OBT ingested with food is metabolically oxidized to HTO during digestion and assimilation and enters the compartment of free body water. Fats and proteins retain more of their OBT during digestion than do carbohydrates.

When exposure stops, OBT concentrations in the body decrease slowly as a result of metabolic oxidation to HTO, which is then excreted. Residence times ${ }^{12}$ of tritium in organic fractions of animals (and humans) have not been widely studied. Following exposures to HTO, experimental results for organic matter in humans, marine animals, and milk in cows indicate one or more slow organic components, normally attributed to OBT, and residence times in the range 100 days to 1 year (Smith et al. 1995). The rate of excretion is determined largely by tissue constituents, such as fatty tissue, brain, and muscle, that have slow turnover rates.

\footnotetext{
${ }^{12}$ Half-life is the amount of time required for a species to drop to one half of its original concentration; residence time is the time required for a species to drop to $1 / \mathrm{e}$ of its original value. Strictly speaking, half-life is about $70 \%$ of the residence time. However, this distinction is sometimes not made because both are of the same order of magnitude and there are generally large uncertainties in the methods used to estimate them.
} 
The uptake and loss of HTO and OBT by animals follows very closely the uptake of water and organically bound (non-exchangeable) hydrogen and can be modeled based on the principles of animal metabolism (Galeriu et al. in press)

\section{Time of Ingestion after Plume Passage}

Whatever was growing during the release will have very high concentrations of HTO for two to three hours after the passage of the plume. The probability that an individual would harvest and eat vegetables at these highest concentrations is low particularly for acute releases that occur during work hours. Grazing animals, however, could eat considerable quantities of vegetation contaminated with HTO during and immediately after the plume passage.

The importance of OBT to ingestion dose is highly dependent upon the stage of growth of the plant, whether it is flowering at the time or already in fruit. Because harvest may take place weeks after the release, and some food may be stored after that, the dose contribution from OBT may continue for quite long after the passage of the plume.

HTO will be lost from foods quite easily by diffusion to the air or through removal by cooking, but OBT is much more resistant to loss. Cooking in general decreases concentrations of HTO and OBT in foods depending upon the method (Watterson and Nicholson 1996). If foods are frozen or canned (or hay is baled or grain ground into flour) at some point after the passage of the contaminated plume, the dose impacts may extend farther into the future.

\section{TRITIUM-SPECIFIC DOSE MODELS}

There are a few time-dependent tritium models that calculate doses after acute releases of both HT and HTO. Documented tritium codes such as UFOTRI (Raskob 1990, 1993; Raskob et al. 1999), ETMOD (Russell and Ogram, 1992; Thompson et al., 1992), and FDMH (Galeriu et al. 1999) were designed to assess off-site consequences from acute releases of tritium. All three models calculate inhalation and ingestion doses. UFOTRI and ETMOD calculate dose from releases of HT and HTO, but FDMH only calculates dose from releases of HTO. All three models include sub-models for time-dependent processes such as dispersion, deposition, re-emission, and synthesis of organically bound tritium (OBT) from HTO; UFOTRI and ETMOD include conversion of tritium gas (HT) into tritiated water (HTO). To account for all the processes and initial dose from tritium, detailed modeling is essential for the first few days. Beyond that, adequate predictions can be obtained using simpler models and longer time steps. The differences in modeling approaches between UFOTRI, ETMOD, and FDMH are described briefly below to demonstrate the complexity of these models.

UFOTRI is freely available for research purposes only; ETMOD, while developed by Ontario Hydro Research Division, is now the property of Atomic Energy of Canada Limited; FDMH is being developed as part of the Real-time On-line DecisiOn Support (RODOS) system. RODOS has been developed under the European Commission Nuclear Safety research program, with participation from institutions in Europe. Japan, France, and Korea are developing models, which are being tested, along with UFOTRI, 
ETMOD, and variants of FDMH ${ }^{13}$ in the International Atomic Energy Agency's Environmental Modelling for Radiation Safety (EMRAS) program's Tritium Working Group. Other time-dependent tritium models have a specific dose endpoint (e.g., dose from inhalation after a release of HT [Bartels 1992]) or an endpoint other than dose (e.g., concentrations in various environmental compartments [Higgins et al. 1996]).

In addition to these complex, process-oriented models that need hourly meteorological input data, STAR-H3, a simple compartment model that needs air concentrations as input was developed by Smith et all. (1995) for the United Kingdom's Ministry of Agriculture, Fisheries, and Food.

No precipitation models are discussed below because none of the acute Livermore releases occurred during rain.

UFOTRI and FDMH use hourly meteorological data for the first 100 hours or so after an acute release. After this initial period, the processes can be adequately accounted for by bulk transfer coefficients that represent long-term equilibrium conditions, and daily time steps are used. ETMOD uses hourly meteorological data for the entire calculation. The time-steps for calculations can be much shorter than 1 hour (e.g., 0.01 or 0.1 per hour). All three models are represented by a series of first-order differential equations that are solved numerically.

\section{Processes as Modeled by the Process-oriented Models, UFOTRI, ETMOD, and FDMH}

Dispersion

\section{UFOTRI}

Air concentrations are calculated using a Gaussian trajectory model in a two-step approach. The concentration in the primary plume arising from direct release to the atmosphere is calculated initially. In the second step, the contribution due to re-emission is taken into account using an area source approach in which the contaminated surface is divided into a number of cells. The total amount of HTO released from each cell is assumed to come from a point source in the centre of the cell, and each plume is subject to initial widening to reflect the crosswind dimension of the cell. Air concentrations can be calculated stochastically based on the probability that a particular set of meteorological parameters is likely to occur.

\section{ETMOD}

ETMOD uses a Gaussian plume model to calculate air concentrations arising from both the direct release of tritium to the atmosphere and tritium re-emitted to the air from soil and vegetation. In contrast to UFOTRI, ETMOD assumes that the wind direction remains constant during the simulation period.

\section{$F D M H$}

FDMH uses the dispersion calculations in RODOS in which there is no special atmospheric transport for tritium, and cesium is used as a surrogate with scaling factors.

\footnotetext{
${ }^{13}$ Dan Galeriu, the principal author of FDMH, has participated in the model tests using versions of FDMH that run on a personal computer,
} 
Atmospheric concentrations, scaled from cesium, are used internally for washout and soil deposition. In a new version of RODOS presently under development, the dispersion of tritium will be modeled uniquely.

Deposition to soil

\section{UFOTRI}

The deposition of HT and HTO to soil is calculated through the use of deposition velocities. The HT deposition velocity is given by an effective diffusion coefficient, which depends on the temperature, water content and tortuosity of the first 5-cm layer of the soil. All deposited HT is assumed transformed into HTO. The HTO deposition velocity is calculated using a resistance approach and accounts for aerodynamic resistance, boundary layer resistance, and soil resistance. Three soil layers are modeled.

\section{ETMOD}

Diffusion of HT into soil and its subsequent oxidation is described by a first order reaction and diffusion model. The reaction coefficient for oxidation is expressed in terms of a deposition velocity that accounts for resistance (aerodynamic, boundary layer, and soil). The transfer of HTO between air and soil is modeled as the product of an exchange velocity and the HTO vapor pressure gradient between air and the water in the surface of the soil. The exchange velocity has the same functional form and numerical value as the deposition velocity but is applied differently and can be used to model the upward as well as the downward tritium flux.

HTO concentrations in soil are calculated from a differential equation that considers diffusion, advection, HTO production via HT oxidation and losses via root uptake, which is driven by transpiration. There are 25 layers of soil.

\section{FDMH}

Based on soil type and information stored in the FDMH data base, the surface resistance is calculated based on the field capacity and the actual volumetric soil moisture in the upper $2 \mathrm{~cm}$. The field capacity depends on the soil texture. A surface resistance with a default value of $300 \mathrm{~s} \mathrm{~m}^{-1}$ is applied to urban surfaces, such as walls.

Deposition to plants and uptake by plants

\section{UFOTRI}

The dominant factor controlling the tritium flux to plants is a combination of aerodynamic resistance, boundary layer resistance, and stomatal resistance, which describes HTO transfer through the leaf epidermis into the plant. Weighting functions account for the effects of insolation, humidity, soil water content, and temperature. At night, stomatal resistance is assumed to increase to ten times its daytime value.

\section{ETMOD}

The transfer of HTO between air and plants is modeled as the product of an exchange velocity and the HTO vapor pressure gradient between air and the water in the surface of the plant. The stomatal resistance is calculated similarly to UFOTRI with corrections applied for insolation and temperature. Nighttime values of stomatal resistance are set very high to prevent any uptake of HTO in the dark. 


\section{FDMH}

A physiological approach is used that relates the canopy resistance (which is the stomatal resistance integrated over the depth of the canopy) to the carbon dioxide concentrations within the leaf and in ambient air, canopy photosynthesis, and factors that account for diffusivity of water vapor and carbon dioxide.

$\underline{\text { Re-emission from soil and plants to the atmosphere }}$

\section{UFOTRI}

Re-emission of HTO is coupled to the evapotranspiration process. An equation for bulk resistance for actual evapotranspiration is used. The evaporating water is assumed to have the same concentration as the plant or soil water. The evaporative flux from the soil is augmented by an additional term that accounts for loss due to diffusion.

\section{ETMOD}

The flux of re-emitted HTO from soil is determined using exchange velocity with the HTO in the surface layers. The flux of HTO from plants via transpiration is calculated. The time-dependent HTO concentrations in plants are calculated using exchange velocity, the saturation humidity at leaf temperature, the average HTO concentration in root zone soil water, and the mass of vegetation water per unit ground surface area. The water flux from the leaf surface is due to transpiration. The flux from soil and plant water is used to calculate the concentration in air due to re-emission.

\section{FDMH}

The flux of HTO from soil to plant water depends on the transpiration rate and HTO concentration in the transpirational flow. The concentration of HTO in plant water is obtained as an average of the tritium concentration in each soil layer, weighted by the root fraction in each soil layer.

\section{Plant growth and OBT formation}

\section{UFOTRI}

The rate of photosynthesis that produces OBT and the hourly build-up of organic matter (growth) are based on the amount of carbon dioxide assimilation modified by functions for the effects of insolation, humidity, soil water content, and temperature to account for stomatal response to stress. OBT formation is determined by photosynthetic rate and the HTO concentration in the plant water and is governed by a simple submodule. OBT is also assumed to form slowly at night through an unspecified exchange process at a rate equal to one-quarter that of the daytime value. The OBT concentration in the green parts of plants is assumed to undergo an exponential decay with a mean loss rate of some tenths of a percent per hour; no OBT is lost from grain or tubers.

\section{ETMOD}

OBT formation in plants is included at a rate that is assumed to be proportional to the HTO concentration in the plant and the rate of organic matter production. The latter quantity is calculated from the net rate of photosynthesis, which is estimated from incoming solar radiation and properties of the plant canopy. 
$F D M H$

The calculation of photosynthesis requires an estimate of solar radiation as input. Net photosynthesis is obtained as the difference between gross photosynthesis and dark respiration. Most of the plant parameters depend on the stage of development of the plant, and some depend upon temperature. The production of OBT is assumed to be proportional to the assimilation (net photosynthesis) rate during daytime and to the basic metabolic rate at night. The newly formed OBT is stored in the edible part of the crop.

Concentrations in animal products

\section{UFOTRI}

HTO and OBT concentrations in milk and beef are calculated using a compartment model. The cow is assumed to take in tritium via inhalation, skin absorption and ingestion of plants and soil. Parameters describing the rates of transfer are average values valid for long time periods and calculated assuming equilibrium conditions. The cows do not produce milk continuously but only in the morning and evening when they are milked.

\section{ETMOD}

The cow model in ETMOD is similar to the one in UFOTRI, but only concentrations of HTO are calculated.

\section{$F D M H$}

Concentrations of HTO and OBT are calculated for milk, meat, and eggs. Contamination of animals occurs only through ingestion of contaminated food, not through inhalation. FDMH can consider complex time-dependent diets consisting of up to four different feeds. Transfer to animals is based upon biological transfer rates. Concentrations in animal feed are calculated from the hourly values at 9 am and 4 pm for the first days after the release.

\section{$\underline{\text { Dose calculations }}$}

In all three models, dose from inhalation of HTO (including dose from skin absorption) is calculated from the concentration of HTO in air, the breathing rate, and dose coefficients. UFOTRI and ETMOD also calculate dose from inhalation of HT.

\section{UFOTRI and ETMOD}

Doses are calculated to an adult by multiplying the intake of HTO or OBT of locally produced food by a dose coefficient. Like regulatory models, it has been assumed that all food is produced locally and can be eaten during the hour at which the concentration is calculated. To that extent, dose predictions will be maximized.

\section{$F D M H$}

The activity in the diet is reduced by storage time after the release and by a single food processing factor of 0.7 . The foodstuffs are assumed to have been produced locally. Doses are calculated to an adult and a five-year old child. 


\section{Compartment model, STAR-H3}

STAR-H3 (Smith et al., 1995) is a dynamic compartment model for tritium similar to those used for the environmental transport of radionuclides other than tritium and carbon14. It is a compromise between the very simple specific activity model for tritium and very complex process-oriented codes. It is formulated as a system of linear, first-order differential equations. As a compartment model, it is unable to simulate processes explicitly but describes them using bulk transfer coefficients, or rate constants. The required values are derived from data on the hydrological cycle or experimental data on tritium transfer in the environment. The latter might include tritium inventories and fluxes in a given compartment or tritium turnover times in the compartment.

Dispersion is not calculated; the model is driven by air concentrations that must be provided. STAR-H3 calculates doses via inhalation, skin absorption and ingestion. It takes account of the deposition and oxidation of HT, re-emission of HTO from the soil, and OBT formation in addition to the more common transport pathways. STAR-H3 accounts for concentrations in, for example, milk from cows either eating pasture directly or eating fodder that was exposed during the passage of the contaminated plume and then cut for consumption. It accounts for dose from animal and plant products that have been frozen and stored, so that the dose impact can come well after the accidental release. If STAR-H3 is run to equilibrium (assuming a constant air concentration), the tritium-tohydrogen ratio in OBT is somewhat greater than that in the HTO compartment of the plant or animal.

\section{TESTING MODELS}

\section{UFOTRI}

UFOTRI was compared with the accident consequence models AXAIRQ (Simpkins 1995a, 1995b) and MACCS2 (Chanin and Young 1998; Blanchard et al. 1998). Only inhalation doses from dispersion under prescribed conditions specific to the Savannah River Site (SRS) were calculated, because UFOTRI is the only one of these models to calculate ingestion. The conclusion identified MACCS2 as the most broadly applicable model for hazard analysis applications, but that either MACCS2 or UFOTRI may be applied to the accident analysis phase. UFOTRI provided a more realistic alternative for later-phase accident analysis. UFOTRI inhalation dose estimates for the SRS maximally exposed offsite individual (MOI) were about $60 \%$ of those predicted by MACCS2. This was due principally to the more realistic UFOTRI dispersion model, which can accommodate wind-shift after the initial plume segment is released, while MACCS2 transports the plume in the initial direction throughout the transport. UFOTRI also has dispersion parameters more suited to surface scale lengths representative of the heavily forested SRS site. Both MACCS2 and UFOTRI are stochastic codes.

\section{International Model Validation Programs}

Models that predict the transfer of tritium through the environment have been tested in international model testing programs since 1991. The purpose of model testing of tritium models is usually three-fold.

1. To test the accuracy of the predictions of environmental assessment models, 
2. To explain differences in model predictions due to differences in model structure, modeling assumptions, and / or differences in selected input data,

3. To recommend priorities for future research to improve the accuracy of model predictions.

The best test of model predictions uses an experimental data set so that predictions can be compared with observations. Failing a data set of observations, hypothetical scenarios can be written for model inter-comparison studies, but much more can be learned when model predictions are compared with observations. Time-dependent models have been tested against observations and each other in two model validation programs.

The first of the programs was the BIOspheric Model Validation Study - Phase II (BIOMOVS II). The BIOMOVS II study $(1991-1996)$ was jointly managed by

- Atomic Energy Control Board of Canada,

- Atomic Energy of Canada Limited,

- Centro de Investigaciones Energéticas Medioambientales y Technólogicas, Spain,

- Empresa Nacional de Residuos Radioactivos SA, Spain.

- Swedish Radiation Protection Institute

The Tritium Working Group of BIOMOVS II tested time-dependent models in three scenarios, one model-model intercomparison. (Technical Report No. 8; BIOMOVS II 1996a) and two with observations (Technical Report No. 13; BIOMOVS II 1996b).

The second of the programs to test time-dependent tritium models ${ }^{14}$ was the International Atomic Energy Agency's EMRAS (Environmental Modelling for RAdiation Safety) program. Launched in September 2003, EMRAS will terminate in November 2007. As well as equilibrium scenarios, in which DCART was tested (see Part 1 of the TDR), there were two scenarios that tested time-dependent models after atmospheric releases. One tested the models against experimental data and the second was a model-model intercomparison.

A group, such as the Tritium Working Group, provides a forum where modelers and experimentalists can meet and exchange ideas. Both experienced and novice modelers can test their models and assumptions in a supportive and non-critical atmosphere. Policy can be discussed (e.g., at EMRAS, a definition of OBT is being refined). What, if anything, each modeler learns and applies to his model depends very much on whether or not the modeler thinks the model has accomplished what it was designed to do (e.g., a model for regulatory purposes would be expected to over-predict doses).

\footnotetext{
${ }^{14}$ Equilibrium tritium models were tested in the BIOMASS (BIOsphere Modelling and ASSessment) program, which ran from 1996 through 2001 and was a coordinated research program of the International Atomic Energy Agency cosponsored by agencies in France, Spain, the United Kingdom, and the United States. Models were tested using observed concentrations in environmental media from Canada, Russia, and France. DCART was tested against these quasi-equilibrium scenarios (see Part 1 of the TDR). In addition, there were two model-model inter-comparisons for equilibrium conditions.
} 
Re-emission from soil and vegetation (BIOMOVS II; Technical Report 13)

Results from a series of field experiments in July 1992 that measured the transfer of HTO from soils and vegetation to the atmosphere were used to test two models, one of which was UFOTRI. Model predictions for the water vapor flux were in reasonable agreement with the experimental values, although both models overestimated the flux by about $60 \%$. However, the observed values themselves may have been systematically low. UFOTRI used an evapotranspiration calculation; the other model used exchange velocity. Both methods depended strongly on the values used for the surface resistances. The validation exercise "helped to uncover and correct problems in the experimental data, rather than in the models". It concluded that further testing of HTO flux models was warranted with better data.

Formation of organically bound tritium in grain of spring wheat (BIOMOVS II; Technical Report 13)

The scenario was based on two experiments (one a daytime exposure and one a nighttime exposure) in which green leaves of wheat were exposed to HTO in a chamber for two hours, and the OBT in the green leaves and its subsequent translocation to grain was measured over time. After exposure, 48 hours of observed meteorological data were provided to the modelers. Six modelers participated; two used their research versions of UFOTRI, the developer of FDMH used an early model, and one used STAR-H3.

The reasons for the different predictions were very difficult to discern. Only the bulk transfer rates used in STAR-H3 could be compared directly with the observed transfer rates. All models tended to underestimate the HTO in leaves at the end of the exposure period except for STAR-H3; predictions of OBT in harvested grain were also too low. When models used the observed concentrations in plant water after exposure to calculate the OBT in grain instead of using the concentrations predicted from the transfer of HTO into the plant, the models overestimated the OBT in the grain for daytime exposures. For nighttime exposures, even with the concentration in HTO normalized to the observed value, the models that assumed some HTO uptake at night still underestimated the concentration of OBT in grain at harvest. None of the calculations included uncertainty, but for UFOTRI and STAR-H3, all values were within a factor of three of the observations.

The scenario was of interest because the observations showed the modelers that uptake of HTO in the dark was about $15 \%$ of that in the light and that the rate of formation of OBT was about the same for light and dark exposures.

Intercomparison of model predictions of contamination in soil, crops, milk and beef after a short exposure to tritiated water vapor in air (BIOMOVS II; Technical Report 8)

Eight modelers with seven models participated in this model intercomparison. UFOTRI and ETMOD were two of the models, and another was the predecessor of FDMH. As described in the scenario, farmland was exposed to $110^{10} \mathrm{~Bq} \mathrm{~m}^{-3} \mathrm{HTO}$ for one hour either at midnight or at 10:00 am thirty days before harvest of crops or slaughter of beef cattle. Cows were assumed to have been milked daily. Modelers were given 30 days of hourly meteorological data and some hydrological and agricultural conditions. They were asked to predict hourly concentrations of HTO and OBT in soil, leafy vegetables, 
grain, milk and beef for the first 24 hours after the start of the exposure and at twice weekly intervals during the remaining 30 days to harvest.

In a model intercomparison, there can be no right or wrong result, because there are no observations against which to compare predictions. Rather, the results are used as a starting point for discussions to attempt to understand the differences. In most case, predicted concentrations among models agreed within an order of magnitude. In a few cases, they agreed within two orders of magnitude. Most disagreement occurred after the nighttime release when concentrations were relatively low and discrepancies were less important radiologically.

\section{EMRAS soybean experiment (in draft)}

Six pots of soybeans at various stages of growth were each exposed to HTO in air for 1 hour. Modelers were asked to predict the HTO concentrations in the free water of the plant body at set times after exposure and to predict OBT concentrations in the plant body and the soybeans at harvest. $95 \%$ confidence intervals were to be included on the predictions.

UFOTRI, ETMOD, a variant of FDMH, and STAR-H3 (two users) participated in this scenario along with seven others. All models over-predicted concentrations of HTO in plant water immediately after the accident. This may have occurred because the temperature in the experimental enclosure was very high and the stomates might have been partially closed (although the more process-oriented models are expected to take this into account).

No model predicted the dynamics of the HTO in plant water very well over time (up to 95 days post-exposure), and predictions of most models after about fourteen days postexposure were more than a factor of 20 below the observed concentrations. This result was unexpected because there have been numerous exposure experiments that measured HTO loss from leaves. The models probably failed because the loss rate of HTO from leaves in this experiment was less than in many other experiments. The modelers had assumed no soil water concentration because the soil had been covered during the experiments. Contaminated soil might account for the higher-than-expected concentrations of HTO in leaves. Measurements of HTO in soil had not been taken, however, so it is unknown whether the soil was contaminated.

The models also had difficulty predicting concentrations of HTO in the developing pods, but predictions of OBT in the seeds (which are the edible parts of the soybean) were usually within a factor of 10. These experiments demonstrated that the OBT concentrations in the pods are related to the stage of growth at which the exposure occurred. The OBT concentration in the seeds increased with each of the first four experiments that covered the period from early to late active plant growth. During the period of rapid growth, the fruit was developing rapidly and most tritium absorbed through the leaves appears to have been transferred directly to the pods rather than being stored in the leaves. The relatively low concentration in the pods for the last experiment when the plants were closest to maturity may have been due to the fact that development of the pods was close to complete when the exposure occurred, which might have caused a reduction in the OBT transfer to the pods. 
The author of the LLNL TDR attempted to calibrate the three pertinent parameter values in STAR-H3 to see if the predictions could match the observed concentrations of HTO in leaves and pods over time. The calibration failed because the model's structure is too simple to account for the changing dynamics of the HTO concentrations, and it cannot account for dilution due to growth or to different transfer rates at different stages of growth.

EMRAS hypothetical scenario

In an effort to give decision-makers practical guidance about countermeasures after a large accidental release of HTO (or HT), a simplified scenario of an hour release of $10 \mathrm{~g}$ of tritium was defined for three different sets of meteorological conditions.

Concentrations of HTO and OBT in various foodstuffs were endpoints of the scenario in addition to doses based on set intakes.

Eight modelers participated in the HTO scenario, and three participated in the HT scenario. UFOTRI and ETMOD were used to predict doses for both scenarios; a predecessor of FDMH was used to predict doses for the HTO release. Results in this scenario were greatly affected by the dispersion modeling which resulted in differences (maximum prediction / minimum prediction) in inhalation dose of between 5.7 and over 100 depending upon the prescribed meteorological conditions. When total dose (i.e., inhalation plus ingestion) was calculated and the dose normalized to the air concentration predicted by each model, the difference between predictions ranged from factors of 6 to about 20 at varying distances downwind from the source for accidental releases that were assumed to occur when it was not raining; the range of difference between model predictions extended to about 200 when rain was assumed.

Ingestion of vegetables and grain contributed the vast majority of the dose predicted by all models. Milk and meat ingestion were relatively unimportant.

The interest generated in the HT scenario was much less because the dose impacts of 10,000 Ci of HT will be much smaller than the dose impacts an HTO release of the same magnitude. UFOTRI was used to model the three different prescribed meteorological conditions, and ETMOD was used for one. The dose normalized to air concentration for one HT scenario varied among three participating models by less than a factor of 20 ; when a fourth model was included, the variation went up to over 400 .

\section{EQUILIBRIUM vs TIME-DEPENDENT MODELING}

Lacking the detailed meteorological data required by time-dependent models, it was felt initially that a maximum dose could be calculated using the equilibrium model, DCART. This is possible because, for some radionuclides, within certain limitations (i.e., only first order reactions and a relatively short biological or environmental half-life), dose from an acute release may be predicted using an equilibrium model, because the dose integral over infinite time per unit of release is numerically equal to the dose at a future steadystate when that release is repeated indefinitely at unit rate (Barry 1979). If it is assumed that the accidental release is spread out over the year and that the winds during that year blow only in one direction, then the integrated air concentration to which the hypothetical MEI is exposed will be the same as that to which the same individual was exposed during 
the accidental release. This much of the relationship is true, as explained in the main portion of this report. Carrying the assumption further, the time-integrated air concentration might be expected to drive the contamination of vegetation and animal products, and because the diet is assumed complete in DCART, the total dose to the MEI might be expected to be no smaller than dose predicted by a time-dependent model that assumes that all foods are potentially contaminated.

Although this relationship holds for concentrations of iodine-131 and cesium-137 in vegetation, milk, and meat after the Chernobyl reactor accident of 1986 (Köhler et al. 1991), it does not hold for tritium. DCART was tested in Hypothetical Scenario of EMRAS, described above, and it quickly became clear that DCART could not be used to calculate dose after an acute release. This is because DCART's predicted ingestion dose from an HTO release is about five times higher than its inhalation dose, but the ingestion/inhalation ratio derived from UFOTRI (which varies according to meteorological conditions) can ranges from 5 through 20. For HT, DCART's ingestion/inhalation dose ratio is about 7.5, while the range derived from UFOTRI (starting however, from a lower inhalation dose after a release of HT than that calculated by DCART) ranges from $80-200$.

Nevertheless, as an exercise, DCART was used to calculate doses to infant, child, and adult after the release in 1970. These doses are compared in Table B1 with those calculated for the TDR using the relationships derived from UFOTRI. As can be seen, the inhalation doses predicted by DCART are much higher than those predicted for the TDR. DCART predicts higher ingestion doses than does the TDR when the realistic ingestion assumptions are used, but it underestimates the TDR ingestion doses by about a factor of two when the entire diet, except grain, is assumed contaminated.

Table B1. Comparison of doses ( $\mu \mathrm{Sv})$ to the MEI predicted by DCART, treating the $1970 \mathrm{HT}$ release as steady-state (occurring over the course of the year), and the time-dependent doses calculated in this TDR. DCT are doses calculated by DCART; TDR-r are doses based on the assumption that only those foods growing at the time of the release were contaminated; TDR-m are doses based on the assumption that the entire diet, except grain, was contaminated. All doses, if rounded, were rounded to two significant figures so doses may not sum to the total.

\begin{tabular}{lcccccccc}
\hline & $\begin{array}{c}\text { Inhalation } \\
\text { and skin } \\
\text { absorption } \\
\text { TDR }\end{array}$ & DCT & TDR-r & $\begin{array}{c}\text { Ingestion } \\
\text { TDR-m }\end{array}$ & DCT & TDR-r & TDR-m & DCT \\
\hline Infant mean & 0.96 & 8.4 & 22 & 190 & 110 & 23 & 190 & 120 \\
Infant 97.5\% CL & 6.2 & 54 & 150 & 1300 & 680 & 150 & 1300 & 730 \\
Child mean & 1.4 & 12 & 22 & 200 & 63 & 24 & 200 & 110 \\
Child 97.5\% CL & 7.9 & 71 & 150 & 1300 & 540 & 150 & 1300 & 610 \\
Adult mean & 1.1 & 10 & 16 & 130 & 77 & 17 & 140 & 86 \\
Adult 97.5\% CL & 6.7 & 59 & 100 & 850 & 450 & 110 & 850 & 510 \\
\hline
\end{tabular}

If DCART predictions had been compared with UFOTRI-derived predictions for a complete diet, DCART would have grossly underestimated the dose from the 1970 accidental release. From the results in Table B1, however, it is clear that, although 
DCART could have been used to predict total doses that were more conservative than the doses predicted by the TDR based on realistic ingestion assumptions, doses based on UFOTRI's ingestion/inhalation ratios had to have been calculated to reach this conclusion.

The $2.5 \%$ confidence limits for adult, child, and infant are about 2 for both the DCART predictions and for the TDR predictions assuming maximum ingestion assumptions. The $2.5 \%$ confidence limits for the TDR predictions assuming realistic ingestion assumptions are about a factor of ten lower. There is considerable overlap in all predictions because of the high uncertainties.

\section{UNCERTAINTY ON DOSE PREDICTIONS}

Lack of knowledge about meteorological conditions at the time of an acute release accounts for most of the uncertainty associated with a past acute release but, even when conditions are known, the uncertainty about dispersion modeling is very great. These uncertainties are superimposed on the uncertainties associated with the model used to calculate the doses after an acute release.

Uncertainty in predictions of environmental transfer models arises from many sources, including the degree of completeness of the conceptual model, how effectively the conceptual model has been described by mathematical approximations in the code, how much is known about the accidental release, the quality of the input data, the uncertainty in parameter values, and the assumptions made by the user. This last aspect is rarely taken into account in uncertainty analyses and usually its potential impact is ignored. Although the uncertainty in the assumptions has not been included explicitly in this TDR, the assumptions have been meticulously documented so that the effect of changing an assumption on the result may be examined.

In general, complex dynamic models lack consensus and wide scale validation. The uncertainty on process-oriented models can be greater than the uncertainly on models based on a few empirically based parameter values. The few model tests above are part of an attempt to address this problem by learning enough about the processes to be able to reduce the uncertainty in the model. However, even when being tested against observations, a difference between predictions and observations does not mean the model is necessarily incorrect. The lack of agreement may arise because of experimental difficulties or poorly conceived scenario descriptions.

Parameter uncertainty and sensitivity analyses were carried out on UFOTRI more than ten years ago (Galeriu et al. 1995). At that time, no previous uncertainty studies on process-oriented models had been done, and, as far as can be determined, no uncertainty studies on any model have been published since 1995 . When a model is sensitive to a parameter, it will have a large effect on the uncertainty in the results. To know that a model is sensitive to a parameter directs further research and study.

The uncertainty on the ingestion predictions is independent of the uncertainty on dispersion, which is large. In the Galeriu et al. test of UFOTRI, it was determined that values of about a factor of three (upper confidence limit divided by lower confidence limit) applied to the concentrations of OBT in all edible plant or animal products; 
uncertainty of about a factor of ten applied to HTO concentrations in grass and soil. The uncertainty range for concentrations in grass after one day post-release was as great as uncertainty at later dates. This confirms that the conditions immediately after release must be well known in the early hours after the release in order to keep this uncertainty from being larger. As a result of this study, several recommendations were made about which parameters had to be investigated further to improve the UFOTRI predictions. These will not be repeated here because several years have elapsed since the publication of the paper and UFOTRI has been modified; also, this level of technical detail is inappropriate in this discussion. The parameters to which UFOTRI was sensitive at that time were leaf area index, minimum stomatal resistance, dry and wet plant mass, and initial soil moisture for the scenario tested. 


\section{REFERENCES}

ATSDR. Agency for Toxic Substances and Disease Registry. Toxicological profile for ionizing radiation. Atlanta, GA. US department of Health and Human Services; 1999.

ATSDR. Public Health Assessment. Community Exposures to the 1965 and 1970 Accidental Tritium Releases. Lawrence Livermore National Laboratory Main Site (USDOE) Livermore, Alameda County, California. EPA Facility ID: CA2890012584. Federal Facilities Assessment Branch, Division of Health Assessment and Consultation, Agency for Toxic Substances and Disease Registry. Atlanta, GA. Final Release. July 11, 2003.

ATSDR. Public Health Assessment Lawrence Livermore National Laboratory Main Site (USDOE) Livermore, Alameda County, California. EPA Facility ID: CA2890012584. Federal Facilities Assessment Branch, Division of Health Assessment and Consultation, Agency for Toxic Substances and Disease Registry. Atlanta, GA. Atlanta Georgia. July 16, 2004.

Arai, K., H. Takeda, and T. Iwakura. Studies on the tritium uptake in some edible plants and transfer to the rat. In: NIRS-M-52, Proceedings of the Second Workshop on Tritium Radiobiology and Health Physics in Chiba, Japan, 35-49. 1985.

Barry, P.J. An introduction to the exposure commitment concept with reference to environmental mercury. A Technical Report, the Monitoring and Assessment Research Centre, Chelsea College, University of London, MARC Report No. 12. 93 pp. 1979.

Bartels, H-W. A simple model to calculate doses for acute tritium releases, based on the HT field experiments in Canada and France. Fusion Technology Vol. 21:544$549 ; 1992$.

Belot, Y., K. Ganthier, H. Camus and C. Caput. Prediction of the flux of tritiated water from the air to plant leaves. Health Physics 37: 575. 1979.

BIOMOVS II. Tritium in the Food Chain. Intercomparison of Model Predictions of Contamination in Soil, Crops, Milk, and Beef after a Short Exposure to Tritiated Water Vapor in Air. Technical Report No. 8. BIOMOVS II Steering Committee. Swedish Radiation Protection Institute, Stockholm, Sweden. September 1996.

BIOMOVS II. Tritium in the Food Chain. Comparison of Predicted and Observed Behaviour. A. Re-emission from Soil and Vegetation. B. Formation of Organically Bound Tritium in Grain of Spring Wheat. Technical Report No. 13. BIOMOVS II Steering Committee. Swedish Radiation Protection Institute, Stockholm, Sweden. September 1996

Blanchard, A.; O'Kula, K.R.; East, J.M. Selection of a tritium dose model: defensibility and reasonableness for DOE authorization basis calculations. Westinghouse Savannah River Company, Aiken, South Carolina. WSRC-MS-98-00016. 1998.

Bowen, B. Personal communications. 2006. 
Brown, M. Memo to J. Steenhoven. Subject: Reassessment of the 8/25/89 tritium release with actual source term data from Building molecular sieve (reference EQVG memo 2159-1989). September 15, 1989.

Bunnenberg,C.; Feinhals, J.; Wiener, B. Differences in the bahaviour of HTO and $\mathrm{H}_{2} \mathrm{O}$ in soil after condensation from the atmosphere and conversion of HT to HTO and OBT in soil relative to moisture content and pore volume. Rad. Prot. Dos. 14: 83$87 ; 1986$.

Cember, H. Introduction to Health Physics. $2^{\text {nd }}$ Edition. P. 350. Pergamon Press, Oxford. 1985.

Chanin, D.I.; Young, M. Code Manual for MACCS2/User's Guide. Sandia National Laboratories, Albuquerque, NM NUREG/CR-6613 (SAND97-0594); 1998.

Dunstall, T.G. and G.L. Ogram. Diffusion and biological oxidation as component processes regulating the deposition of tritiated hydrogen to soils. Ontario Hydro Technologies, Pickering, Ontario. Report, 90-235-K. 1991.

Dunstall, T.G.; Ogram, G.L.; Spencer, F.S. Elemental tritium deposition and conversion in the terrestrial environment. Fusion Technol. 8: 2551-2556; 1985.

Facility Safety Procedures. Tritium Facility Building 331. FSP-331 Triennial Review. Revised 7/89.

File 331. This is a hand-written three-page "report" entitled "Summary of environmental monitoring results from incident on 6-8-84". There is no author. 1984.

Förstel, H. 1986. Uptake of elementary tritium by the soil. Radiat. Protect. Dosim. 16: $75-81$.

Foster, J.S., Jr. Memo to Dr. A.R. Van Dyken, Assistant Director of Research for Chemistry Programs, U.S. Atomic Energy Commission, Washington, D.C. Subject: Release of Tritium to the Atmosphere for period November 1, 1963 to January 31, 1964. February 10, 1964. Confidential, Restricted Data; status changed to unclassified, August 12, 1975. 1964a.

Foster, J.S., Jr. Memo to Dr. A.R. Van Dyken, Assistant Director of Research for Chemistry Programs, U.S. Atomic Energy Commission, Washington, D.C. Subject: Release of Tritium to the Atmosphere for period February 1 to April 30, 1964. May 19, 1964. Confidential, Restricted Data; status changed to unclassified, August 12, 1975. 1964b.

Foster, J.S., Jr. Memo to Dr. A.R. Van Dyken, Assistant Director of Research for Chemistry Programs, U.S. Atomic Energy Commission, Washington, D.C. Subject: Release of Tritium to the Atmosphere for period May 1 to July 31, 1964. August 18, 1964. Confidential, Restricted Data; status changed to unclassified, August 12, 1975. 1964c.

Foster, J.S., Jr. Memo to Dr. A.R. Van Dyken, Assistant Director of Research for Chemistry Programs, U.S. Atomic Energy Commission, Washington, D.C. Subject: Release of Tritium to the Atmosphere for period August 1 to December 
31, 1964. January 26, 1965. Confidential, Restricted Data; status changed at a later date. 1965.

Friedrich, B.; Schwartz, E. Molecular biology and hydrogen utilization in aerobic chemolithotrophs. Ann. Rev. Microbiol. 47: 351; 1993.

Galeriu, D.; Davis, P.; Chouhan, S.; Raskob, W. Uncertainty and sensitivity analysis for the environmental tritium code UFOTRI. Fusion Technology Vol. 28: 853-858; October 1995.

Galeriu, D.; Melintescu, A.; Beresford, N.A.; Takeda, H.; Crout, N. The dynamic transfer of ${ }^{3} \mathrm{H}$ and ${ }^{14} \mathrm{C}$ in mammals - a proposed generic model. J. of Environmental Radioactivity. In press.

Galeriu, D.; Raskob, W.; Melintescu, A.; Turcanu, C. Model of the tritium food chain and dose module FDMH in RODOS PV4. Draft RODOS(WG3)-TN(99)-54. 1999.

Galles, H. Draft letter to Ed Howell, Alameda County Health Care, Oakland, CA. April $5,1991$.

Garland, J.A. and M. Ameen. Incorporation of tritium in grain plants. Health Physics 36: 35-38. 1979.

Garland, J.A. and L.C. Cox. The absorption of tritium gas by English soils, plants and the sea. Water, Air and Soil Pollution 14: 103-114. 1980.

Garcia, T. Sandia/CA. Email to Ring Peterson 10/17/2006.

Garcia, T.B.; Gorman, T.P. Radiological characterization and final facility status report Tritium Research Laboratory. Sandia CA, Livermore, CA. Sandia Report. SAND96-8004UC-407. August 1996.

Gouveia, F.J.; Chapman, K.R. Climatology of Lawrence Livermore National Laboratory. Lawrence Livermore National Laboratory, Livermore, CA. UCID-21686; September 1989.

Gudiksen, P.H. Semiannual report of the environmental levels of radioactivity in the vicinity of Lawrence Livermore Laboratory, January through June 1971. Lawrence Livermore Laboratory, Livermore, CA. UCRL-51093; July 12, 1971.

Gulden, W.; Raskob, W. Accidental tritium doses based on realistic modelling. Fusion Technology Vol. 21: 536-543; March 1992.

Hafner, R. Personal communications. 2006.

Harrison, J.D.; Khursheed, A.; Lambert, B.E. Uncertainties in dose predictions for intakes of tritiated water and organically bound forms of tritium by members of the public. Radiation Protection Dosimetry 98(3):299-311; 2002.

Hicks, B.B., D.D. Baldocchi, T.P. Meyers, J.R. Hosker and D.R. Matt. A preliminary multiple resistance routine for deriving dry deposition velocities from measured quantities. Water, Air and Soil Pollution 36: 311-330. 1987.

Higgins, N.A., P.V. Shaw, S.M. Haywood and J.A. Jones. TRIF, a dynamic model for predicting the transfer of tritium through the terrestrial foodchain. National Radiological Protection Board Report, NRPB-R278. 1996. 
Hill, R.W. Memo to R.M. Alire . Subject: LLNL Incident Analysis Report, Serial No. 0317 Tritium Releases B331. June 29, 1984.

Holland, R. Site Environmental Report for 1998. SAND99-8004. June 1999

Homann, S.G. HOTSPOT; Health Physics Codes for the PC. Lawrence Livermore National Laboratory. UCRL-MA-106315; 1994.

Howe, H. Jr. Memo to Clark Souers, January 22, 1985. Subject: Dose Equivalent Estimates - Tritium Release, June 8, 1984. 1985a.

Howe, H. Jr. Memo to C. Souers, February 26, 1985; Subject: Tritium Release from Building 331 - January 24, 1985. 1985 b.

Ichimasa, Y.; Ichimasa, M.; Jiang, H.; Katsuno, K. In vitro determination of HT oxidation activity and tritium concentration in soil and vegetation during chronic HT release experiment at Chalk River. Fusion Technol. 28: 877-882; 1995.

Indeka, L. Incorporation of tritiated water from the atmosphere into aqueous and organic components of plants. In: Biological Incorporation of Tritium. Jaworowski, Z. (ed.) Final Report to the United States Environmental Protection Agency concerning Research Contract No. 05-536-3, CLOR-115/D. 21-27. 1981.

Jacobson, K.W. Calculation of doses from unplanned airborne releases. Air Quality Group, Los Alamos National Laboratory.ESH-17-503 R1. November 4, 1999.

Jones, C.G. A review of the history of U.S. radiation protection regulations, recommendations, and standards. Health Physics 88(2):105-124; 2005.

Jow, H-N, J. L. Sprung, J. A. Rollstin, L. T. Ritchie, D. I. Chanin, A MELCOR Accident Consequence Code System (MACCS), Model Description, NUREG/CR-4691, SAND86-1562, Vol. 2 (February 1990).

Kirchmann, R., P. Charles, R. van Bruwaene, J. Remy, G. Koch and J. van den Hoek. Distribution of tritium in the different organs of calves and pigs after ingestion of various tritiated feeds. Curr. Topics Radiat. Res. Quart. 12: 291-312; 1977.

Köhler, H.; Peterson, S-R.; Hoffman, F.O. Multiple Model Testing using Chernobyl Fallout Data of I-131 in Forage and Milk and Cs-137 in Forage, Milk, Beef, and Grain. BIOMOVS Technical Report Scenario A4. National Institute of Radiation Protection, Stockholm, Sweden. March 1991.

May, M.M. Memo "Release of Tritium to the Atmosphere" for period April 1 through June 301966 to Dr. A.R. Van Dyken, Assistant Director of Research for Chemistry Programs, U.S. Atomic Energy Commission, Washington, D.C. July 11, 1966. Confidential Restricted Data unclassified August 12, 1975.

McFarlane, J.C. Tritium fractionation in plants. Environ. Exp. Botany 16: 9-14; 1976.

McFarlane, J.C.; Rogers, R.D.; Bradley, D.V. Environmental tritium oxidation in surface soil. Env. Sci. Technol. 12: 590-593; 1978.

Moses, V; Calvin, M. Photosynthesis studies with tritiated water. Biochim. Et Biophys. Acta 33:297-312; 1959. 
Myers, D.S.; Tinney, J.F.; Gudiksen, P.H. Health physics aspects of a large accidental tritium release. In: Moghissi, A.A.; Carter, M.W., eds. Tritium. Phoenix: Messenger Graphics; 611-622; 1973

Napier, B. Computer modeling codes for radiological and chemical airborne releases. Operational Radiation Safety, Health Physics 81(supplement):S15-S17; 2001.

Napier, B.A.; Strenge, D.L.; Ramsdell, Jr., J.V.; Eslinger, P.W.; Fosmire, C. GENII Version 2.0 Software Design Document. Prepared for US Environmental Protection Agency. November 2002.

Nasstrom, J.S; Sugiyama, G.; Baskett, R.; Larsen, S.; Bradley, M. The National Atmospheric Release Advisory Center (NARAC) Modeling and Decision Support System for Radiological and Nuclear Emergency Preparedness and Response. Lawrence Livermore National Laboratory, Livermore, CA. UCRL-JRNL211678. April 2005.

National Committee on Radiation Protection and Measurements (NCRP). Maximum permissible exposure to man (April 15, 1958). Washington, D.C. US Department of Commerce's Addendum to the US National Bureau of Standards Handbook 59. 1958.

Ng, Y.C.; Burton, C.A.; Thompson, S.E.; Tandy, R.K.; Kretner, H.K.; Pratt, M.W. Prediction of the maximum dosage to man from the fallout of nuclear devices, IV Handbook for estimating the maximum internal dose from radionuclides released to the Biosphere. Lawrence Radiation Laboratory, Livermore CA. UCRO-50163, Part IV. 1968.

NRC. RASCAL version 3.0 radiological assessment system for consequence analysis, incident response operations. Rockville, MD: Nuclear Regulatory Commission, March 2001.

Ogram, G. The Canadian HT Dispersion Experiment at Chalk River - June 1987: Summary Report. Canadian Fusion Fuels Technology Project, Toronto, Canada. CFFTP-G-88027; September 1988.

Olsen, J.L. "Lawrence Laboratory Inventory Data". Subject of letter to D.B. Campbell, US Atomic Energy Commission, San Francisco. November 9, 1973.

Peterson, S-R. Historical Doses from Tritiated Water and Tritiated Hydrogen Gas Released to the Atmosphere from Lawrence Livermore National Laboratory. Part 1. Description of Tritium Dose Model (DCART) for Chronic Releases from LLNL Lawrence Livermore National Laboratory, Livermore, CA. UCRL-TR205083-REV-1; October 2006.

Peterson, S-R. Historical Doses from Tritiated Water and Tritiated Hydrogen Gas Released to the Atmosphere from Lawrence Livermore National Laboratory. Part 2. LLNL Annual Site-specific data 1953 - 2005. Lawrence Livermore National Laboratory, Livermore, CA. UCRL-TR-211722-REV-1; September 17, 2007 a.

Peterson, S-R. Historical Doses from Tritiated Water and Tritiated Hydrogen Gas Released to the Atmosphere from Lawrence Livermore National Laboratory. Part 
3. Routine Releases 1973 - 2005. Lawrence Livermore National Laboratory, Livermore, CA. UCRL-TR-234657: September 17, $2007 \mathrm{~b}$.

Peterson, S-R. Historical Doses from Tritiated Water and Tritiated Hydrogen Gas Released to the Atmosphere from Lawrence Livermore National Laboratory. Part 4. Routine Releases 1953 - 1972. Lawrence Livermore National Laboratory, Livermore, CA. UCRL-TR-234644: September 14, $2007 \mathrm{c}$.

Peterson, S-R.; Davis, P.A.; Rao, R.R. Modeling doses from tritium and ${ }^{14} \mathrm{C}$ in the environment. Atomic Energy of Canada Limited, Chalk River Laboratories, Chalk River, ON. RC-1951. October 1997.

Peterson, S-R.; Gallegos, G.M.; Harrach, R.J. A review of the January 20, 1965, tritium release from Lawrence Radiation Laboratory. Lawrence Livermore National Laboratory, Livermore, CA. UCRL-AR-148811. July 2002.

Peterson, S-R.; Hoffman. F.O.; Köhler, H. Summary of the BIOMOVS A4 Scenario: Testing Models of the Air-Pasture-Cow Milk Pathway Using Chernobyl Fallout Data. Health physics 71(2): 149-159; 1996.

Pobanz, Brenda, Ed. Technical Notes in NARAC NEWS, the NARAC DOE Users Newsletter. April 2006.

Raskob, W. UFOTRI: Program for assessing the offsite consequences from accidental tritium releases. Report KfK-4605, Kernforschungszentrum Karlsruhe, Germany. 1990.

Raskob, W. Description of the new version 4.0 of the tritium model UFOTRI including user guide. Report KfK-5194, Kernforschungszentrum Karlsruhe, Germany. 1993.

Raskob, W. 2006. Personal communications.

Raskob, W.; Hasemann, I.; DiPace, L. Final documentation on dose assessments for three potential European ITER candidate sites with updated source terms from ITER NSSR-2. Report KfK-64044, Forschungszentrum Karlsruhe GmbH, Karlsruhe, Germany. 1999.

Robertson, J.S. Tritium turnover rates in mammals. In: A.A. Moghissi and M.W. Carver (Eds.), Tritium, pp. 322-326. Messenger Graphics, Phoenix, AZ. 1973.

Russell, S.B. and G.L. Ogram. ETMOD: A new environmental tritium model Fusion Tech. 21: 645-650. 1992.

Silver. W.J. Memo to B331 File. Subject: Summary of Tritium Stack Release Test. January 20, 1970.

Simpkins, A. AXAIRQ User's Manual, Westinghouse Savannah River Company; WSRC-RP-95-709. October 1995a.

Simpkins, A. Verification of AXAIRQ (U), Westinghouse Savannah River Company; WSRC-RP-95-708. October 1995b.

Smith, G.M., P.C. Robinson and M.J. Stenhouse. 1995. H-3 foodchain modelling following short-term release to atmosphere. Report IE3947-1, Version 2.0, Intera 
Information Technologies, Chiltern House, 45 Station Rd., Henley-on-Thames, Oxfordshire, U.K.

Souers, C. "Tritium Releases from Building 331", presented to the Director's Office, June 1988.

Souers, C. Email to Ring Peterson, March 10, 2006.

Spencer, F.S.; Ogram, G.L.; Brown, R.M. Field studies of HT behaviour in the environment: 3. Tritium deposition and dynamics in vegetation. Fusion Technol. 14:1176-1181; 1988.

Spencer, F.G.; Vereecken-Sheehan, L. HTO concentration relationships between air, soil, and vegetation and seasonal dependence of HT deposition to soil. Ontario Hydro Technologies, Pickering, Ontario, Canada. Report \# A-NBR-94-36-K; July 29, 1994.

Stanhope, Chester M. Memo to Dusty Meadors. Subject: $T_{2}$ accident and personnel involved, October 13, 1954. October 26, 1954.

Sullivan, J.T.; Ellis, J.S.; Foster, C.S.; Foster, K.T.; Baskett, R.L.; Nasstrom, J.S.; Schalk III, W.W. Atomspheric Release Advisory Capability: Real-time modeling of airborne hazardous materials. Bulletin of the American Meteorological Society, pp. 2343-2361; 1993.

Sweet, C.W.; Murphy, Jr. C.E. Oxidation of molecular tritium by intact soils. Environ. Sci. Technol. 15: 1485-1487; 1981.

Taeschner, M., C. Bunnenberg, H. Camus and Y. Belot. Investigations and modeling of tritium reemission from soil. Fusion Technology 28: 976-981. 1995.

Thaxter, M.D. Memo to N. B. Garden. Subject: Modification of existing facilities Tritium Room Bldg 102 Livermore; CLL-440-54; November 9, 1954.

Thiessen, K.M. et al. Environmental models undergo international test. Environmental Science \&Technology 31 (8) 358-363. 1997.

Thomas, B.A.; Hoffman, F.O.; Gifford, F.A. Review of atmospheric dispersion models to predict tritium concentrations resulting from releases from the National Tritium Labeling Facility. SENES Oak Ridge Inc. Center for Risk Analysis. October 5, 1999.

Thompson, J.W., J.A. Kennedy and J.M. Lina. ETMOD software quality assurance documentation, Volume I. CFFTP P-9205/CFFTP-03421 (577). 1992.

Thompson, R.G.; Nelson, C.D. Photosynthetic assimilation and translocation of ${ }^{3} \mathrm{H}$ and ${ }^{14} \mathrm{C}$ organic compounds after ${ }^{3} \mathrm{HHO}$ and ${ }^{14} \mathrm{CO}_{2}$ were simultaneously offered to a primary leaf of soybean. Can. J. Bot. 49: 757-766. 1971.

United Nations Scientific Committee on the Effects of Atomic Radiation (UNSCEAR). Sources And Effects Of Ionizing Radiation. UNSCEAR 2000 Report to the General Assembly. Volume 1 (Annex A, Chapter I, Section B3). New York: United Nations; 2000. 
United States Environmental Protection Agency. Exposure Factors Handbook (EFH). National Center for Environmental Assessment. Office of Research and Development. Washington, D.C. EPA/600/C-99/001. February 1999.

Valley Times. Radioactive Gas Excapes (sic) at LNL No Danger Found. January 21, 1965.

van den Hoek, J., R. Kirchmann and N.B. Juan. Transfer and incorporation of tritium in mammals. In: Behaviour of Tritium in the Environment. IAEA-SM-232/74, pp. 433-444, Vienna, Austria. 1979.

van den Hoek, J. M.H.J. ten Have and G.B. Gerber. The metabolism of tritium and water in the lactating dairy cow. Health Physics 44: 127-133. 1983.

van den Hoek, J. M.H.J. ten Have, G.B. Gerber and R. Kirchmann. The transfer of tritium-labeled organic material from grass into cow's milk. Radiat. Res. 103: 105-113. 1985.

Watterson, J.; Nicholson, K.W. Change in radionuclide content of crops as a result of food preparation. J. Radiol. Prot. Vol. 16 No. 3 191-200; 1996.

Yoder, R.E. Memorandum to J.S. Kane. Subject: LRL Incident/Accident Report Serial No. 003. April 26 (?), 1971.

Yousef, M.K. Tritiated water turnover in desert mammals. In Tritium. A.A. Moghissi and M.W. Carter, editors. Messenger Graphics, Las Vegas, NV;. 333-341; 1973. 


\section{ABBREVIATIONS, ACRONYMS AND DEFINITIONS}

ATSDR
BIOMOVS II
CL
DCART
Dilution Factor

Distribution

Agency for Toxic Substances and Disease Registry

Biospheric Model Validation Study, a coordinated research program of the IAEA

Confidence Limit

Doses from Chronic Atmospheric Releases of Tritium; a steady-state, stochastic dose model (Peterson 2006)

A term that refers to the air concentration for unit source strength (or $\chi / \mathrm{Q}$ ); units are $\mathrm{Bq} \mathrm{m}^{-3} / \mathrm{Bq} \mathrm{s}^{-1}$ (or $\mathrm{Ci} \mathrm{m}^{-3} / \mathrm{Ci} \mathrm{s}^{-1}$. The term, although standard for $\chi / \mathrm{Q}$, can be misleading, because the higher the dilution factor, the higher the air concentration.

A function of a discrete random variable yielding the probability that the variable will have a given value. Types of distributions include

The probability distribution of any random variable

Lognormal whose logarithm is normally distributed. It can be expressed as a geometric mean and geometric standard deviation. It is commonly used for dilution factors.

A theoretical frequency distribution for a set of variable data, usually represented by a bell-shaped curve

Normal symmetrical about the mean and is expressed as a mean and standard deviation. Also called Gaussian distribution. Source terms are commonly distributed normally.

Triangular A distribution with three terms: minimum, likely, and maximum.

Uniform A distribution in which all values in the range have an equal probability of being sampled

DOE Department of Energy

DT deuterium hydrogen gas

DTO a form of water in which the hydrogen is replaced by deuterium and tritium

EFH Exposure Factors Handbook of the Environmental Protection Agency

EMRAS Environmental Modeling for Radiation Safety, a coordinated research program of the IAEA

ETMOD Environmental Tritium Model for assessing accidental releases 


\section{ABBREVIATIONS, ACRONYMS AND DEFINITIONS continued}

FDMH

GMT

HOTSPOT

HT

HTO

IAEA

LLNL

MEI

MRL

NARAC

NESHAPs

OBT

PDST

PHA

RODOS

$\mathrm{SNL} / \mathrm{CA}$

STAR-H3

TDR

TRL

UCL

UFOTRI

UNCLE

USGS
Food Dose Module Hydrogen; the module in RODOS for assessing dose from releases of tritium

Greenwich Mean Time

Accident consequence model (Homann 1994)

Tritiated hydrogen gas

Tritiated water

International Atomic Energy Agency

Lawrence Livermore National Laboratory

Maximally Exposed Individual (to releases from one facility)

Minimum Risk Level (1 mSv [100 mrem]) as defined by ATSDR)

National Atmospheric Response Advisory Capability (at LLNL)

National Emission Standards for Hazardous Air Pollutants (40 CFR

61 Subpart H. (National Emission Standards for Emissions of

Radionuclides other than Radon from Department of Energy

Facilities).

organically bound tritium

Pacific daylight savings time

Public Health Assessment

Real-time On-line Decision Support System (for Europe)

Sandia National Laboratory, Livermore, CA

compartment model to assess dose from accidental releases

Tritium Dose Reconstruction (LLNL, 1953 - 1972, both routine and accidental releases

Tritium Research Laboratory (SNL/CA)

upper confidence limit of a $95 \%$ (normally) distribution of dose predictions (i.e., the $97.5 \%$ confidence limit

Unfallfolgenmodell für Tritiumfreisetzungen; a program for assessing the off-site consequences from accidental releases (Raskob 1990, 1993)

UNiversity of California Lawrence Livermore Laboratory Employees Credit Union

United States Geological Survey 